\title{
Systematic revision of the Potamotrygon motoro (Müller \& Henle, 1841) species complex in the Paraná-Paraguay basin, with description of two new ocellated species (Chondrichthyes: Myliobatiformes: Potamotrygonidae)
}

\author{
Thiago Silva Loboda and Marcelo Rodrigues de Carvalho
}

\begin{abstract}
A systematic revision of the Potamotrygon motoro (Müller \& Henle, 1841) species complex in the Paraná-Paraguay basin based on morphological characters was undertaken. Morphological systems analyzed include external morphology, coloration, dermal denticles, and spines, canals of the ventral lateral-line system, and skeletal components. Potamotrygon motoro is widely distributed in the Paraná-Paraguay basin and some of its diagnostic characters are: ocelli present on dorsal disc tricolored, well-defined and evenly distributed, with diameter similar or greater than eye-length; ventral coloration with relatively large whitish central region, with gray or brown area predominant on outer ventral disc margins; dermal denticles well-developed and star-shaped over central disc; labial grooves absent; monognathic heterodonty present in upper and lower jaws of adults. Potamotrygon pauckei Castex, 1963 and Potamotrygon labradori Castex, Maciel \& Achenbach, 1963, are synonymized with P. motoro; Potamotrygon alba Castex, 1963, is a nomen dubium in accordance with previous authors. Additionally, two new ocellated species of Potamotrygon from the Paraná-Paraguay basin are described: Potamotrygon pantanensis, sp. nov. and Potamotrygon amandae, sp. nov. These are described and compared with P. motoro and other congeners. Potamotrygon pantanensis, sp. nov. is described from the northern Pantanal region; Potamotrygon amandae, sp. nov. is widespread in the Paraná-Paraguay basin.
\end{abstract}

Uma revisão sistemática do complexo de espécies Potamotrygon motoro (Müller \& Henle, 1841) na bacia Paraná-Paraguai, baseada em caracteres morfológicos, foi realizada. Os caracteres morfológicos analisados incluem morfologia externa, coloração, dentículos dérmicos e espinhos, sistema de canais ventrais da linha lateral e componentes do esqueleto. Potamotrygon motoro é amplamente distribuída na bacia Paraná-Paraguai e alguns dos seus caracteres diagnósticos são: ocelos presentes no dorso do disco tricolores, bem definidos e bem distribuídos, com diâmetro similar ou maior do que o comprimento do olho; coloração ventral com região central do disco branca e com tonalidades marrom ou cinza presentes nas margens do disco; dentículos dérmicos bem desenvolvidos e com formato estrelado na região central do disco; sulcos labiais ausentes; heterodontia monognática presente nas maxilas superior e inferior nos adultos. Potamotrygon pauckei Castex, 1963 e Potamotrygon labradori Castex, Maciel \& Achenbach, 1963, são sinonimizadas com P. motoro, e Potamotrygon alba Castex, 1963, é considerada um nomen dubium em acordo com autores anteriores. Além disso, duas espécies novas oceladas de Potamotrygon da bacia Paraná-Paraguai são descritas: Potamotrygon pantanensis, sp. nov. e Potamotrygon amandae, sp. nov. Estas espécies novas são descritas e comparadas com P. motoro e outras espécies do gênero. Potamotrygon pantanensis, sp. nov. é descrita da região norte do Pantanal e Potamotrygon amandae, sp. nov. é amplamente distribuída na bacia Paraná-Paraguai.

Key words: Batoidea, Freshwater stingrays, Morphology, Neotropical region, South American river basins, Taxonomy.

\section{Introduction}

Potamotrygon motoro (Müller \& Henle, 1841) is the most wide-ranging species of the family Potamotrygonidae, occurring in most freshwater systems in South America where potamotrygonids are known to inhabit, such as the Amazon, Orinoco, Paraná-Paraguay, and Uruguay basins (Garman, 1913; Rosa, 1985; Compagno \& Cook, 1995; Carvalho et al.,

Departamento de Zoologia, Instituto de Biociências, Universidade de São Paulo, Rua do Matão, Trav. 14, nº 101, 05508-090 São Paulo, SP, Brazil.loboda_bio@yahoo.com.br(TSL); mrcarvalho@ib.usp.br (MRC) 
2003; Rosa \& Carvalho, 2007), as well as the Mearim system of northern Brazil (Soares, 2005). The species was originally described from specimens collected by the Austrian naturalist Johann Natterer between 1828 and 1829 in the Cuiabá River, in the upper Paraná-Paraguay basin, and from the Guaporé River, an upper tributary of the Madeira River in the Amazon basin, both localities in the State of Mato Grosso, Brazil (Müller \& Henle, 1841; Teixeira \& Papavero, 1999). After Müller \& Henle's (1841) description, this species has been quoted by many authors from different localities, and Miranda Ribeiro (1907) summarized its wider geographic distribution to include the Paraná-Paraguay and Amazon basins, followed by Garman (1913) and Fowler (1951). The first authors who cited P. motoro from the Uruguay River were Devincenzi \& Teague (1942), and the first report of P. motoro in the Orinoco basin was published by Mago-Leccia (1971). It was Rosa (1985), however, that presented the most comprehensive geographic distribution of $P$. motoro, indicating it occurs from the río Orinoco in Venezuela to the La Plata system in Argentina and Uruguay, and being absent only from the AtratoMagdalenae, Maracaibo, and Parnaíba basins among the rivers in which potamotrygonids are known to occur.

Possibly because it was one of the first species described in the family, $P$. motoro has a complex taxonomic history with many nominal species in its synonymy and lingering doubts as to whether it represents a single species or species complex. Its widespread distribution, together with significant variation in some morphological characters (e.g., dorsal disc coloration) between populations of different basins, and even in closely adjacent areas, has led some authors to indicate that a taxonomic subdivision of $P$. motoro may be necessary (Castex, 1964; Carvalho et al., 2003). To complicate this scenario, the original type-series of $P$. motoro, collected and sent to Europe by Johann Natterer in the $19^{\text {th }}$ century, was originally composed of six syntypes, of which just a single juvenile specimen has been recognized as the last remaining type-specimen by most recent authors (a female specimen preserved in the Zoologisches Museum der HumboldtUniversität, Berlin; Rosa, 1985; Paepke \& Schmidt, 1988; Carvalho et al., 2003). The others syntypes were considered to have been lost, possibly during World War II (Paepke \& Schmidt, 1988). However, three additional specimens from the type-series of $P$ motoro have been reported from the ichthyological collection of the Naturhistoriches Museum Wien, Austria (Ludwig, 2009), and due to their better state of preservation provide a significant opportunity to confirm the morphological characteristics reported by Müller \& Henle (1841) for P. motoro in its original description. A further complicating factor in addition to the significant variation in dorsal coloration and the possibility of a heterogeneous typeseries (detailed below), is that three other nominal species described from the Paraná-Paraguay basin, Potamotrygon pauckei Castex, 1963, Potamortygon alba, Castex, 1963, and Potamotrygon labradori Castex, Maciel \& Achenbach, 1963, have been synonymized with P. motoro (Rosa, 1985; Carvalho et al., 2003).

Consequently, to understand the morphology and taxonomy of $P$. motoro in the Paraná-Paraguay basin, we examined as much material as possible from collections and from recent fieldwork of colleagues, as well as from our own collections. Our focus in the Paraná-Paraguay basin (principally the region near Cuiabá) and Guaporé River of the Amazon basin (the frontier between the Paraná-Paraguay and Amazon basins) was necessary to better understand the morphological variation in $P$. motoro from where Natterer collected the type-series in the $19^{\text {th }}$ century. Data from specimens from many localities of the Paraná-Paraguay system were also taken and compared with type-specimens of available nominal species from this basin (as well as from other basins), including all remaining syntypes of P. motoro. In the course of this study, some recently collected specimens were found to display an ocellated dorsal disc color that is significantly and consistently different from P. motoro and from the other potamotrygonid species in the Paraná-Paraguay system that do not possess ocelli, namely $P$. histrix (Müller \& Henle, 1834), P. brachyura (Günther, 1880), P. falkneri Castex \& Maciel, 1963 and P. schuhmacheri Castex, 1964, (some P. falkneri specimens possess irregular ocelli, however always in association with other types of spots; Silva $\&$ Carvalho, 2011). In addition to dorsal disc coloration, these specimens are morphologically differentiated from P. motoro in ventral disc coloration, dentition, morphology and distribution of dermal denticles and spines, morphological proportions (such as spiracular length, interspiracular distance, length of claspers), as well as in internal morphology (e.g., features of the neurocranium, ventral lateral-line canals). After detailed study we were able to separate all examined specimens from the Paraná-Paraguay basin into three specific groups representing Potamotrygon motoro and two other forms for which available nominal species cannot be applied; these are described here as Potamotrygon pantanensis, sp. nov., and Potamotrygon amandae, sp. nov. The present study anticipates the publication of a larger morphological and taxonomic revision of P. motoro in the Amazon basin (based on Loboda, 2010).

\section{Material and Methods}

Specimens studied are deposited in the Museu de Zoologia da Universidade de São Paulo (MZUSP), or were obtained on loan or examined during visits to the following institutions: Museo Argentino de Ciencias Naturales Bernadino Rivadavia (MACN, Buenos Aires), Museo de Ciencias Naturales Florentino Ameghino (MFA, Santa Fé), Núcleo de Pesquisa em Limnologia, Ictiologia e Aqüicultura of the Universidade Estadual de Maringá (NUPELIA, Maringá), and Zoologisches Museum der Humboldt-Universität (ZMB, Berlin). Photographs 
and radiographs of syntypes were obtained from the ZMB and the Naturhistorisches Museum Wien (NMW, Vienna). Specimens collected in the northern Pantanal region in July 2006 and June 2007 are deposited in MZUSP.

Measurements and counts were modified from Bigelow \& Schroeder (1953) and Rosa (1985) with the addition of dorsal and ventral pseudosiphon lengths. A total of 28 measurements and 14 counts were extracted from specimens. Tooth row counts follow Stehmann (1978). Terminology for morphological features are as follows: Deynat \& Séret (1996) for dermal derivatives; Garman (1888), Lovejoy (1996), Carvalho \& Lovejoy (2011) for lateral-line system; Taniuchi \& Ishihara (1990) and Carvalho \& Lovejoy (2011) for clasper structures; Compagno (1977), Nishida (1990), Carvalho et al. (2004), and Carvalho \& Lovejoy (2011) for skeletal structures. Disc width is abbreviated throughout as DW, and disc length as DL. External morphological characters scrutinized include dorsal and ventral coloration, morphology and distribution of dermal denticles and spines, morphology and arrangement of teeth, and morphology of external clasper components. Internal morphological features studied are the ventral canals of the lateral-line system and the following skeletal components: neurocranium and mandibular arch elements for P. motoro, P. pantanensis sp. nov. and P. amandae sp. nov., and cervicothoracic synarcual, scapulacoracoid, pelvic girdle, and clasper skeleton for P. motoro. Radiographs of specimens were taken in the Hospital das Clínicas da Faculdade de Medicina de Ribeirão Preto, Universidade de São Paulo, with Kodak mammography film (Min-R2000). For skeletal preparations, specimens of $P$. motoro were boiled with potassium hydroxide to remove flesh (see Compagno, 1988), or cleared-andstained following Dingerkus \& Uhler (1977). Specimens of Potamotrygon histrix (Müller \& Henle, 1834) were measured and radiographed to substantiate its morphological separation from $P$. amandae sp. nov.

\section{Family Potamotrygonidae Garman, 1913 Genus Potamotrygon Garman, 1877 Potamotrygon motoro (Müller \& Henle, 1841) Figs. 1-20, 21b-c, 22}

\section{Synonymy of Potamotrygon motoro in the Paraná-Paraguay basin:}

Taeniura motoro: -Müller \& Henle, 1841: 197-198 [original description, type locality: Cuiabá River, Brazil ("Fluss Cuyaba in Brasilien”, p. 197)]; -Günther, 1870: 484 [brief description, synonymy].

Ellipesurus motoro: -Miranda Ribeiro, 1907: 184-186, plate XVIII 1-2 [identification key, description, distribution]; -Miranda Ribeiro, 1923: 40-43 [description].

Potamotrygon motoro: -Garman, 1913: 417, 423 [identification key, synonymy, description, distribution]; -Devicenzi \&
Teague, 1942: 97-98, fig. p. 97 [identification key, description, color pattern]; -Miranda Ribeiro, 1959: 6 [material in Museu Nacional, Rio de Janeiro, listed; only specimens with numbers 565 and 566 from Paraná-Paraguay basin]; -Castex, 1963a: 38, 49-51, fig. 9, p. 51 [citation for Argentina]; -Castex, 1963b: 7-17, fig. p. 8, fig. p. 9, figs. p. 10 [color pattern, number of stings and sexual maturation]; -Castex, 1963c: 289-294, fig. p. 293 [references, color pattern, disc format]; -Castex, 1963d: 7, 25-27, 29, 31, 33-34, 44-46, 51, 54-56, 81, 83, fig. 10, p. 33, fig. 11, p. 34 [references, color pattern, taxonomic discussion, synonymy, description]; -Castex \& Maciel, 1965: 7-11, 14, 15, fig. 2, p. 8, fig. 3, p. 9, fig. 4, p. 10, fig. 5, p. 11 [distribution]; -Castex, 1967a: 487489, fig. 7, p. 488, figs. 8-9, p. 489 [morphology of dermal denticles]; -Castex, 1967b: 493-494, fig. 1, p. 494, fig. 2, p. 494 [morphology of teeth]; -Castex \& Castello, 1970: 16-21 [morphological remarks, references]; -Castello, 1975: 30, 34, fig. p. 34 [biological remarks]; -Achenbach \& Achenbach, 1976: 2, 4, 10-11, 15-20, 29-32, 34, plates III-IV, p. 29, plates V-VI, p. 30, plate VII, p. 31, plate VIII, p. 32, plate XI, p. 34 [color pattern, distribution, ecological data, reproduction, description]; -Rosa, 1985: v, viii, xi, xiii, xvi, 5, 34-35, 37 , 88, 96-97, 104-107, 142, 158-159, 193-194, 222, 256-267, 270-271, 274-275, 277, 324-325, 336, 355-357, 397, 400-402, 420-421, 424, 428, 432, 441-442, 456, 462, 467, 470, 482, 491-493, fig. 4, p. 34, fig. 20a-b, p. 97, fig. 24, p. 105, fig. 25 , p. 107 , fig. 64 , p. 267 , fig. 66 , p. 271 , fig. 68 , p. 275 , fig. 101 , p. 442 [synonymy, diagnosis, redescription, morphology of skeleton]; -Päepke \& Schimidt, 1988: 181, 189 [type-catalog of ZMB]; -Taniuchi \& Ishihara, 1990: 10-16, fig. 2, p. 11 [external and internal morphology of claspers]; -Brooks \& Amato, 1992: 393-398 [parasites]; -Compagno \& Cook, 1995: 67, 72, 74, 80, 85 [distribution]; -Ishihara \& Taniuchi, 1995: 91, 95-97, fig. 7, p. 95 [meristics, measurements, and skeleton of pelvic girdle]; -Lovejoy, 1996: 216, 219, 224, 226, 228, 235, 256-257, fig. 4a, p. 216, fig. 10d, p. 228 [ventral lateral-line canals, mandibular arch, branchial arches, synarcual, scapulocoracoid, vertebrae, in phylogenetic analysis]; -Teixeira, Papavero \& Bragança Júnior, 1999: 80, fig. p. 80 [reprint of original illustration by Natterer of syntype NMW 78566, designated lectotype below]; -Marques, 2000 : 39, 42, 55, 57, 63-64, 67-68, 72, 75-76, 107, 121, 159, 160, 162-169, 195, 235, 243-271, 287-316 [parasites]; -Carvalho, Lovejoy \& Rosa, 2003: 22, 24-26 [taxonomic discussion, distribution, synonymy]; -Marques, Brooks \& Araújo, 2003: 368-369, 371, 374-375, 377, 382, 385, 388 [parasites]; -Garrone Neto et al., 2007: 206-207, fig. 3, p. 207 [distribution in Paraná-Paraguay basin]; -Rosa \& Carvalho, 2007: 17, 185, 189 [listed in catalog]; -Rosa, Carvalho \& Wanderley, 2008: 1-3, 7-8 [taxonomic comparisons]; -Ludwig, 2009: 30-34, figs. $2-3$, p. 31 , fig. 5 , p. 32 , fig. 6 , p. 33, figs. 7, 9 , p. 34 [discussion of type-series]. 

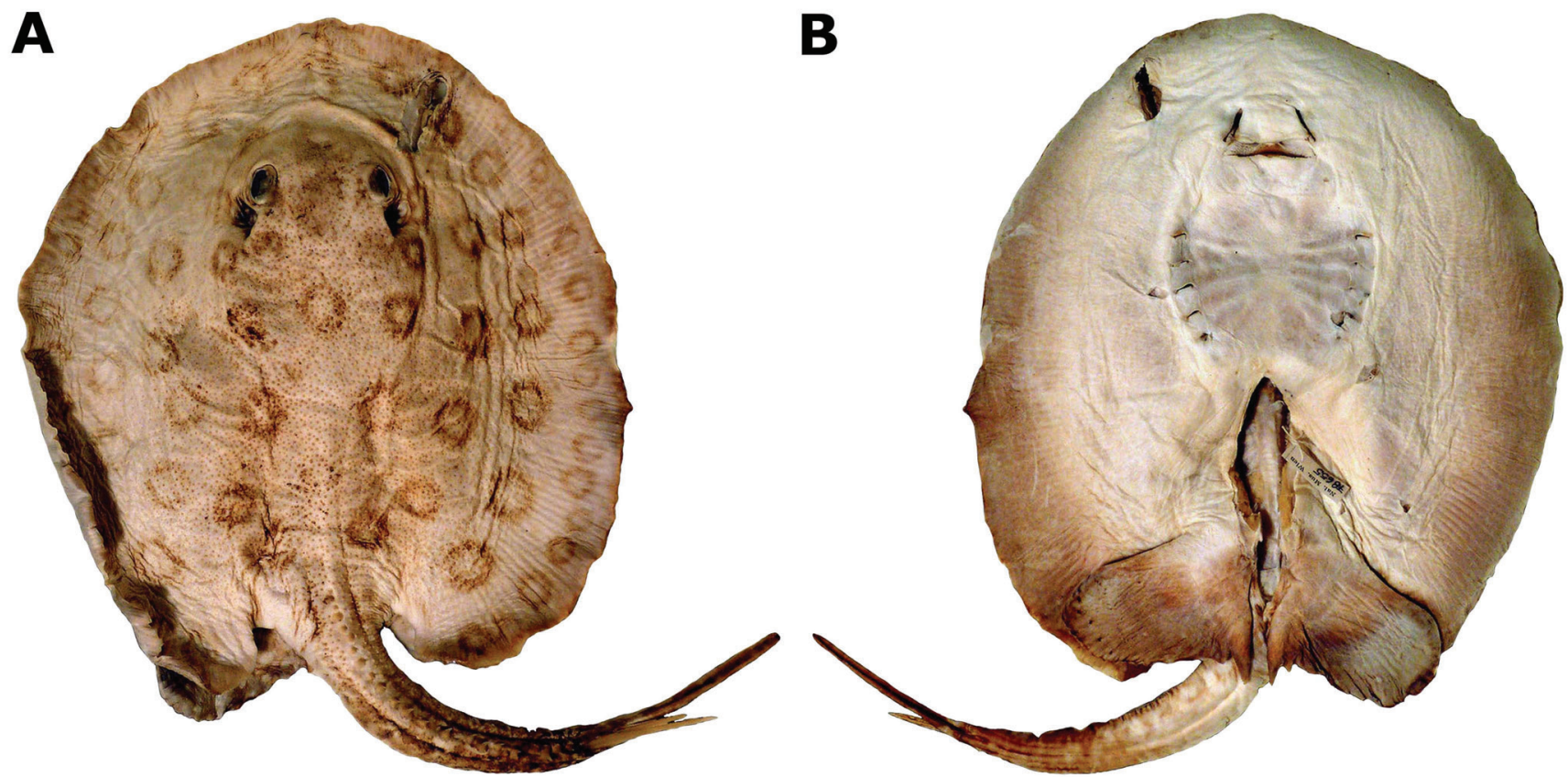

Fig. 1. Potamotrygon motoro. Dorsal (a) and ventral (b) views of lectotype, NMW 78655, juvenile male, 208 mm DW, Guaporé River.

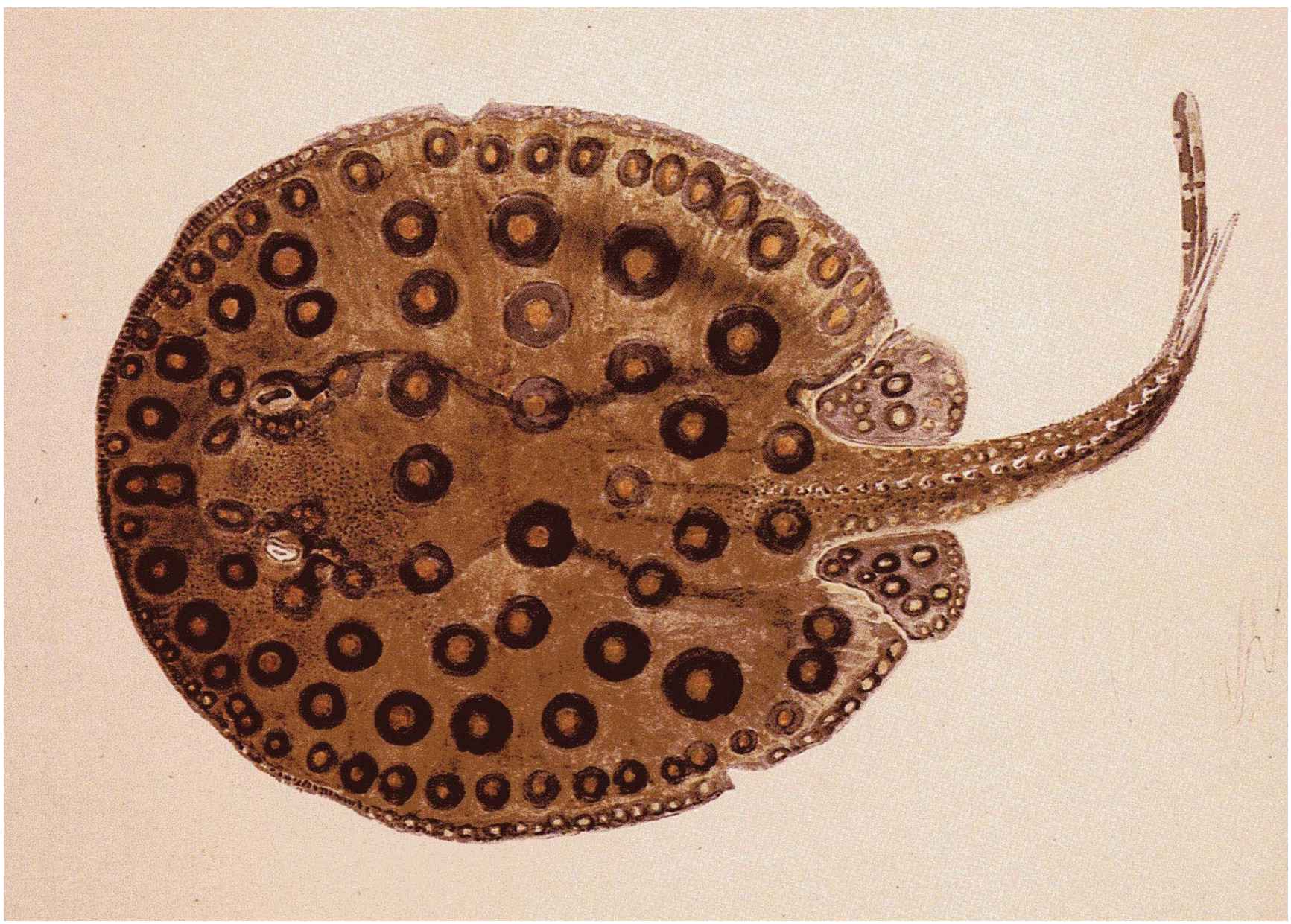

Fig. 2. Original illustration of NMW 78655 made by Johann Natterer after he collected the specimen; observe the position of ocelli on the disc compared to Fig. 1 (identical to specimen). Modified from Teixeira et al. (1999). 
A

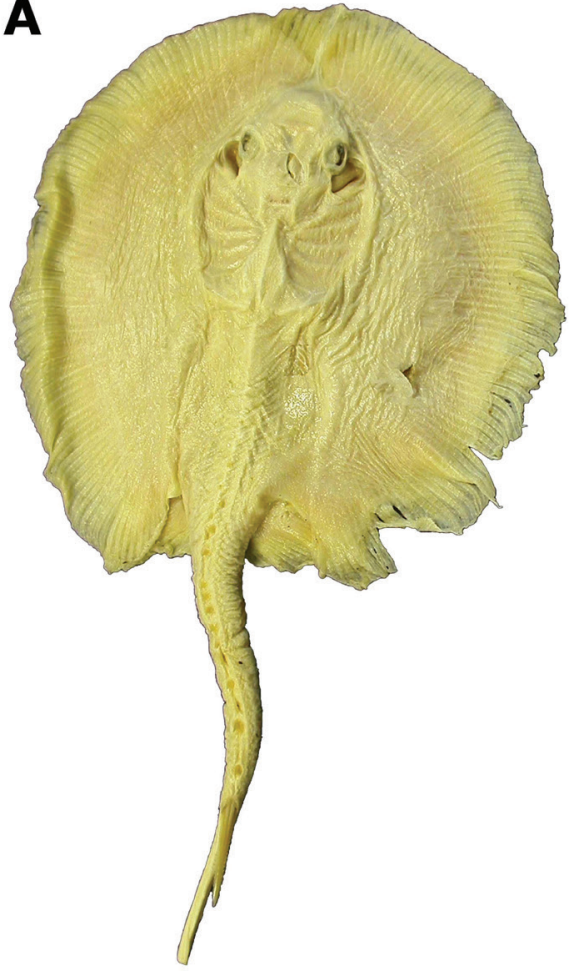

B

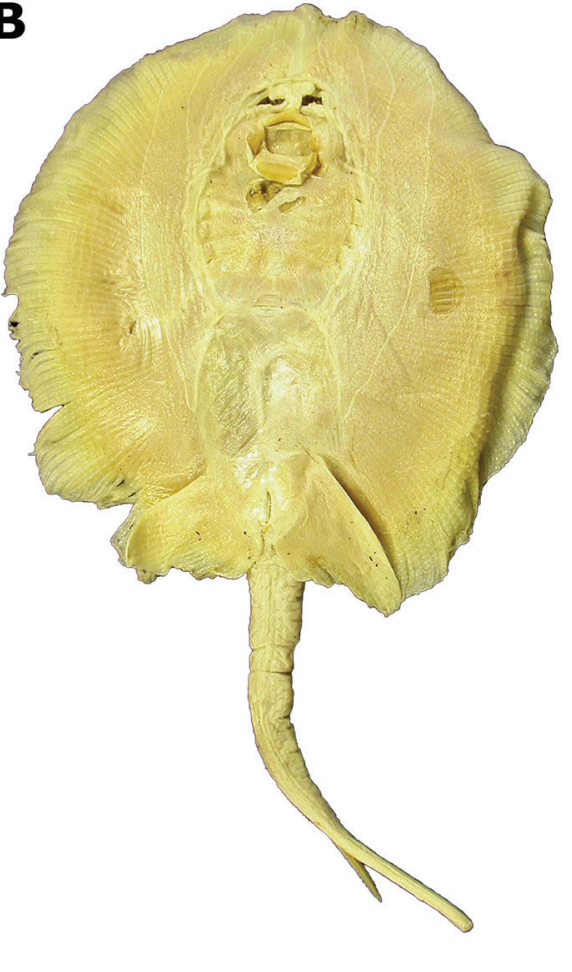

Fig. 3. Potamotrygon motoro. Dorsal (a) and ventral (b) views of paralectotype, ZMB 4662, juvenile female, $183 \mathrm{~mm}$ DW, Cuiabá River.

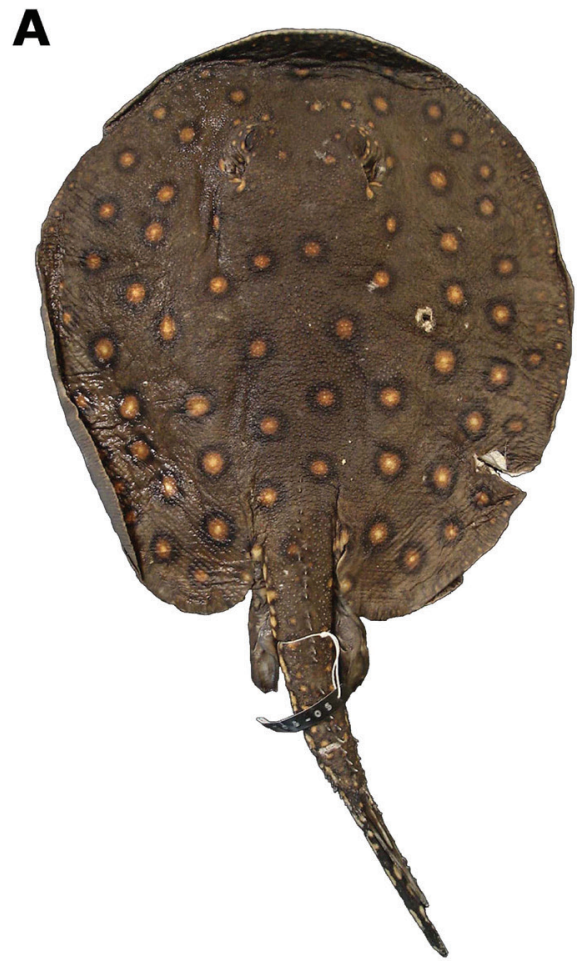

B

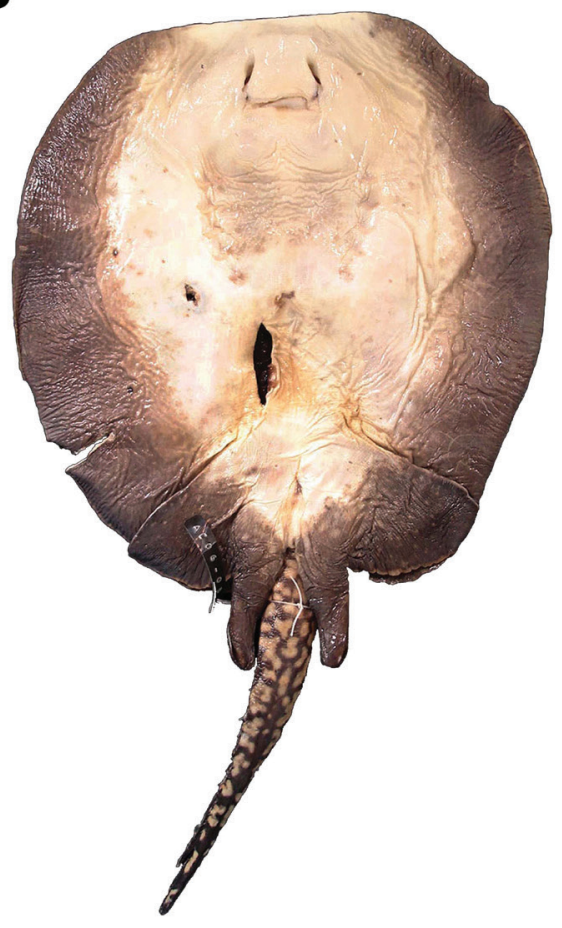

Fig. 4. Potamotrygon motoro. Dorsal (a) and ventral (b) views of an adult male specimen, MZUSP 111906, $310 \mathrm{~mm}$ DW, from the Mutum River. 
A

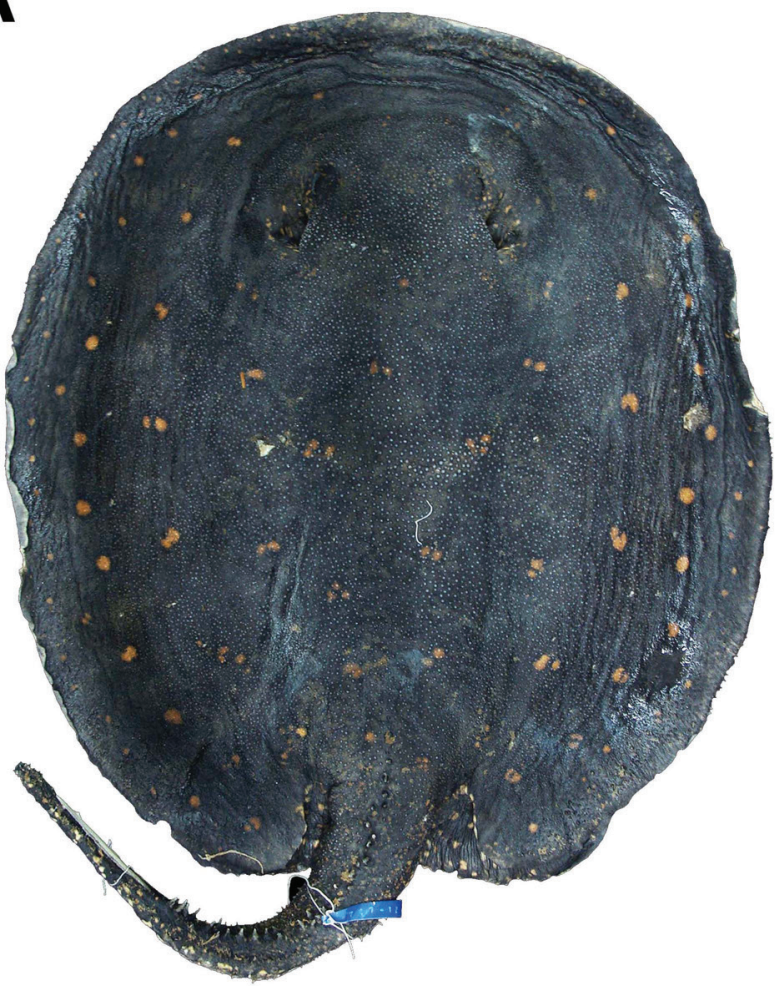

B

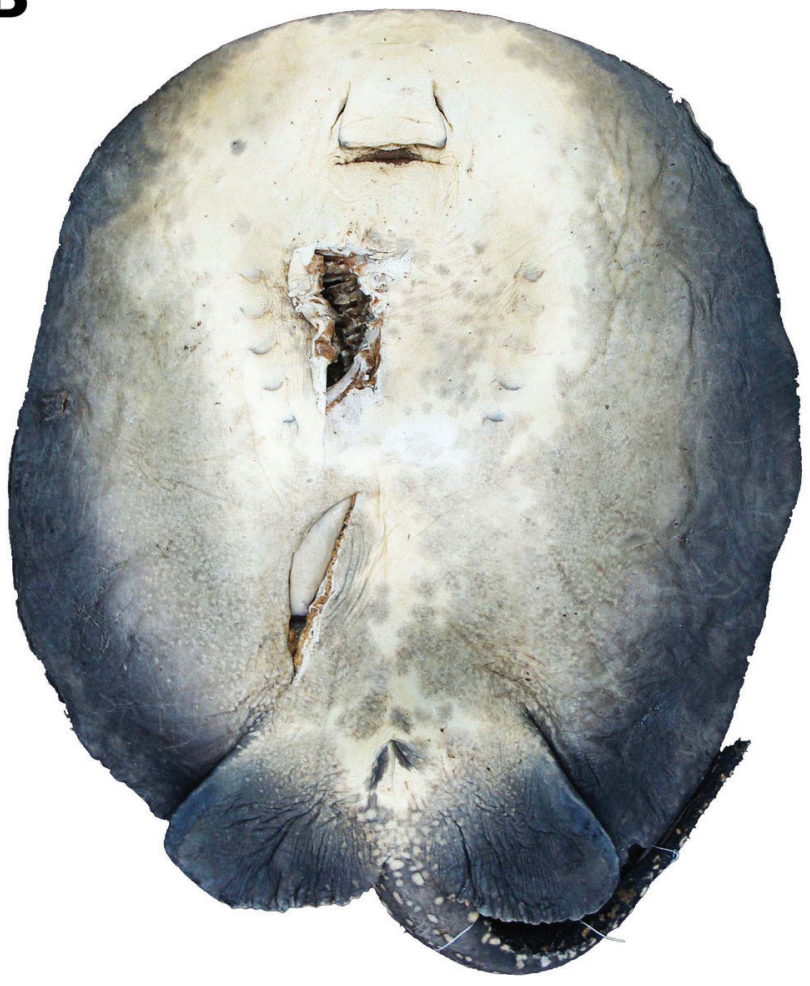

Fig. 5. Potamotrygon motoro. Dorsal (a) and ventral (b) views of an adult female specimen, MZUSP 110924, 479 mm DW, from the Padre Inácio River.
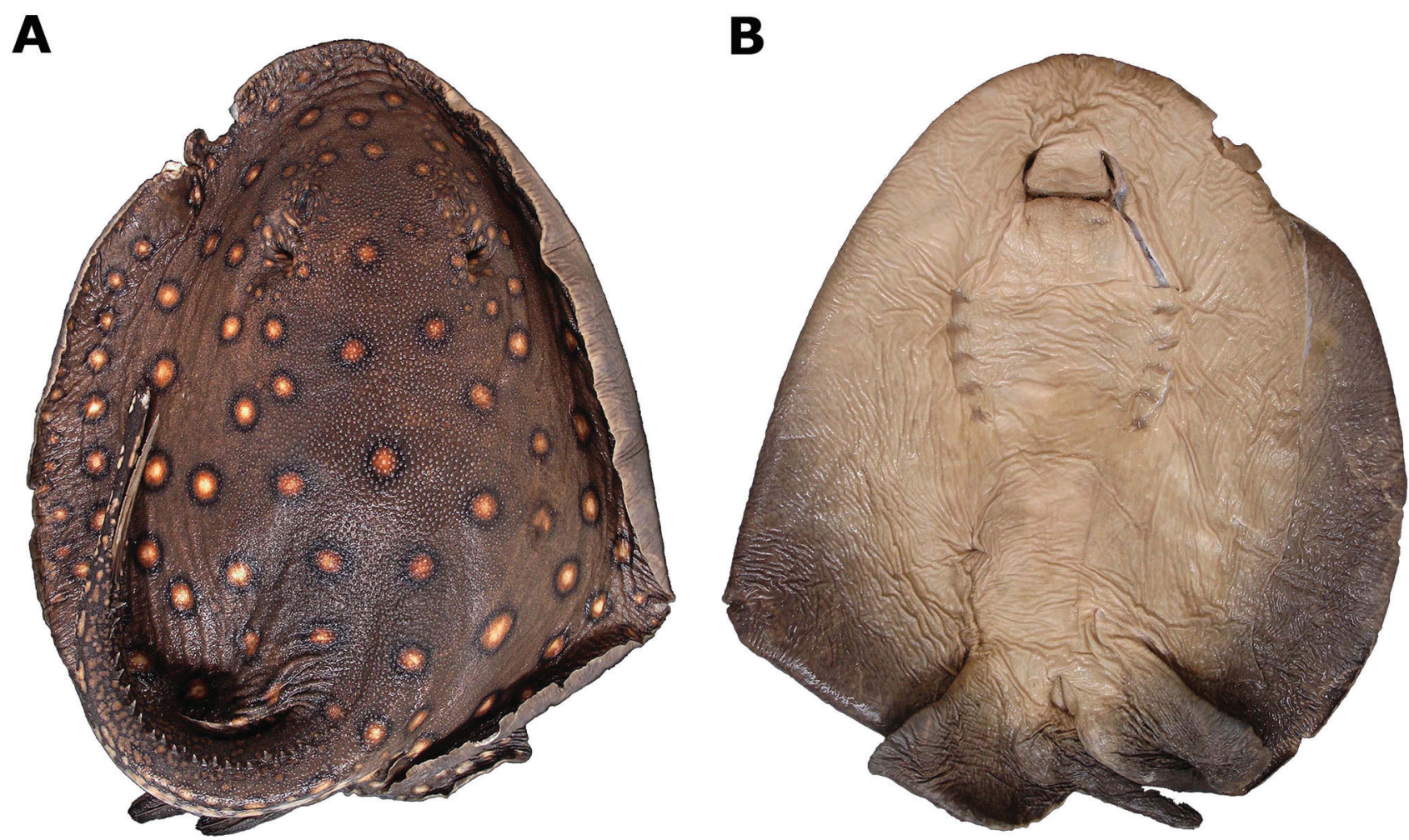

Fig. 6. Potamotrygon motoro. Dorsal (a) and ventral (b) views of an adult male specimen, NUP 4136, $275 \mathrm{~mm}$ DW, from the Cuiabá River. 
Paratrygon motoro: -Fowler, 1951: 8 [synonymy, distribution]. Potamotrygon labratoris: -Castex, 1963a: 54-55, fig. 12, p. 55 [citation to Santa Fé, Argentina] (nomen nudum).

Potamotrygon labradori: -Castex, Maciel \& Achenbach, 1963: 117-121, fig. 1, p. 118 [original description, type locality: Colastiné River, city of Santa Fé, Argentina ("Puerto de la ciudad de Santa Fe", p. 117)]; -Castex, 1963c: 289, 291 [taxonomic discussion]; -Castex 1963d: 7, 27, 35, 44-45, 48, 54-56, 72, 81, 83, fig. 12, p. 35 [references, taxonomic discussion, toxicity]; -Castex, 1964: 9, 12-13, 31 [references, external morphology, coloration, denticles and spines, redescription]; -Castex \& Maciel, 1965: 8-10, 14, fig. 2, p. 8, fig. 3, p. 9, fig. 4, p. 10 [distribution]; -Castex, 1967a: 487, 489, fig. 12, p. 489 [morphology of dermal denticles]; -Castex, 1967b: 493 [morphology of teeth]; -Achenbach \& Achenbach, 1976: 4, 27-28, plate II, fig. 1, p. 27 [taxonomic discussion, color pattern].

Potamotrygon pauckei: -Castex, 1963c: 289-294, fig. p. 292, [original description, type locality: Paraná River, city of Santa Fé, Argentina ("rio Paraná en las circanias de la ciudad de Santa Fé”, p. 289)]; -Castex, 1963d: 7, 27-28, 31, 36, 44-46, 48, 54, 56, 57, 72, 81, 83, 87, fig. 13, p. 36 [references, taxonomic discussion, toxicity]; -Castex, Maciel \& Achenbach, 1963: 120-121 [external morphology, coloration, denticles and spines]; -Castex, 1964: 9, 12, 30 [references, description, toxicity, distribution]; -Castex \& Maciel, 1965: 7-9, 14, fig. 2, p. 8, fig. 3, p. 9 [distribution]; -Castex, 1967a: 487, 489, figs. 10-11, p. 489 [morphology of dermal denticles]; -Castex, 1967b: 493-494 fig.3, p. 494. fig. 4, p. 494 [morphology of teeth].

Lectotype. NMW 78655, juvenile male, 208 mm DW, rio Guaporé, district of Vila Bela da Santíssima Trindade, State of Mato Grosso, Brazil, 08-09 Aug 1828, J. Natterer. Lectotype herein designated.

Paralectotypes: (3 specimens). NMW 77987, juvenile male specimen of Potamotrygon falkneri, $201 \mathrm{~mm}$ DW, rio Cuiabá, district of Cuiabá, State of Mato Grosso, Brazil; J. Natterer. NMW 78613, adult male specimen of P. falkneri, 344 mm DW, rio Cuiabá, district of Cuiabá, State of Mato Grosso, Brazil; J. Natterer, Aug 1824. ZMB 4662, juvenile female, $183 \mathrm{~mm}$ DW, Cuiabá River, district of Cuiabá, State of Mato Grosso, Brazil, J. Natterer coll.

Non-type specimens examined: (30 specimens). Brazil. State of Mato Grosso: MZUSP 111908, adult female, $343 \mathrm{~mm}$ DW, Mutum River, district of Barão de Melgaço; R. G. Gobbo \& M. Cardoso, 08 Jul 2006. MZUSP 111907, adult female, 336 mm DW, Mutum River, district of Barão de Melgaço; M. Cardoso \& V. Bueno, 07 Jul 2006. MZUSP 111910, adult female, 316 mm DW, Mutum River, district of Barão de Melgaço; F. P. L. Marques \& M. Cardoso, 08 Jul 2006. MZUSP 111905, adult male, 310 mm DW, Mutum River, district of Barão de Melgaço; F. P. L. Marques \& M. Cardoso, 05
Jul 2006. MZUSP 111906, adult male, 267 mm DW, Mutum River, district of Barão de Melgaço; F. P. L. Marques, 05 Jul 2006. MZUSP 111915, juvenile female, $220 \mathrm{~mm}$ DW, Mutum River, district of Barão de Melgaço; F. P. L. Marques \& M. Cardoso, 08 Jul 2006. MZUSP 111903, juvenile female, 214 mm DW, Mutum River, district of Barão de Melgaço; F. P. L. Marques \& M. Cardoso, 05 Jul 2006. MZUSP 111904, juvenile female, 214 mm DW, Mutum River, district of Barão de Melgaço; F. P. L. Marques \& M. Cardoso, 05 Jul 2006. MZUSP 111909, juvenile male, 188 mm DW, Mutum River, district of Barão de Melgaço; F. P. L. Marques \& J.P.C.B. da Silva, 08 Jul 2006. MZUSP 110924, adult female, $479 \mathrm{~mm}$ DW, Padre Inácio River, district of Cáceres; M. Cardoso \& M. V. Domingues, 29 Jun 2007. MZUSP 110917, adult female, $448 \mathrm{~mm}$ DW, same data as previous. MZUSP 110920, adult female, $405 \mathrm{~mm}$ DW, same data as previous. MZUSP 110919, adult female, $373 \mathrm{~mm}$ DW, same data as previous. NUP 2106, adult female, $405 \mathrm{~mm}$ DW, Cuiabá River, district of Chapada dos Guimarães, 1441'857''S 56²15'274' 'W, W. J. da Graça, 22 Aug 2003. MZUSP 110887, adult female, $396 \mathrm{~mm}$ DW, Cuiabá River, district of Rosário do Oeste; W. J. da Graça, 21 Apr 2000. MZUSP 110902, adult female, 362 mm DW, Cuiabá River, district of Rosário do Oeste, W. J. da Graça, 24 Apr 2000. MZUSP 110925, adult female, 348 mm DW, Manso reservatory, Manso River, district of Chapada dos Guimarães, W. J. da Graça, 23 Nov 2003. NUP 2969, adult female, 325 mm DW, same data as previous. NUP 4136, adult male, $275 \mathrm{~mm}$ DW, baia Sinhá Mariana, tributary of Cuiabá River, district of Barão de Melgaço, $16^{\circ} 20^{\prime} 20,5^{\prime}$ 'S 545' 10,3'”, W. J. da Graça, Oct 2003. MZUSP 14856, adult male, $265 \mathrm{~mm}$ DW, restinga de Taiamã, Paraguai River, district of Porto Estrela; R. M. C. Castro, 11 Aug 1980. NUP 3428, juvenile female, $220 \mathrm{~mm}$ DW, baia Sinhá Mariana, tributary of Cuiabá River, district of Barão de Melgaço, 16²0'S 55²54'W, W. J. da Graça, Jul 2002. State of Mato Grosso do Sul: MZUSP 110911, adult female, 404 mm DW, Paraguai River, subdistrict of Albuquerque, district of Corumbá, 19² $1^{\prime}$ 'S 573' W, F. P. L. Marques, F. Reyda, J. Caira \& W. Santana, 12 Dec 2003. MZUSP 110908, subadult male, 334 mm DW, Paraguai River, subdistrict

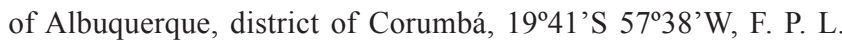
Marques, F. Reyda \& W. Santana, 09 Dec 2003. Argentina. Province of Santa Fé: MACN 9087, adult female, 375 mm DW, Colastinésul River, 11 Feb 2002. MACN 9089, adult female, $351 \mathrm{~mm}$ DW, Alto Verde; 02 Feb 2002. MACN 9091, adult male, 292 mm DW, Colastiné River. MACN 5706, juvenile female, 208 mm DW, Paraná Guazú River. MFA 231, holotype of P. labradori, subadult female, 298 mm DW, "Puerto de la ciudad de Santa Fe", Colastiné River, near of the harbor of district of Santa Fé, Nov 1962. MFA 232, holotype of $P$. pauckei, adult female, Colastiné River. Province of Entre Rios: MFA 236 (adult female, 495 mm DW), Paraná River.

Diagnosis. Potamotrygon motoro can be distinguished from all species of Potamotrygon, including $P$. histrix (Müller \& Henle, 1834), P. brachyura (Günther, 1880), P. falkneri Castex \& Maciel, 1963 and P. schuhmacheri Castex, 1964 (the four 
other valid species of Potamotrygon occurring in the ParanáParaguay basin), by the presence of conspicuous tricolored ocelli (with a central yellowish spot, intermediate orange ring, and external black ring), on a gray or brown dorsal disc background, and by presenting enlarged star-shaped dermal denticles covering the entire dorsal side of disc. The following characters in combination further distinguish $P$. motoro from the two new species of potamotrygonids also from the ParanáParaguay basin described below: dorsal disc background coloration gray or brown, with ocelli well-distributed above the entire disc surface including base of tail (some specimens of Potamotrygon pantanensis, sp. nov. and P. amandae, sp. nov. without ocelli or with ocelli distributed irregulary over disc and tail); ocelli of central disc region with diameter greater than eye-length (P. pantanensis, sp. nov. and $P$. amandae, sp. nov. present the majority of ocelli with diameter smaller than or equal to eye-length); all, or almost all, ocelli welldefined, rounded, and generally tricolored, with few ocelli bicolored or tetracolored (P. pantanensis, sp. nov. and $P$. amandae, sp. nov. with bicolored ocelli presenting rounded and vermiculate shapes, and some specimens of both species with less apparent ocelli); ventral disc coloration with a whitish central region, with disc outer margins gray or brownish gray (P. pantanensis, sp. nov. with ventral disc coloration either whitish in anterocentral region of disc or darker on rest of disc, and $P$. amandae, sp. nov. with a predominantly grayish ventral disc); dermal denticles present over almost entire dorsal disc area but more concentrated and larger on central disc region ( $P$. pantanensis, sp. nov. with dermal denticles present just on central disc, and $P$. amandae, sp. nov. with two morphological types of denticles on central disc with smaller size than P. motoro); a single dorsal row of relatively large, tall and vertically straight spines on dorsal tail (P. pantanensis, sp. nov. with double rows of small and curved spines, and $P$. amandae, sp. nov. with double or triple rows of small and straight spines); labial grooves absent (P. pantanensis, sp. nov. and $P$. amandae, sp. nov. with labial grooves); monognathic heterodonty present in adult specimens, with intermediate rows of dental plates with larger teeth ( $P$. pantanensis, sp. nov. and $P$. amandae, sp. nov. have teeth with similar size in all rows of dental plates); relatively greater length of external and internal margins of claspers, ranging from 17 to $21 \% \mathrm{DW}$ and 26.8 to $31.8 \% \mathrm{DW}$, respectively (length of external and internal margins of claspers in P. pantanensis, sp. nov. ranging, respectively, from 13.1 to $14.4 \% \mathrm{DW}$ and 24.3 to $27.9 \% \mathrm{DW}$, in P. amandae, sp. nov. ranging, respectively, from 10 to $13.9 \%$ DW and 23.2 to $26.7 \% \mathrm{DW}$ ); frontoparietal fontanelle relatively wide (frontoparietal fontanelle in P. pantanensis, sp. nov. and $P$. amandae, sp. nov. clearly more narrow); anterior and posterior angular cartilages with similar proportions (P. pantanensis, sp. nov. and $P$. amandae, sp. nov. with anterior angular cartilage clearly much greater than posterior angular cartilage).
Description. See Figs. 1-7, 21b-c, and 22 for general appearance. Proportional measurements and counts are presented, respectively, in Tables 1 and 2. The following account is based on all specimens of P. motoro examined, except for the skeletal description, which is based on specimens from the Cuiabá River.

External morphology. Disc subcircular, slightly longer than broad (disc length ranges from 105.1 to $120.7 \%$ DW). Head large, with relatively wide interorbital space ranging from 12.4 to $17.7 \% \mathrm{DW}$, interspiracular distance $17.5 \%$ to $25 \% \mathrm{DW}$, and internasal distance 7.7 to $11.1 \%$ DW. Prenasal distance 13.3 to $17.5 \% \mathrm{DW}$, and preoral distance 17.5 to $25.1 \% \mathrm{DW}$. Mouth relatively large, 8.6 to $14.4 \% \mathrm{DW}$, presenting five buccal papillae, with three in central region and two lateral. Labial grooves absent from mouth corners, but some smaller specimens present undeveloped striations similar to labial grooves. Small, distinct rostral protuberance lacking. Eyes bulging dorsally, relatively large. Spiracles muscular, relatively large and trapezoidal. Branchial basket relatively broad and short, distance between fifth pair of branchial slits greater than distance between first and fifth pairs of branchial slits (Table 1).

Teeth arranged in quincunx and relatively large; tooth from intermediate rows of upper jaw reaching some four millimeters in width in sexually mature specimens. In adults, teeth sexually dimorphic: males with cusps on central row of both jaws, females with flattened teeth in all rows (Fig. 8); smaller specimens without sexual dimorphism. In both sexes, adults present monognathic heterodonty in both upper and lower jaws. In males, cusps on lower jaw slightly greater than cusps on upper jaw. Lateral tooth rows in upper jaw with larger teeth than central rows; on lower jaw, central rows with larger teeth than lateral rows. In females, upper jaw presents intermediate rows with larger teeth than central and lateral rows; lower jaw with teeth in central rows slightly larger than teeth on lateral rows. Tooth rows 23-32/26-34, with 3-7/4-10 median tooth rows (Table 2).

Pelvic fins generally covered dorsally by disc or protruding only slightly, not so triangular, with lateral margin slightly rounded and posterior margin undulated; anterior margins of pelvic fins oblique to midline, with range 17.5 to $32.8 \%$ DW. Claspers relatively conical, slightly tapered posteriorly. Distance from clasper tip to distal margin of cloaca in adults (in sexually mature males) ranges from $26.8 \%$ to $31.8 \% \mathrm{DW}$ (mean 29.7\% DW). Distance from clasper tip to external margin of pelvic fins ranges from 17 to $21 \% \mathrm{DW}$ (mean 18.9\% DW). Clasper groove originates dorsally on medial clasper region near insertion of pelvic fin, at same level of posterior margins of pelvic fins. Clasper groove extends slightly laterally and then straight posteriorly to more or less posterior margin of dorsal pseudosiphon (Fig. 9). Dorsal pseudosiphon well-developed and inclined medially, with mean length in 
mature males 3.5\% DW (ranging from 3.3 to $3.9 \% \mathrm{DW}$ ). Ventral pseudosiphon also well-developed, extending from lateral portion of clasper near level of dorsal pseudosiphon to posterior margin of lateral clasper; mean length of ventral pseudosiphon $11.9 \%$ DW (ranging from 9.4 to $12.9 \% \mathrm{DW}$ ).
Tail thick and moderately short, mean tail length $78.5 \%$ DW, mean tail width $13.4 \%$ DW. Dorsal and ventral folds present but only moderately developed. Younger specimens with proportionally longer tails compared to adults, and also with more developed tail folds.
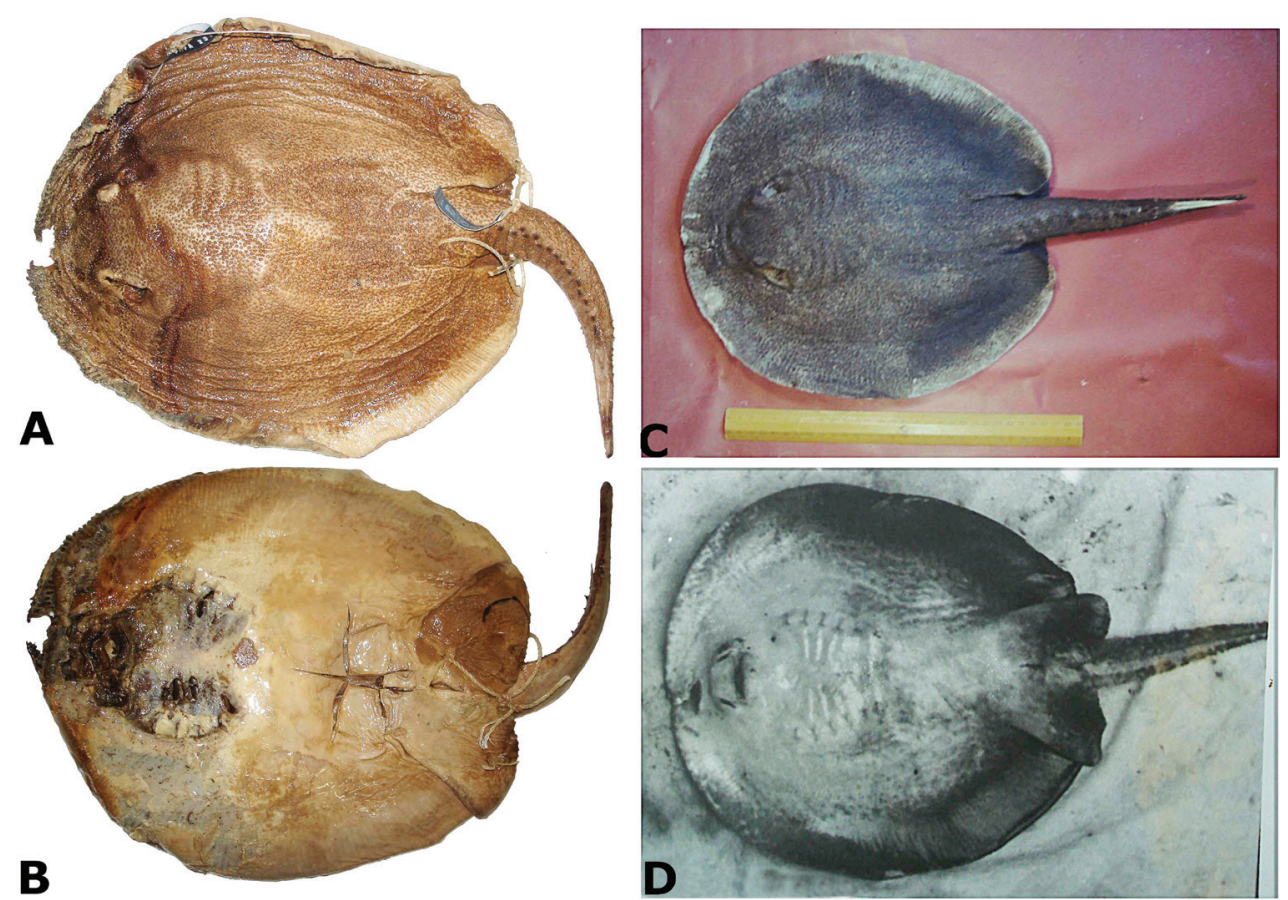

Fig. 7. Potamotrygon motoro. Dorsal (a) and ventral (b) views of an adult female specimen, MFA 231, 298 mm DW, designated as holotype of Potamotrygon labradori by Castex et al. (1963), from the Colastiné River. Dorsal (c) and ventral (d) views of MFA 231 from photographs found in the archives of M. Castex, in the MFA, Santa Fé.
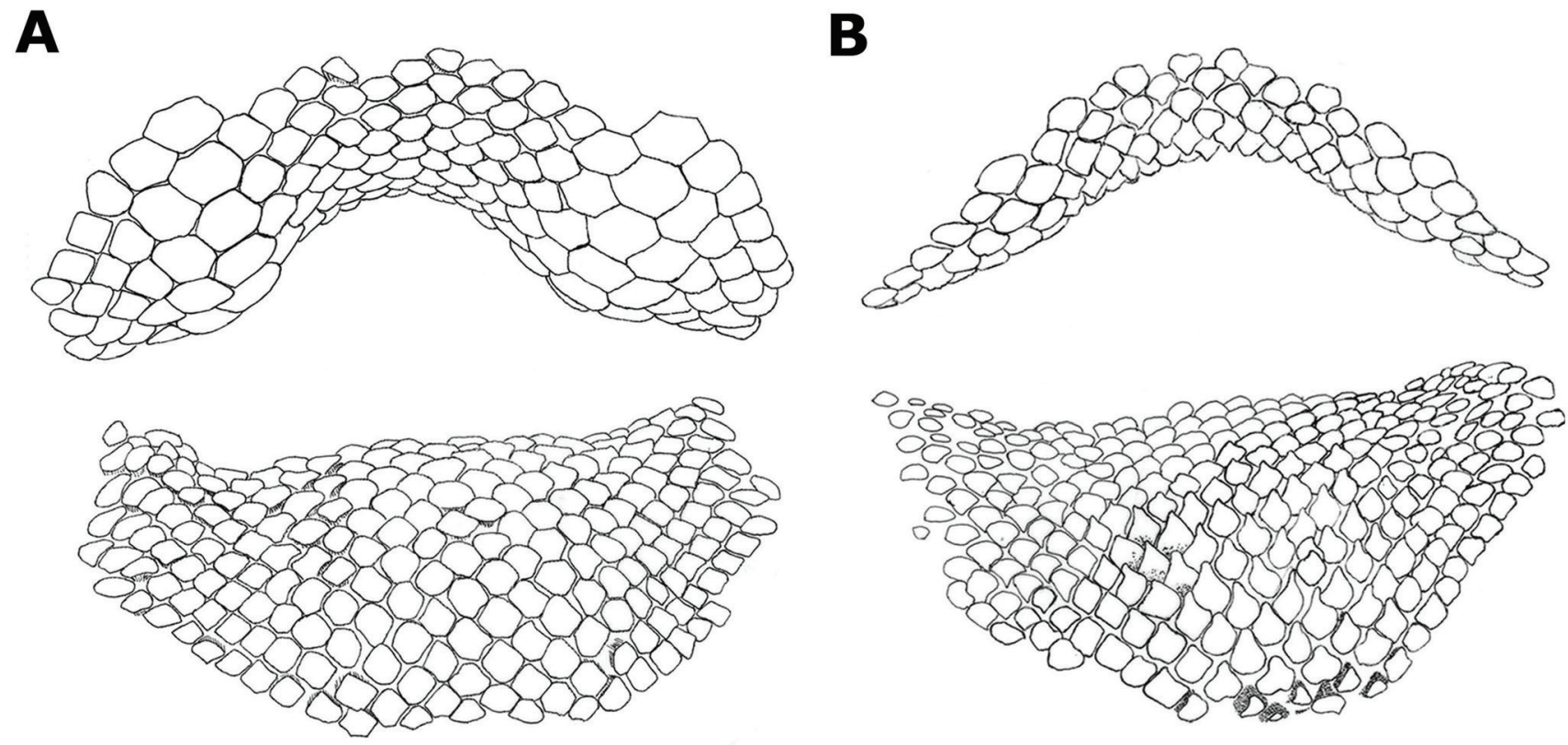

$10 \mathrm{~mm}$

$5 \mathbf{~ m m}$

Fig. 8. Potamotrygon motoro. Jaws of adult specimens showing dimorphic sexual morphology. Left (a) an adult female, MZUSP 110902, $362 \mathrm{~mm}$ DW, and right (b) an adult male, NUP 4136. Note the morphological differences between the teeth of both specimens and between the rows in the same specimen. 


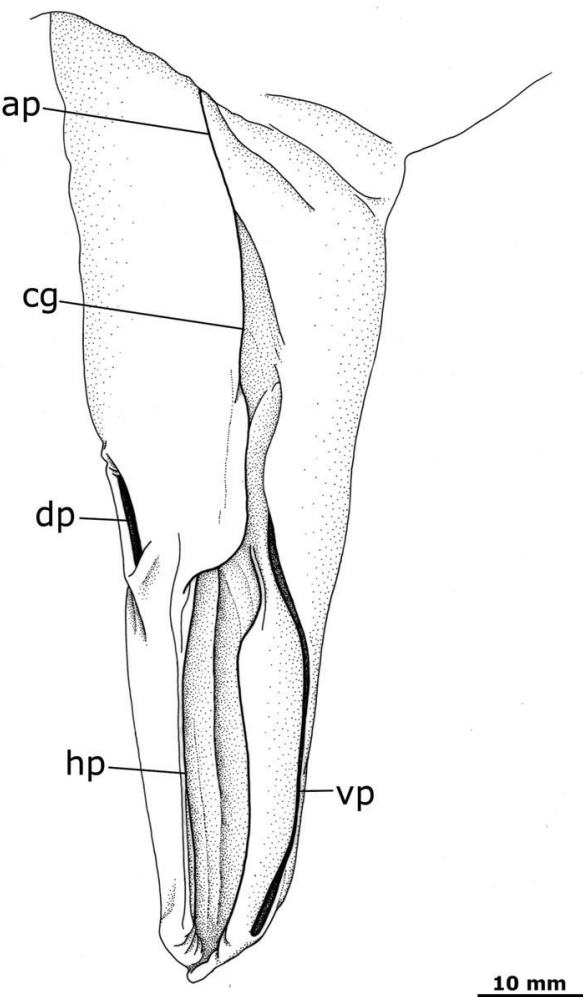

Fig. 9. Potamotrygon motoro. Dorsal view of right clasper of an adult male, NUP 4136. Abbreviations: ap, apopyle; cg, clasper groove; dp, dorsal pseudosiphon; hp, hypopyle; vp, ventral pseudosiphon.

Coloration. Dorsal disc background gray, dark gray, olive, olivaceous brown, or dark brown, with ocelli distributed over entire disc to base of tail (Figs. 1a, 2, 4a, 5a, 6a, 7c, 21b-c). Most specimens present relatively large ocelli, larger or with size about equal to eye-length; largest ocelli present on central region of disc. Ocelli reduce in size and increase in number proximal to disc margins. Ocelli generally with three welldefined color bands, but sometimes with two or four color bands (Fig. 10). Ocelli always present a peripheral dark ring. Ocelli center yellowish or orange, and with an intermediate band (a single band in tricolored ocelli, two bands in tetracolored ocelli). Intermediate band yellow, orange, beige, reddish, or similar to background disc color. Region of eyes and spiracles with whitish or orangish small spots, much smaller than eyes. Few specimens with ocelli with irregular outer band, mostly over central and intermediate disc regions, grouped very closely with two or three smaller ocelli; these specimens frequently lack ocelli on outer disc margins. Younger specimens present more closely grouped ocelli on disc compared to adults. Dorsal coloration of pelvic fins similar to disc, but with ocelli more faint in color. Dorsal coloration of tail at base similar to dorsal disc color. Small orange and yellow spots present on tail base extending posteriorly to caudal sting. Dorsal tail with small orange spots near dorsal row of spines, and yellow spots on
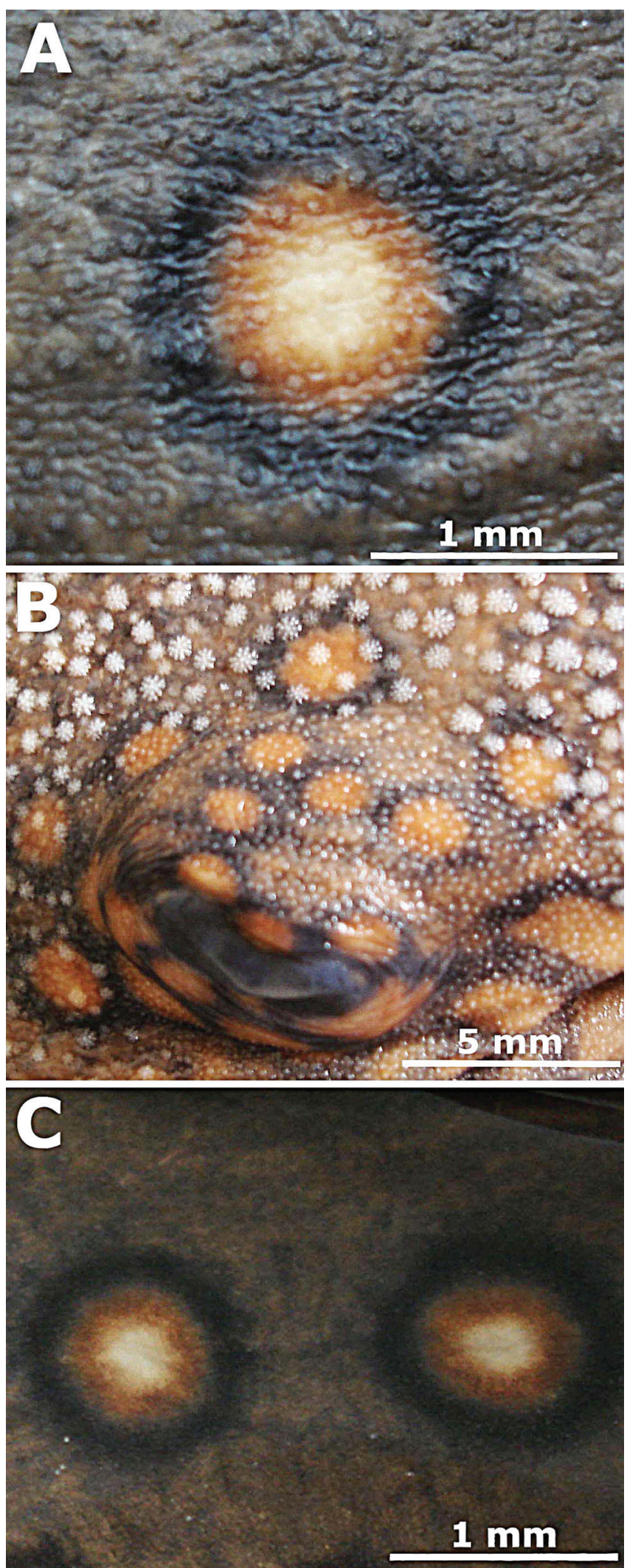

Fig. 10. Potamotrygon motoro. Detail of dorsal coloration: (a) tricolored ocelli in NUP 2106, adult female, $405 \mathrm{~mm} \mathrm{DW,} \mathrm{(b)}$ bicolored ocelli around eyes of NUP 2106, (c) tetracolored ocelli founded in NUP 4136. 
lateral tail aspect. Some specimens present only yellow spots on tail. Striped pattern of alternating light and dark bands with some whitish spots occurring posterior to caudal stings.

Ventral disc coloration divided into two regions, one lighter colored at disc center, usually whitish, light yellow or beige, and another on outer disc periphery with a darker gray or light brown color; an intermediate tone sometimes present between both regions (Figs. 1b 4b, 5b, 6b, 7d). The light colored central area of disc extends from the tip of the snout to the insertions of pelvic fins; small dark spots sometimes present on lateral or central disc. Darker outer disc margin more intense toward posterior disc, pelvic fins and claspers; anterior margin of disc sometimes with darker color, lacking over ventral snout. In some specimens dark margins of disc with small whitish spots, mostly posteriorly. Intermediate region generally with spots; some specimens with intermediate band more prominent on posterocentral disc region. Ventral tail coloration at base with several whitish spots on a predominantly dark background; middle region of ventral tail with spots more closely positioned.
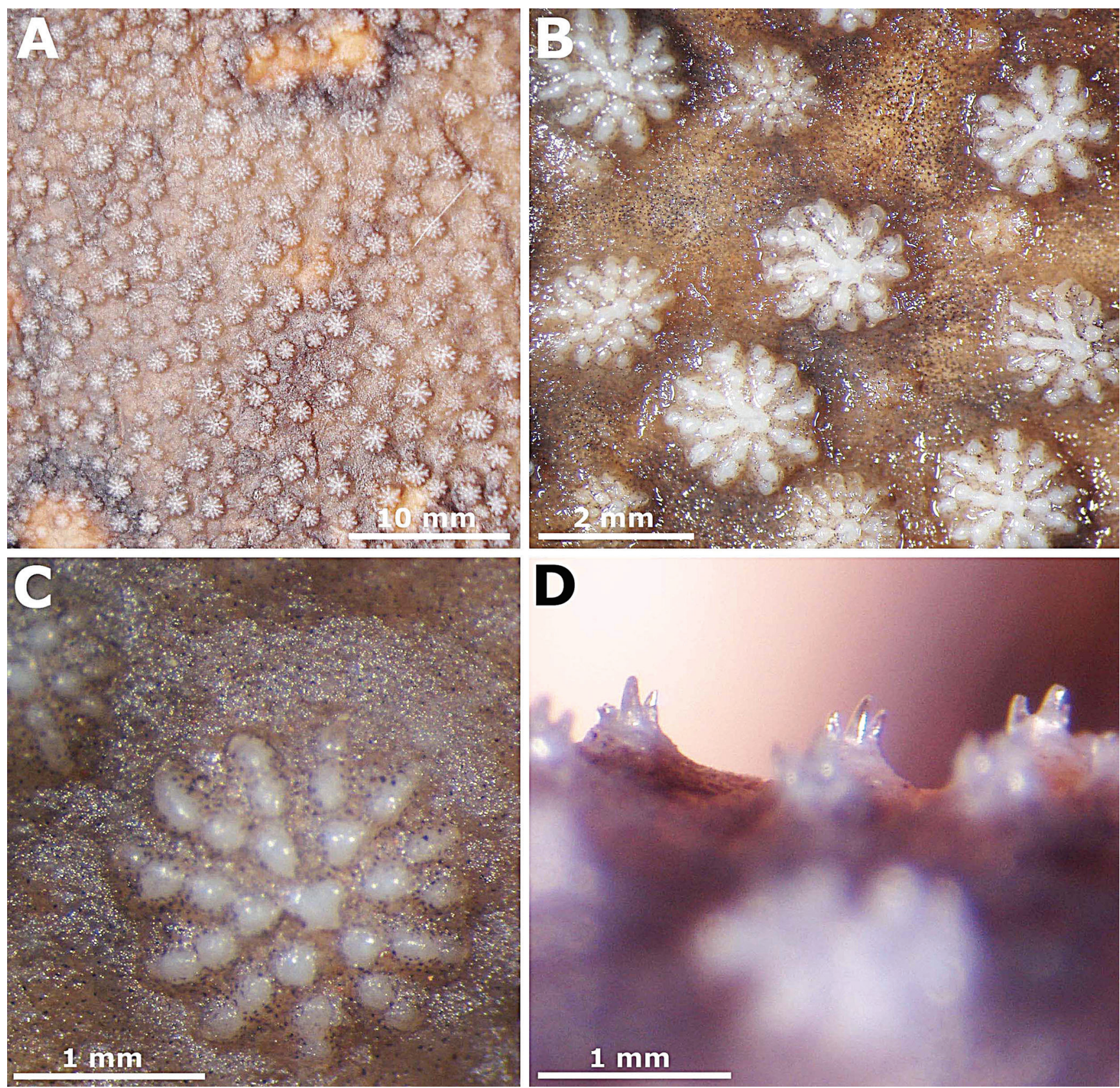

\section{D}

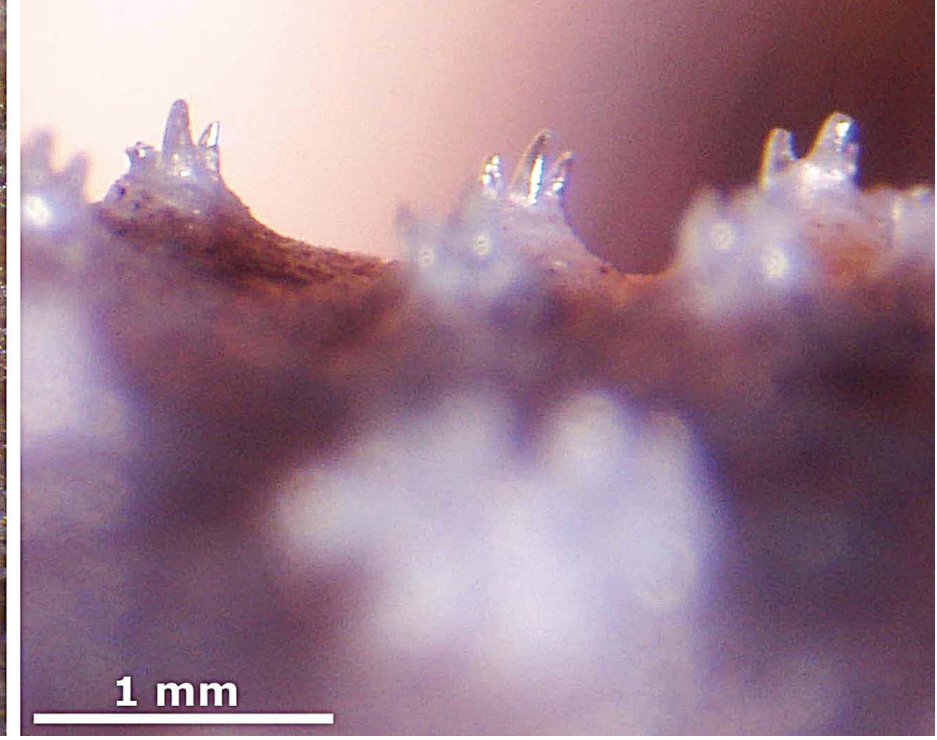

Fig. 11. Potamotrygon motoro. Details of dermal denticles in an adult female, MZUSP 110902. Morphology and concentration of dermal denticles on dorsal disc in (a) and (b), a typical star-shaped denticle in (c) showing the crown with its central plate and dichotomous ridges, and in (d) trichotomous denticles present in spiracular openings. 
In alcohol, specimens preserved for many years present ocelli light yellow or whitish, losing characteristic orange and dark yellow rings (Fig. 3); outer bands of ocelli lighter, similar to brown background color of dorsal disc. Ventral disc margins lighter, usually beige.

Squamation. Dermal denticles present on entire dorsal region of disc and tail. Largest denticles on central part of dorsal disc, with star-shaped crowns and dichotomous outer ridges (Figs. 11a-c, 22). Denticles more concentrated on central part of disc, mostly above branchial basket, especially in adult females. Marginal region of disc, and area of spiracles and eyes, presenting pointed dermal denticles with diameters smaller than star-shaped dermal denticles. Most specimens with minute, three-ridged denticles on spiracular margins (Fig.

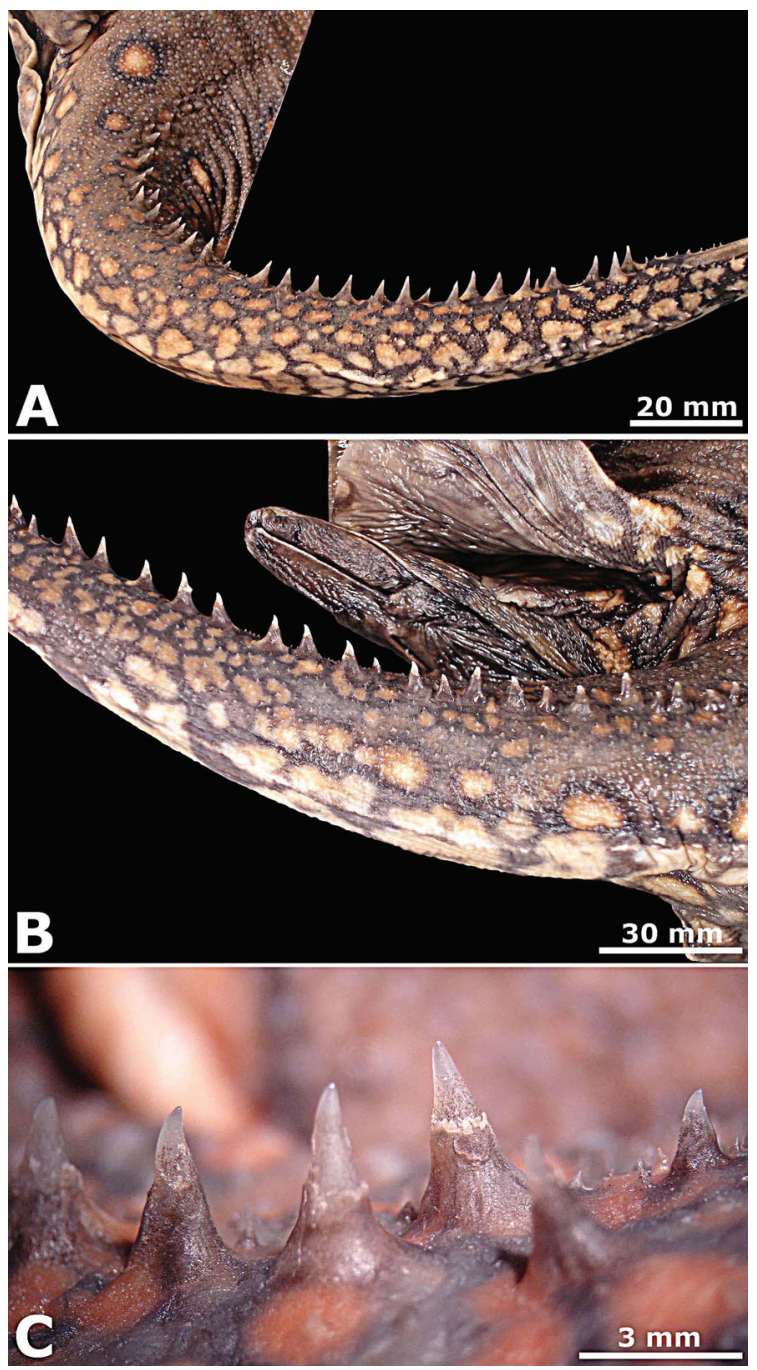

Fig. 12. Potamotrygon motoro. (a) dorsal view of tail showing entire dorsal row of pointed spines and the well-developed lateral rows in an adult female, MZUSP 110887, $396 \mathrm{~mm}$ DW; (b) showing the single row and format of enlarged pointedspines in an adult male, NUP 4136; (c) detail of some enlarged pointed-spines of dorsal row in adult female (MZUSP 110887). 11d). Crown plate with a single pointed denticle or with a threeridged form. Some specimens display more developed pointed denticles on anterior disc margin and at extremities of posterior disc margins. Denticles with a transitional morphology between star-shaped and acuminate forms between central and marginal disc regions.

Transitional denticles also on tail base, taller and more pointed than those over central disc, but with smaller diameters. Number of these transitional denticles varies little between specimens, and some specimens with only a few star-shaped denticles present on tail base. Denticles with pointed crowns of varying size posterior to tail base, from mid-tail to distal tail extremity. A single row of pointed spines on dorsal tail; in few specimens dorsal row resembles two irregular rows (Fig. 12a). Row generally begins at region of tail origin (near disc insertion), but in some specimens it originates slightly anteriorly. Dorsal row terminates near insertion of caudal sting (Fig. 12b). Pointed spines greater in size, with large and rounded base, and pointed, straight and higher crowns, sometimes with tip slightly curved (Fig. 12c). Spines positioned near caudal sting generally more inclined. Number of spines present in dorsal row varies between 18 and 41 (Table 2). Single lateral row of pointed spines becomes irregular near caudal sting. Lateral rows begin near mid-tail region and terminate at tail distal tip in females, and near caudal sting in males. Lateral pointed spines morphologically similar to dorsal spines, but smaller and without curved tips.

Ventral lateral-line canals. Description based on four adult specimens, two males (NUP 4136, 275 mm DW; MZUSP 111906, $267 \mathrm{~mm} \mathrm{DW})$ and two females (MZUSP 110925, 348 mm DW; MZUSP 111908, 343 mm DW) (Fig. 13).

Hyomandibular canal (hyc) originates between anterior portion of nostrils and extends to anterior disc margin, curving to lateral disc region, and continuing parallel to disc margin to posterior disc region (as the subpleural component of hyomandibular canal; spc), where it forms an elliptical curve (subpleural loop; spl) close to level of pelvic fin origin. Straight, short and unramified subpleural tubules (spt) occur on anterior portion of hyomandibular canal, extending in parallel toward anterolateral disc margin. A single, unramified posterior subpleural tubule (pst) extends posteriorly and slightly diagonally from posterior subpleural loop. The hyomandibular canal extends anteriorly from the subpleural loop to arch around the branchial slits as the jugular component of the hyomandibular canal (jch). The jugular component continues more or less straight in direction of first pair of branchial slits, where it deflects medially as the angular component of the hyomandibular canal (ach). The angular component makes a pronounced curve before connecting with the nasal canal (nas) anteriorly near level of mouth opening. 


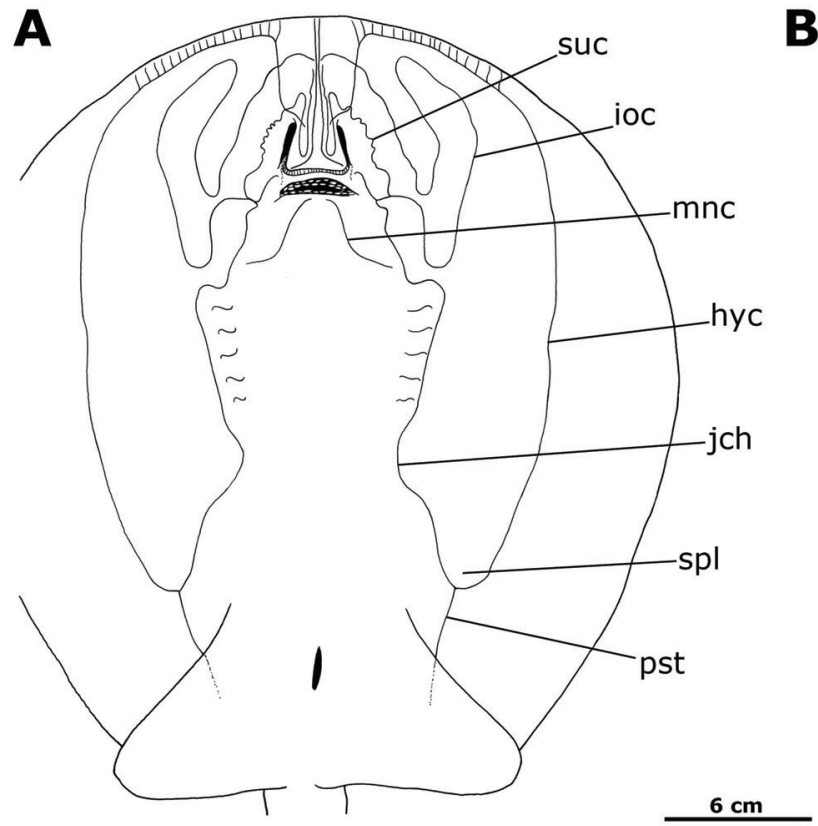

B

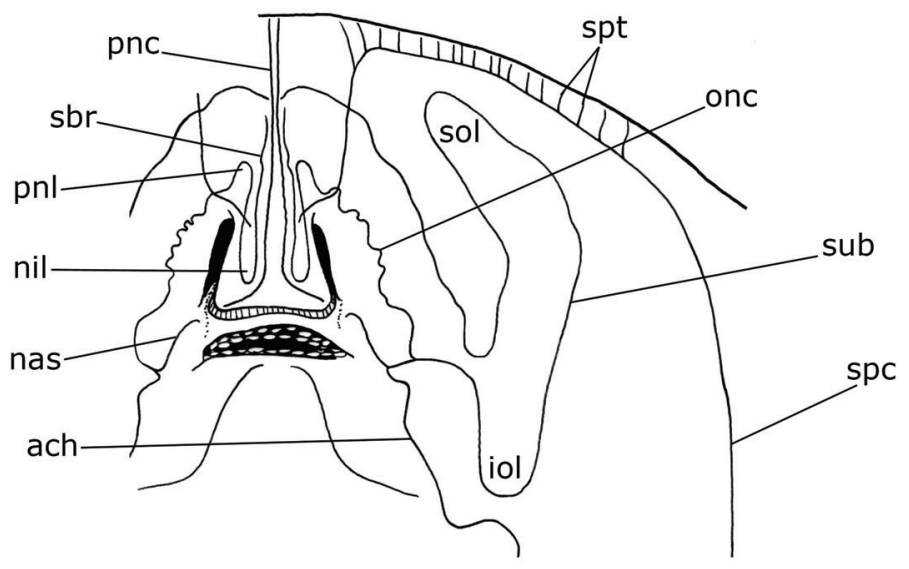

Fig. 13. Potamotrygon motoro. Ventral canals of lateral line system in an adult female, MZUSP 111908, $343 \mathrm{~mm}$ DW. Abbreviations: hyc, hyomandibular canal; ioc, infraorbital canal; mnc, mandibular canal; nas, nasal canal; suc, supraorbital canal; ach, angular component of hyomandibular canal; iol, infraorbital loop; jch, jugular component of hyomandibular canal; nil, nasointernal loop; onc, orbitonasal component of supraorbital canal; pnc, prenasal component of nasal canal; pnl, prenasal loop; pst, posterior subpleural tubule; sbr, subrostral component of supraorbital canal; sol, suborbital loop; spc, subpleural component of hyomandibular canal; spl, subpleural loop; spt, subpleural tubules; sub, suborbital component of infraorbital canal.

Infraorbital (ioc) and supraorbital (suc) canals connect with the angular component of hyomandibular canal and nasal canal at close to level of mouth opening. Infraorbital canal extends laterally to form large and conspicuous suborbital component of infraorbital canal (sub). Posterior section of this component formed by large infraorbital loop (iol) reaching posteriorly to close to first gill opening; anterior portion composed of supraorbital loop (sol) extending anteriorly to close to hyomandibular canal. Supraorbital loop significantly curved anteromedially. Infraorbital canal continues anteromedially from suborbital component, crossing hyomandibular canal and terminating very close to prenasal component of nasal canal (pnc), where it deflects internally to penetrate disc.

Sinuous, highly undulated orbitonasal component of supraorbital canal (onc) extends anteromedially from junction with infraorbital canal. Orbitonasal component runs slightly parallel to ascending branch of infraorbital canal, reaching hyomandibular canal just anterior to nostrils, and extending anteromedially and then posteriorly to form prenasal loop (pnl). Prenasal loop extends posteriorly to about middle of nasal curtain, where it forms nasointernal loop (nil), before recurving anteriorly to reach mid-snout region as subrostral component of supraorbital canal (sbr). Suborbital component ascends in direction of anterior disc margin where it penetrates into disc near final part of infraorbital canal.
Nasal canal (nas) continuous with final portion of hyomandibular canal, and ascends diagonally in direction of posterior corner of nostrils where it penetrates disc. Posterior portion of prenasal component of nasal canal (pnc) extends diagonally over posterior nasal curtain, very close to nasointernal loop (nil). Prenasal component extends straight anteriorly to anterior disc margin, in parallel to subrostral component. Mandibular canal (mnc) elongate, extending diagonally from just posterior to central margin of lower jaw to near lower part of angular component of hyomandibular canal.

Neurocranium. Nasal capsules (NC) ventrolaterally expanded, hialine, formed by thin sheets of cartilage. Internasal septum separating capsules very slender. Nasal capsules anteriorly very rounded, with very broad nasal apertures (NA). Condyle for articulation with antorbital cartilage condyle (AOC) on posterolateral portion of nasal capsules (Figs. 14a-c). Antorbital cartilages very slender, dorsoventrally flattened, triangular and tapering posteriorly. Preorbital process (PRP) well-developed, tapering significantly, and extending posterolaterally. Two preorbital canals cross the preorbital process; posterior canal more diagonal than anterior. Foramina of preorbital canals divided in anterior foramen of preorbital canal I (AFP I) and anterior foramen of preorbital canal II (AFP II), and posterior foramen of preorbital canal I (PFP I) and posterior foramen of preorbital canal II (PFP II). Two anterior canals located dorsally on the base of preorbital 

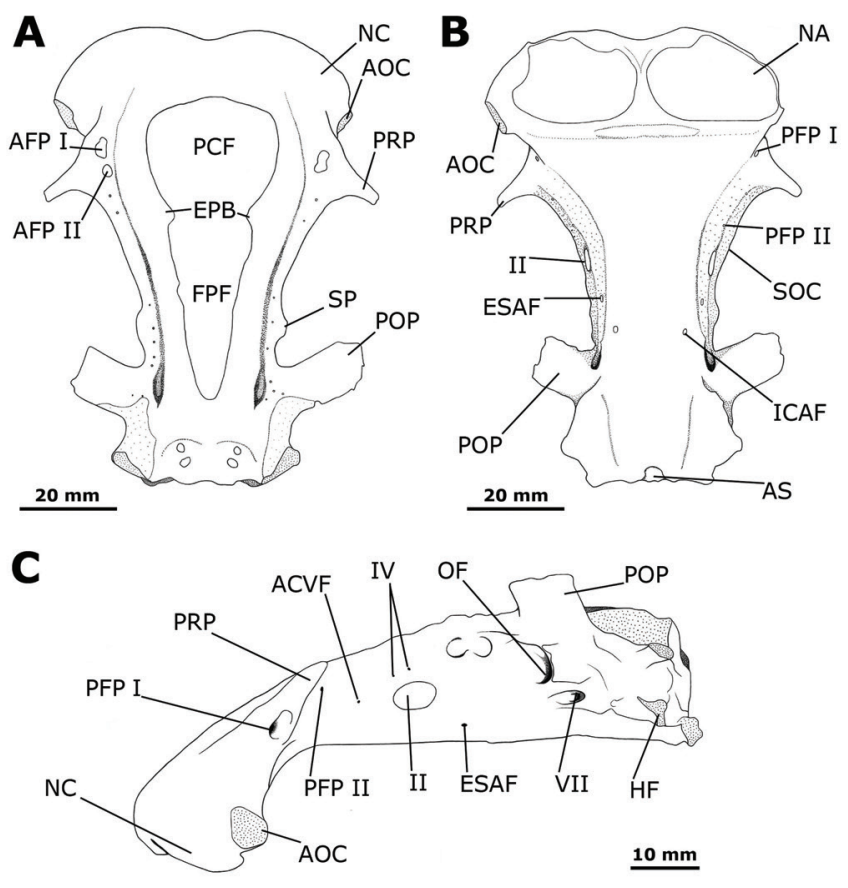

D

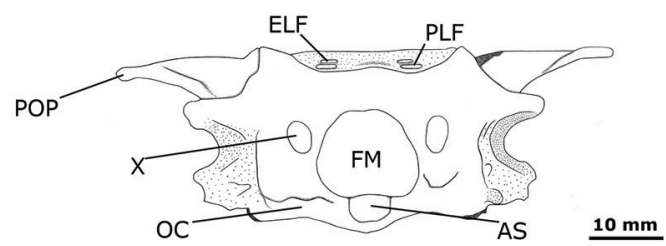

Fig. 14. Potamotrygon motoro. Neurocranium of an adult male specimen, MZUSP 111905, $310 \mathrm{~mm}$ DW, in (a) dorsal, (b) ventral, (c) lateral and (d) posterior views. Abbreviations: ACVF, anterior cerebral vein foramen; AFP I and II, anterior foramen of preorbital canal I and II; AOC, antorbital cartilage condyle; AS, articular surface; ELF, endolymphatic foramen; EPB, epiphysial bar; ESAF, efferent spiracular artery foramen; FPF, frontoparietal fontanelle; FM, foramen magnum; HF, hyomandibular facet; ICAF, internal carotid artery foramen; NA, nasal aperture; NC, nasal capsule; OC, occipital condyle; OF, orbital fissure; PCF, precerebral fontanelle; PFP I and II, posterior foramen of preorbital canal I and II; PFL, perilymphatic foramen; POP, postorbital process; PRP, preorbital process; SOC, supraorbital crest; SP, supraorbital process; II, optic nerve foramen; IV, trochlear nerve foramen; VII, facial nerve foramen; $\mathbf{X}$, vagus nerve foramen.

process; first foramen greater and positioned more anteriorly than the second; second positioned closer to supraorbital crest (SOC). Posterior foramina positioned ventrolaterally in relation to preorbital process near beginning of supraorbital crest (Fig. 14b); anterior foramen larger and located ventrally near junction of preorbital process with nasal capsule. Eye-stalk (ES) goblet-like, extending from the lateral wall of orbit just posterior to optic nerve foramen (II), situated in central portion of orbital wall (Fig. 15a, b). Oculomotor nerve foramen (III) just dorsolateral to eye-stalk

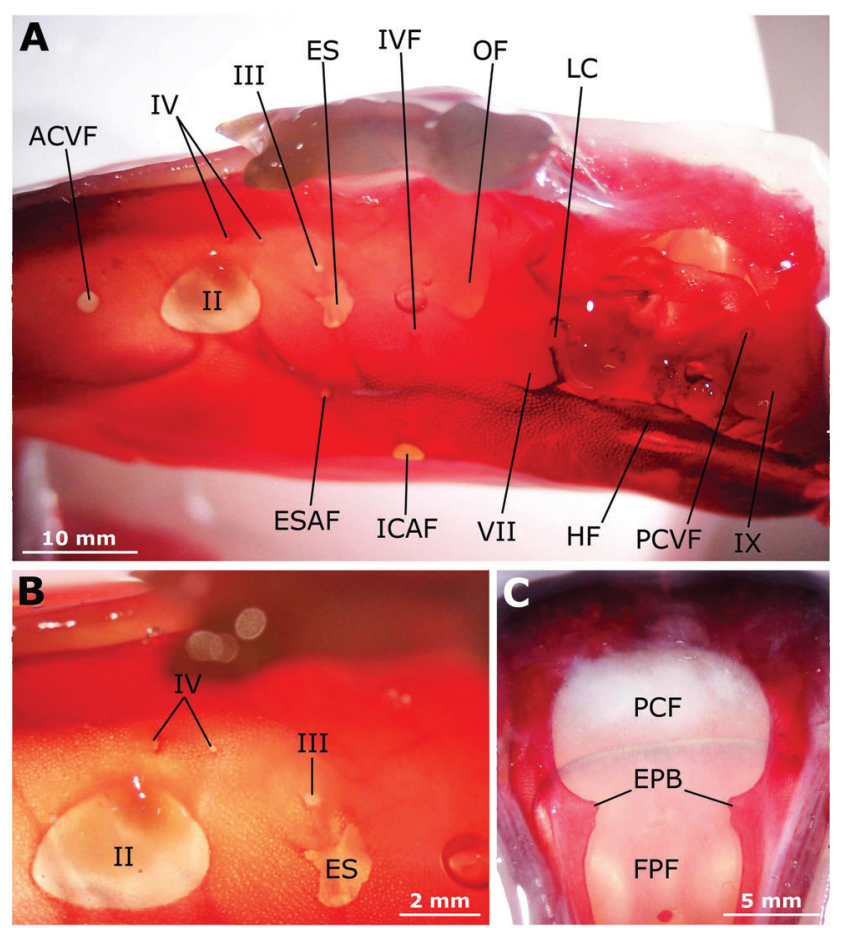

Fig. 15. Potamotrygon motoro. Cleared-and-stained neurocranium of a juvenile male specimen (MZUSP 111909, $188 \mathrm{~mm}$ DW) in lateral (a) view, showing details of foramina and their locations. Detail of foramina in orbital region (b) and of epiphysial bar in dorsal fontanelle (c). Abbreviations: ACVF, anterior cerebral vein foramen; EPB, epiphysial bar; ES, eye-stalk; ESAF, efferent spiracular artery foramen; FPF, frontoparietal fontanelle; HF, hyomandibular facet; ICAF, internal carotid artery foramen; IVF, interorbital vein foramen; LC, lateral comissure; $\mathbf{O F}$, orbital fissure; PCF, precerebral fontanelle; PCVF, posterior cerebral vein foramen; II, optic nerve foramen; III, oculomotor nerve foramen; IV, trochlear nerve foramen; VII, facial nerve foramen; IX, glossopharyngeal nerve foramen.

(Fig. 15a, b). Anterior cerebral vein foramen (ACVF) anterodorsal in relation to optic nerve foramen (Fig. 15a). Efferent spiracular artery foramen (ESAF) posteroventral to eye-stalk (Figs. 14c, 15a). Two small foramina for trochlear nerve (IV) dorsal to optic nerve foramen (Figs 14c, 15a, b). Orbital fissure (OF) relatively large, posteroventrally located near junction of orbit and optic capsule, within a small concavity (Figs. 14b, 15a). Interorbital vein foramen (IVF) just ventrolateral to orbital fissure (Fig. 15a).

Supraorbital crest (SOC) moderately demarcated from base of preorbital process to base of postorbital process, pierced by very minute foramina for branches of superficial ophthalmic nerve. Supraorbital process (SP) broadly triangular, moderately developed and just anterior to postorbital process (POP). Postorbital process very flattened, rectangular, and welldeveloped; distance between postorbital processes widest portion of neurocranium, and relatively considerable in P. motoro (Fig. 14). Dorsally on neurocranium precerebral and frontoparietal 
$\mathbf{A}$

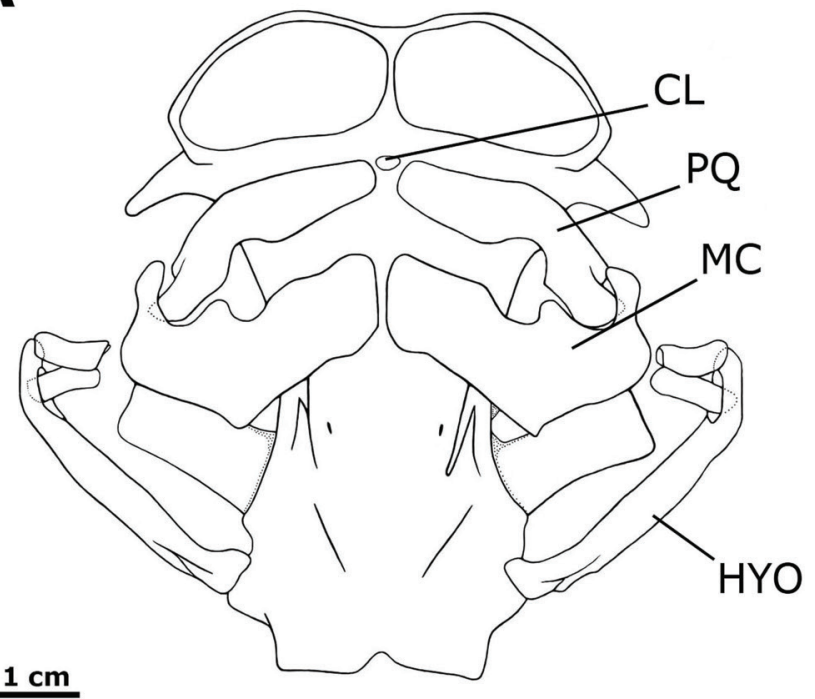

B

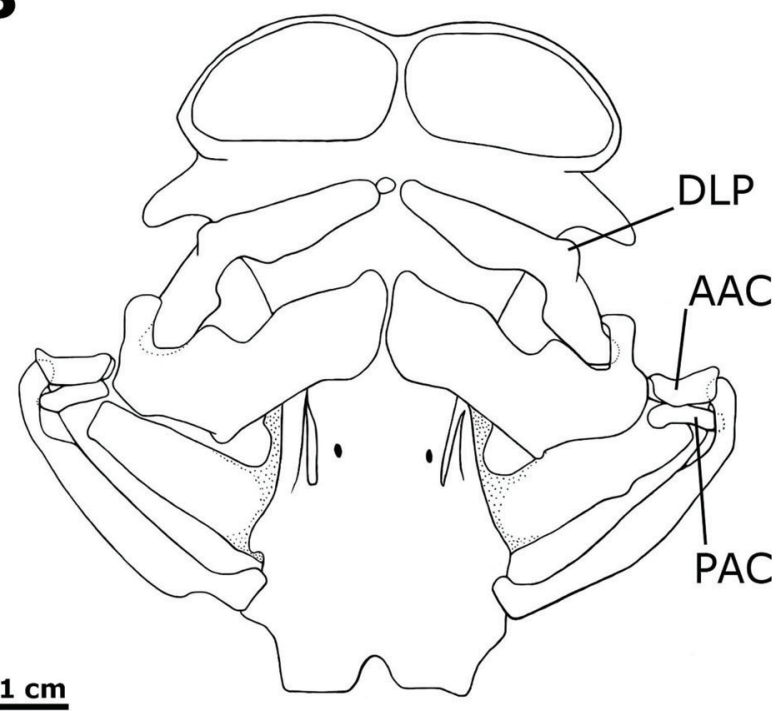

Fig. 16. Potamotrygon motoro. Dorsal and ventral views of neurocranium and mandibular arch of specimen MZUSP 110908 showing mandibular arch structures. Abbreviations: AAC, anterior angular cartilage; $\mathbf{C L}$, calcified ligament; DLP, dorsolateral process; HYO, hyomandibula; MC, Meckel's cartilage; PAC, posterior angular cartilage; PQ, palatoquadrate.
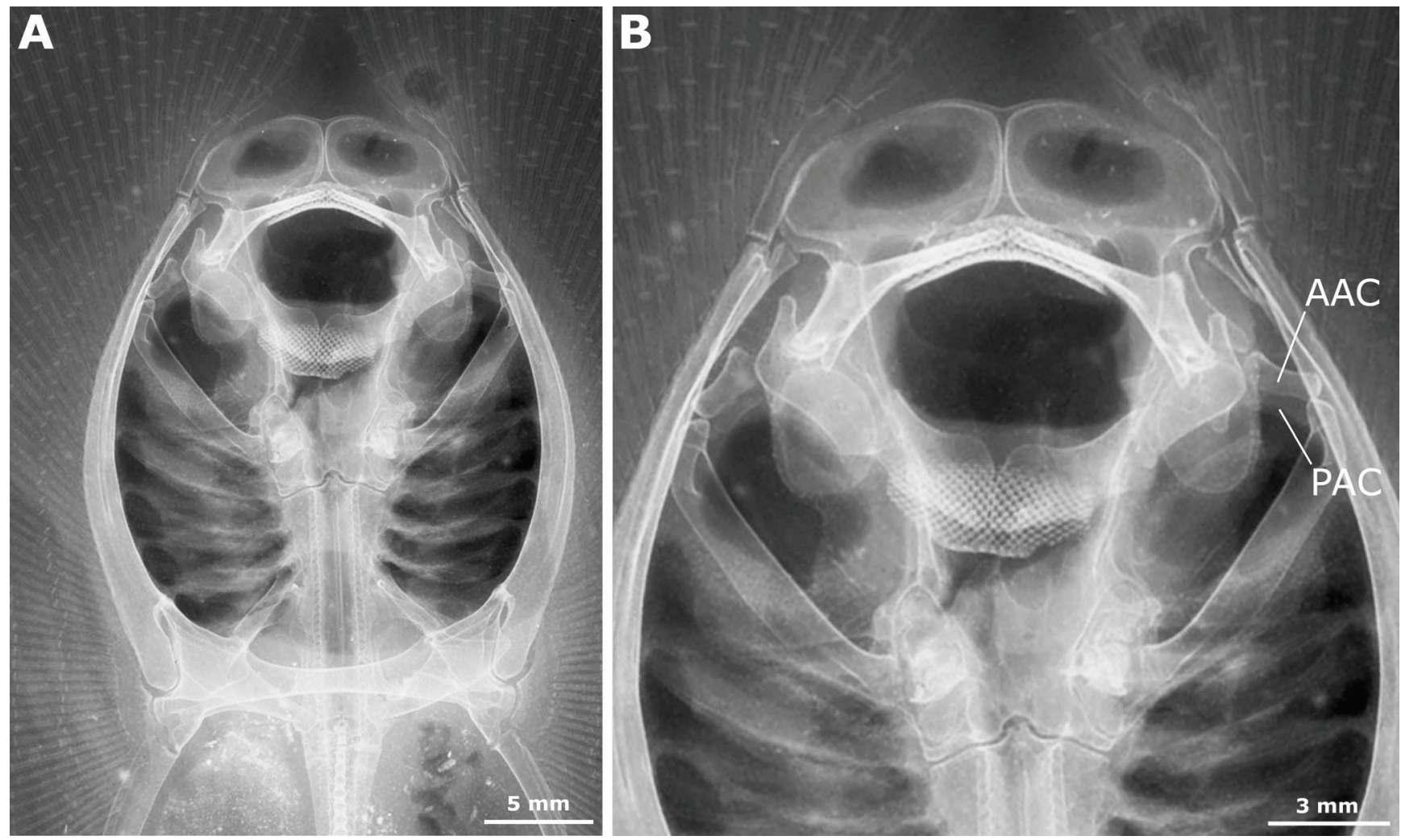

Fig. 17. Potamotrygon motoro. Anatomical details from radiographs of lectotype NMW 78655 (a) and paralectotype ZMB 4662 (b). Abbreviations: AAC, anterior angular cartilage; PAC, posterior angular cartilage.

fontanellae (comprising the dorsal fontanelle) extend from posterior part of nasal capsules to area between postorbital process. Dorsal fontanelle keyhole-shaped, with greater and very circular anterior, (precerebral) component (PCF), separated from posterior (frontopariental) portion (FPF) by slender, incomplete (in adults) epiphysial bar (EPB) (Figs. 14a. 15c). Frontoparietal fontanelle widens slightly just posterior to epiphysial bar, but tapering posteriorly to mid-length of postorbital process. Epiphysial bar represented by two subtriangular projections in adults (Fig. 14a), but more acute in juveniles (Fig. 15c). 
A
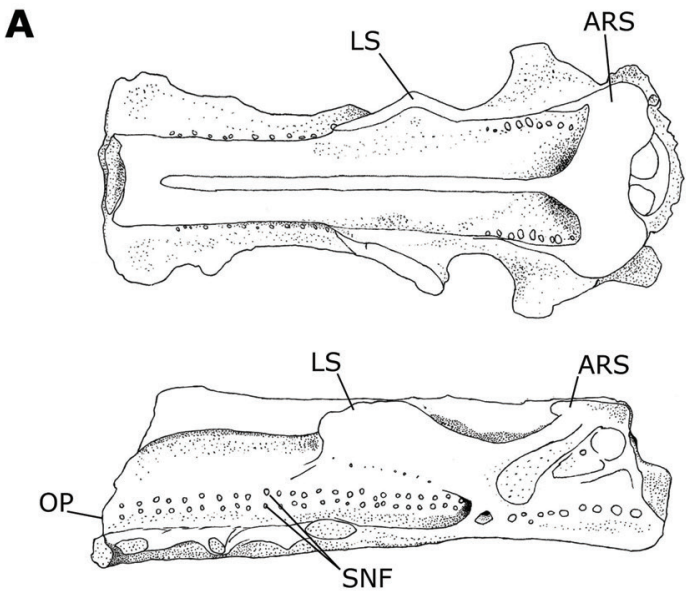

$1 \mathrm{~cm}$

B

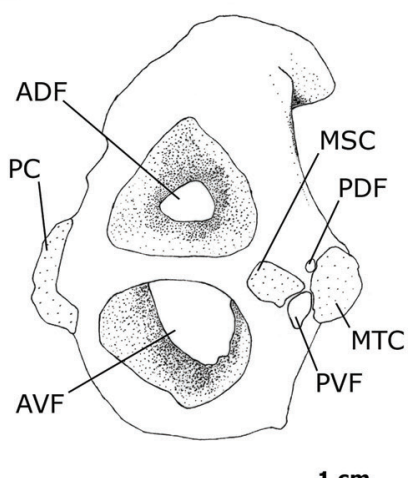

$1 \mathbf{c m}$

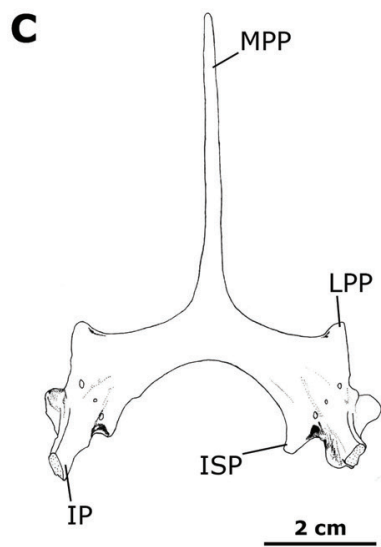

Fig. 18. Potamotrygon motoro. (a) dorsal and lateral views of synarcual cartilage, (b) lateral view of scapulocoracoid, and (c) dorsal view of pelvic girdle of an adult male specimen (MZUSP 111905). Abbreviations: ADF, anterodorsal fenestra; ARS, articular synarcual surface; AVF, anteroventral fenestra; IP, iliac process; ISP, isquial process; LPP, lateral prepelvic process; LS, lateral stay; MPP, median prepelvic process; MSC, mesocondyle; MTC, metacondyle; OP, odontoid process; PC, procondyle; PDF, postdorsal fenestra; PVF, postventral fenestra; SNC, spinal nerve canal; SNF, spinal nerve foramen.

Dorsal otic region with two pairs of closely set, small foramina: anterior endolymphatic foramina (ELF) and posterior, larger, perilymphatic foramina (PLF) (Figs. 14a, d). Lateral comissure (LC), a bridge-like structure, located very closely and posterior to facial nerve foramen (VII) in the lateral wall of otic capsule, near the delimitation between orbital and otic regions (Fig. 15a). Hyomandibular facet (HF) subtriangular, positioned at posteroventral corner of otic region. Posterior cerebral vein foramen (PCVF) dorsolateral to hyomandibular facet (Fig. 15a). Glossopharyngeal nerve foramen (IX) posterior to hyomandibular facet (Fig. 15a).

Foramen magnum (FM) large and circular. Vagus nerve foramen $(\mathrm{X})$ lateral to foramen magnum, large and oval.
Articular surface (AS) semicircular, located just below foramen magnum. Occipital condyles (OC) rectangular, low and broad extending to posterolateral corners of neurocranium (Figs. 14b, d). Basal plate flattened, presenting a pair of foramina for internal carotid artery (ICAF) at about level of postorbital processes (Figs. 14b, 15a).

Hyoid and mandibular arches. Hyomandibula (HYO) with a small expansion dorsally to articulate with neurocranium through slender hyomandibular facet (Fig. 16). Hyomandibula elongate and laterally compressed, with a pronounced groove to accommodate anterior angular cartilage anteriorly. Both angular cartilages, anterior (AAC) and posterior (PAC), similar in size, subcylindrical and anteriorly weakly concave; angulars connect Meckel's cartilage and hyomandibula within well-developed hyomandibular-Meckelian ligament. In adult specimens, anterior angular slightly larger than posterior angular cartilage (Figs. 16, 17). Meckel's cartilages (MC) flattened and robust, greater than palatoquadrates. Small concavity present on dorsal margin near corner of mouth opening, and ventral margin with a distinct pointed edge. Palatoquadrate (PQ) also anteroposteriorly flattened, with clearly demarcated dorsolateral projections (DLP) present in some adult specimens, and a small concavity on ventral margin near corner of mouth opening (Fig. 16b). Adult specimens present a strong calcified ligament $(\mathrm{CL})$ between the palatoquadrates at symphysis; in general, older specimens with more strongly calcified upper and lower jaws.

Synarcual cartilage. Anterior portion of synarcual articulates with neurocranium through robust, anteriorly projecting odontoid process (OP) (Fig. 18a). Anterolateral surface of synarcual with broad and low articular areas for occipital condyles. Spinal nerves emerge from dorsal and ventral rows of spinal nerve foramina (SNF) on lateral surface of synarcual. Lateral stay (LS) projects anterodorsally at just posterior to mid region of synarcual. Articular synarcual surfaces (ARS) that articulate with scapulae extending anterodorsally from posterior synarcual region. Anteroventral region with articular facets for pharyngobranchial cartilages.

Scapulocoracoid. Coracoid cartilage dorsoventrally flattened, with concave anterior and posterior margins. Scapular processes rhomboidal in lateral view (Fig. 18b), with several foramina for vessels and nerves and condyles for pectoral pterygia. Procondyle (PC), mesocondyle (MSC), and metacondyle (MTC) aligned on horizontal axis of scapular processes. Procondyle greater than meso- and metacondyle, vertically elongate. Mesocondyle oval, adjacent to larger metacondyle. Anterodorsal fenestra (ADF) subtriangular, dorsal to condyle axis; anteroventral (AVF) fenestra directly ventral to anterodorsal fenestra and more circular. 
Table 1. Measurements of specimens of Potamotyrgon motoro examined in the present study, including the lectotype (A) NMW 78655, paralectotype (B) ZMB 4662, and the type-specimen of P. labradori (C) MFA 231. Mean ( $x$ ) and Standard Deviation (SD) are expressed as proportions of disc width $(\% \mathrm{DW})$, and ranges are expressed in millimeters $(\mathrm{mm})$ and proportion of disc width $(\% \mathrm{DW})$. Clasper measurements were only taken from adult specimens.

\begin{tabular}{|c|c|c|c|c|c|c|c|c|c|c|c|}
\hline & \multicolumn{2}{|c|}{$\mathbf{A}$} & \multicolumn{2}{|c|}{ B } & \multicolumn{2}{|c|}{ C } & \multirow[t]{2}{*}{$\mathbf{n}$} & \multicolumn{2}{|c|}{ Range } & \multirow{2}{*}{$\begin{array}{c}\mathrm{x} \\
\% \mathrm{DW}\end{array}$} & \multirow{2}{*}{$\begin{array}{c}\text { SD } \\
\% \mathrm{DW}\end{array}$} \\
\hline & $\mathrm{mm}$ & $\% \mathrm{DW}$ & $\mathrm{mm}$ & $\% \mathrm{DW}$ & $\mathrm{mm}$ & $\% \mathrm{DW}$ & & $\mathrm{mm}$ & $\% \mathrm{DW}$ & & \\
\hline Disc width & 208 & & 183 & & 298 & & 30 & $183-479$ & & & \\
\hline Disc length & 224 & 107.7 & 202 & 110.4 & 314 & 105.4 & 30 & $202-531$ & $105.1-120.7$ & 108.4 & 3.8 \\
\hline Total length & 375 & 180.3 & 339 & 185.2 & 475 & 159.4 & 26 & $339-776$ & $150.6-187.5$ & 175.9 & 9.8 \\
\hline Interorbital distance & - & - & 26 & 14.2 & 39 & 13.1 & 29 & $26-75$ & $12.4-17.7$ & 14.1 & 1.4 \\
\hline Interspiracular distance & - & - & 32 & 17.5 & 65 & 21.8 & 29 & $32-113$ & $17.5-25.0$ & 20.7 & 1.4 \\
\hline Preorbital distance & - & - & - & - & - & - & 20 & $54-118$ & $21.2-28.0$ & 24.3 & 1.8 \\
\hline Eye diameter & - & - & 10 & 5.5 & 12 & 4.0 & 29 & $10-19$ & $3.3-6.4$ & 4.7 & 0.7 \\
\hline Spiracular length & - & - & 16 & 8.7 & 21 & 7.0 & 29 & $15-35$ & $6.7-9.8$ & 8.0 & 0.9 \\
\hline Prenasal distance & - & - & 32 & 17.5 & - & - & 28 & $31-70$ & $13.3-17.5$ & 16.4 & 0.9 \\
\hline Preoral distance & - & - & 40 & 21.9 & - & - & 28 & $39-107$ & $17.5-25.1$ & 21.9 & 1.6 \\
\hline Internasal distance & - & - & 14 & 7.7 & - & - & 28 & $14-44$ & $7.7-11.1$ & 8.4 & 0.7 \\
\hline Mouth width & - & - & 19 & 10.4 & - & - & 28 & $19-60$ & $8.6-14.4$ & 10.7 & 1.4 \\
\hline Space between $1^{\text {st }}$ branchial slits & - & - & 44 & 24.0 & - & - & 28 & $44-138$ & $24.0-30.1$ & 25.6 & 1.4 \\
\hline Space between $5^{\text {th }}$ branchial slits & - & - & 36 & 19.7 & - & - & 28 & $35-100$ & $17.5-22.3$ & 19.8 & 1.4 \\
\hline Branchial basket length & - & - & 31 & 16.9 & - & - & 28 & $28-78$ & $13.7-18.0$ & 16.5 & 1.0 \\
\hline Length ant. margin of pelvic fin & - & - & 60 & 32.8 & 78 & 26.2 & 29 & $45-97$ & $17.5-32.8$ & 27.5 & 3.6 \\
\hline Pelvic fins width & - & - & 90 & 49.2 & 154 & 51.7 & 29 & $89-260$ & $42.8-63.7$ & 52.5 & 5.2 \\
\hline Length ext. margin of clasper & - & - & - & - & - & - & 4 & $45-65$ & $17.0-21.0$ & 18.9 & 1.5 \\
\hline Length int. margin of clasper & - & - & - & - & - & - & 4 & $71-94$ & $26.8-31.8$ & 29.7 & 1.8 \\
\hline Cloaca to tail tip & - & - & 162 & 88.5 & 203 & 68.1 & 25 & $161-350$ & $63.0-98.6$ & 78.5 & 9.4 \\
\hline Tail width between pectoral insertions & - & - & 27 & 14.8 & 39 & 13.1 & 29 & $23-68$ & $10.5-14.8$ & 13.4 & 1.2 \\
\hline Snout to cloaca & - & - & 161 & 88.0 & - & - & 27 & $161-427$ & $82.6-100.8$ & 88.6 & 3.9 \\
\hline $\begin{array}{l}\text { Distance between pectoral axil and } \\
\text { posterior margin of pelvic fin }\end{array}$ & - & - & 24 & 13.1 & 36 & 12.1 & 29 & $23-66$ & $9.4-16.4$ & 12.8 & 1.7 \\
\hline Cloaca to caudal sting & - & - & 102 & 55.7 & 147 & 49.3 & 25 & $80-245$ & $38.5-63.0$ & 51.0 & 5.8 \\
\hline Caudal sting length & - & - & 38 & 20.8 & - & - & 23 & $37-86$ & $14.7-24.5$ & 20.1 & 2.5 \\
\hline Caudal sting width & - & - & 6 & 3.3 & - & - & 28 & $4-10$ & $1.3-3.4$ & 2.7 & 0.6 \\
\hline Dorsal pseudosiphon length & - & - & - & - & - & - & 4 & $9-12$ & $3.3-3.9$ & 3.5 & 0.3 \\
\hline Ventral pseudosiphon length & - & - & - & - & - & - & 4 & $25-40$ & $9.4-12.9$ & 11.9 & 1.6 \\
\hline
\end{tabular}

Postventral fenestra (PVF) located ventrally, and smaller postdorsal fenestra (PDF) situated dorsally between meso- and metacondyle. Two articular surfaces for closely positioned posterior extremities of last cerato- and epibranchial cartilages present on anterior aspect of scapulocoracoid.

Pelvic girdle. Anterior margin of pelvic girdle slightly concave lateral to median prepelvic process; posterior margin semicircular (Fig. 18c). Puboischiadic bar moderately arched, nearly twice as wide as long. Three obturator foramina on each side, anteriormost largest. Median prepelvic process (MPP) elongated, projects anteromedially from anterior margin of puboischiadic bar, almost reaching second synarcual anteriorly. Iliac process (IP) well-developed, curved and extending posterodorsally at lateral extremities of puboischiadic bar. Lateral prepelvic processes (LPP) small and broadly triangular. Isquial processes (ISP) triangular and short, located on the inner corners of pelvic girdle.

Clasper skeleton. Axial cartilage (AX) elongate, slender and slightly curved distally (Fig. 19). Basal segment 1 (B1) connects the axial cartilage to basipterygium, and basal segment 2 (B2) articulates with proximal part of axial cartilage. Beta cartilage (BE) elongate, tapering distally, and extending from basal segment 1 to close to mid-length of axial cartilage. Dorsal terminal 2 cartilage (DT2) rectangular, flattened, with a furrow on proximal aspect. External borders of dorsal marginal (DM) and 
dorsal terminal 2 cartilages externally delimit clasper groove. Internal margin of posterior part of dorsal marginal cartilage externally delimits the pseudosiphon. Ventral terminal cartilage (VT) very large and rectangular-oval shaped. Ventral marginal cartilage (VM) long and narrow with posterior extremity pointed. Accessory terminal (AT) arched and fusiform, its outer border delimiting externally the ventral pseudosiphon.

Geographic distribution. The distribution of $P$. motoro in the Paraná-Paraguay basin embraces practically all of its sub-basins except the portion of the Paraná River above the Itaipu hydroelectric dam (Fig. 20). Note that the lectotype (NMW 78655) was collected in the Guaporé River (tributary of Madeira River, Amazon basin; see below).

Etymology. The species name motoro was the common name used by locals for this species in the region of Mato Grosso state where Johann Natterer collected the type-specimens (Miranda Ribeiro, 1907; Teixeira et al., 1999).

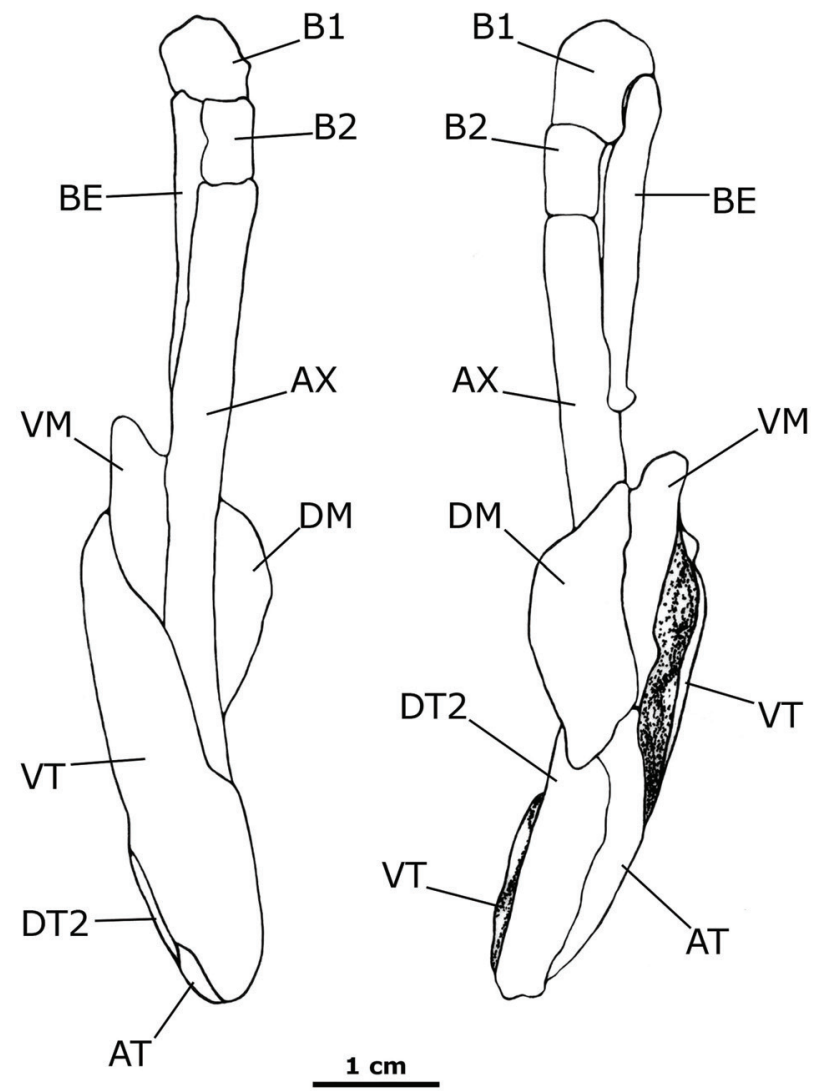

Fig. 19. Potamotrygon motoro. Dorsal and ventral views of clasper skeletal structures, MZUSP 111905. Abbreviations: AT, accessory terminal; AX, axial cartilage; $\mathbf{B E}, \beta$-cartilage; B1, basal segment 1; B2, basal segment 2; DM, dorsal marginal cartilage; DT2, dorsal terminal 2 cartilage; VM, ventral marginal cartilage; VT, ventral terminal cartilage.
Table 2. Meristic data taken from specimens of Potamotyrgon motoro, including lectotype (A) NMW 78655 and paralectotype (B) ZMB 4662 .

\begin{tabular}{lccccc}
\hline & A & B & n & Range & Mode \\
\hline Precaudal vertebrae & 41 & 40 & 10 & $38-55$ & 42 \\
Caudal vertebrae & 83 & 91 & 10 & $72-91$ & 83 \\
Total vertebrae & 124 & 131 & 10 & $116-$ & 123 \\
& & & & 133 & \\
Diplospondylic vertebrae & 99 & - & 9 & $90-99$ & 99 \\
Propterygial radials & - & 41 & 9 & $41-50$ & 47 \\
Mesopterygial radials & - & 15 & 9 & $12-16$ & 14 \\
Metapterygial radials & - & 30 & 9 & $30-40$ & 38 \\
Total pectoral radials & - & 86 & 9 & $86-101$ & 99 \\
Pelvic radials & 21 & 23 & 10 & $20-27$ & 20 \\
Tooth rows of upper jaw & - & - & 12 & $23-32$ & 30 \\
Tooth rows of lower jaw & - & - & 12 & $26-34$ & 29 \\
Symphysis of upper jaw & - & - & 12 & $3-7$ & 4 \\
Symphysis of lower jaw & - & - & 12 & $4-10$ & 5 \\
Enlarged dorsal & 24 & 16 & 19 & $16-41$ & 22 \\
pointed-spines & & & & & \\
\hline
\end{tabular}

Remarks on the original type-series of Potamotrygon motoro. The original type-series of $P$. motoro collected by J. Natterer was composed of six specimens, of which three were deposited in the collection of the Naturhistorisches Museum Wien and three were sent to Berlin and deposited in the ZMB (Müller \& Henle, 1841). Müller \& Henle (1841) mentioned all six specimens in their original description. Three specimens, preserved in alcohol and currently in Vienna, are mentioned in the middle of the description: "Drei Exemplare, aus dem Fluss Cuyaba in Brasilien, in Weingeist im kaiserlichen Naturalienkabinet in Wien, durch Natterer" ("Three specimens, from Cuiabá River, Brazil, in alcohol in imperial natural office, Vienna, by Natterer") (Müller

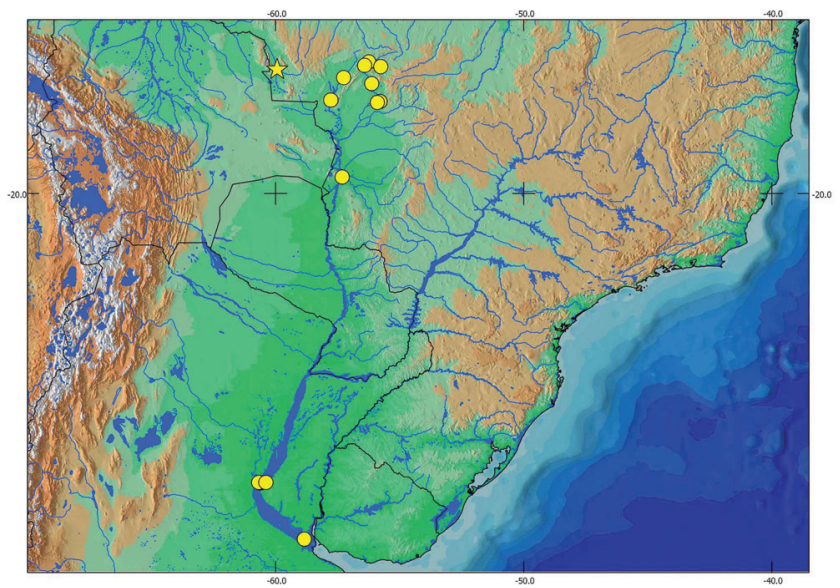

Fig. 20. Distribution of Potamotrygon motoro in the ParanáParaguay system. Yellow circles show localities where specimens of $P$. motoro were examined in this study. Yellow star indicates Guaporé River, the type locality of $P$. motoro. 
\& Henle, 1841, p. 198). A fourth specimen, also preserved in alcohol, is described shortly thereafter (Müller \& Henle, 1841, p. 198: "Ein diesen in den Verhältnissen ganz älmliches Exemplar, [...] zu Taeniura motoro gehöre.”) (“Another specimen in the same condition, [...] belongs to Taeniura motoro."), as are two other dried specimens described at the end of the text (Müller \& Henle, 1841, p. 198: "Noch fanden sich zwei trocke zu Taeniura motoro [...] aus dem Cuyaba.") ("Still, there were two dry specimens of Taeniura motoro [...] from Cuyaba."). The latter three specimens also form part of type-series (syntypes) and were deposited in Berlin.

The three specimens sent to Vienna were recently reexamined in the NMW collection (Ludwig, 2009) and are in relatively good condition: NMW 77987, a juvenile male specimen of Potamotrygon falkneri Castex \& Maciel, 1963 from the Cuiabá River; NMW 78613, an adult male P. falkneri specimen from the Cuiabá River, and NMW 78655, a juvenile male $P$. motoro specimen from the Guaporé River (Rio Madeira basin, an Amazonian tributary). The three specimens are preserved in alcohol (e.g., Ludwig, 2009, fig. 3, p. 31). We have examined photographs and have been provided measurements and radiographs of these specimens. Specimens NMW 78613 and NMW 78655 were illustrated by Natterer, but only published much later by Teixeira et al. (1999, p. 80), and subsequently also by Ludwig (2009, fig. 2, p. 31). Of the three specimens sent to Berlin only one is believed to be extant (ZMB 4662), a juvenile female specimen whose connection to the type-series is recorded on the label that clearly shows "Natterer" as the collector and "Wien Mus." (referring to the NWM) as its provenance (Päepke \& Schmidt, 1988). Rosa (1985), who examined specimen ZMB 4662, cited in addition to the label ZMB catalogue information corroborating the syntypic status of this specimen, which he cites as indicating "species originalis, from Müller and Henle's collection, and collected in Cuiabá by Natterer" (p. 257).

We have designated specimen NMW 78655 (Fig. 1) lectotype of $P$. motoro due to its superior preservation (with dorsal color still very evident), and because it was illustrated by Natterer shortly after its capture (see Teixeira et al., 1999, p. 80; Fig. 2 here), as well as for clearly being in accordance with the original description of $P$. motoro. Müller \& Henle (1841) cited that the analysis they undertook was based on specimens of both Vienna and Berlin. In the first part of their description, the authors described morphological characters of $P$. motoro and then proceeded to immediately cite the three Vienna specimens. Only then did they cite the other three Berlin specimens, one of which was preserved in alcohol and had the distal tip of the tail removed, whereas the other two were preserved as dry specimens. In the original description, Müller \& Henle did not favor any specimen that could presently be interpreted as the holotype of $P$. motoro, thus all six cited specimens are considered syntypes.
Despite the fact that paralectotype ZMB 4662 has lost its coloration (Fig. 3), other morphological characters diagnostic of $P$. motoro are easily recognized, such as the unique row of pointed-spines on dorsal tail, proportions of disc and head region, the two angular cartilages of more or less equal dimensions, and the specific outline of the fontanelle in the dorsal neurocranium (Fig. 17b; see above for character description). Ludwig (2009), however, questioned the type status of ZMB 4662, arguing that if it really were one of the three Berlin syntypes, it would have the final portion of the tail missing or damaged, following the information provided by Müller \& Henle (1841, p. 198) in the original description. Ludwig (2009) indicated that the final portion of the tail is not broken in ZMB 4662, thus concluding that this specimen cannot be part of original syntypic series of $P$. motoro. However, examination of the skeleton of this specimen through radiographs revealed otherwise. The final portion of the tail is in fact missing, as can be clearly seen in the cartilaginous distal rod and corresponding dorsal calcifications (neural processes) that abruptly terminate as if the posterior tail segment had been sharply removed. The radiograph also shows that the dorsal keel is very evident, a character also in accordance with the description of Müller \& Henle (1841, p. 198: "Die Oberseite des Schwanzes bildet bei diesem Exemplar einem hohen knöchernen Kiel, an welchem die obere Flosse") ("The dorsal side of tail forms in this specimen a boned keel, on their upper fin"). This keel is also clearly seen externally, without radiographs. Therefore, the inclusion of ZMB 4662 as part of original type-series of $P$. motoro is, in our view, strongly corroborated, as reported by Rosa (1985), Päepke \& Schmidt (1988), and Carvalho et al. (2003). Our examinations of this specimen in Berlin also corroborated that the tail extremity is broken in this specimen.

Ludwig (2009, p. 31) also states that according to Article 8.1 of the International Code of Zoological Nomenclature (ICZN, 1999) the Ph.D. dissertation of Rosa (1985) is irrelevant for nomenclatural matters because it is an unpublished work, as also interpreted by Rosa himself (e.g., Rosa et al., 1987). Therefore, the indication of ZMB 4662 as lectotype in Rosa (1985) is not valid. Indeed, Article 9.7 of the ICZN clearly indicates that Rosa (1985), and other such theses (printed and obtained on demand from an unpublished document), cannot be considered a published work. There is no denying, of course, the fundamental relevance of Rosa's (1985) thorough systematic revision (e.g., Carvalho \& Lovejoy, 2011). ZMB 4662 was also considered part of the type-series of P. motoro by Paepke \& Schmidt (1988) and Carvalho et al. (2003), and, as stated above, is morphologically in accordance with the original description. Ludwig (2009, p. 30) further states that Castex (1964) refers to specimen ZMB 4662 as part of the original series of P. motoro. However, Castex (1964, p. 21) does not mention at any time ZMB 4662 in his text, and simply points out that there are specimens extant in the Vienna museum (also mentioned by Rosa, 1985, p. 257). 
Nominal species taxonomically related to Potamotrygon motoro in the Paraná-Paraguay basin. In relation to the three nominal species considered to be junior synonyms of P. motoro in the Paraná-Paraguay basin, type-specimens of two of these species were found and examined in the Museo de Ciencias Naturales Florentino Ameghino, in Santa Fé (Argentina): Potamotrygon labradori Castex, Maciel \& Achenbach, 1963 and Potamotrygon pauckei Castex, 1963. Type-specimens of Potamotrygon alba Castex, 1963 were not found (discussed below).

The adult female (MFA 231) designated as holotype of P. labradori by Castex et al. (1963, p. 118, fig. 1) (type locality: Colastiné River, near Santa Fé, Argentina), as other authors have noted (Rosa, 1985; Carvalho et al., 2003), is

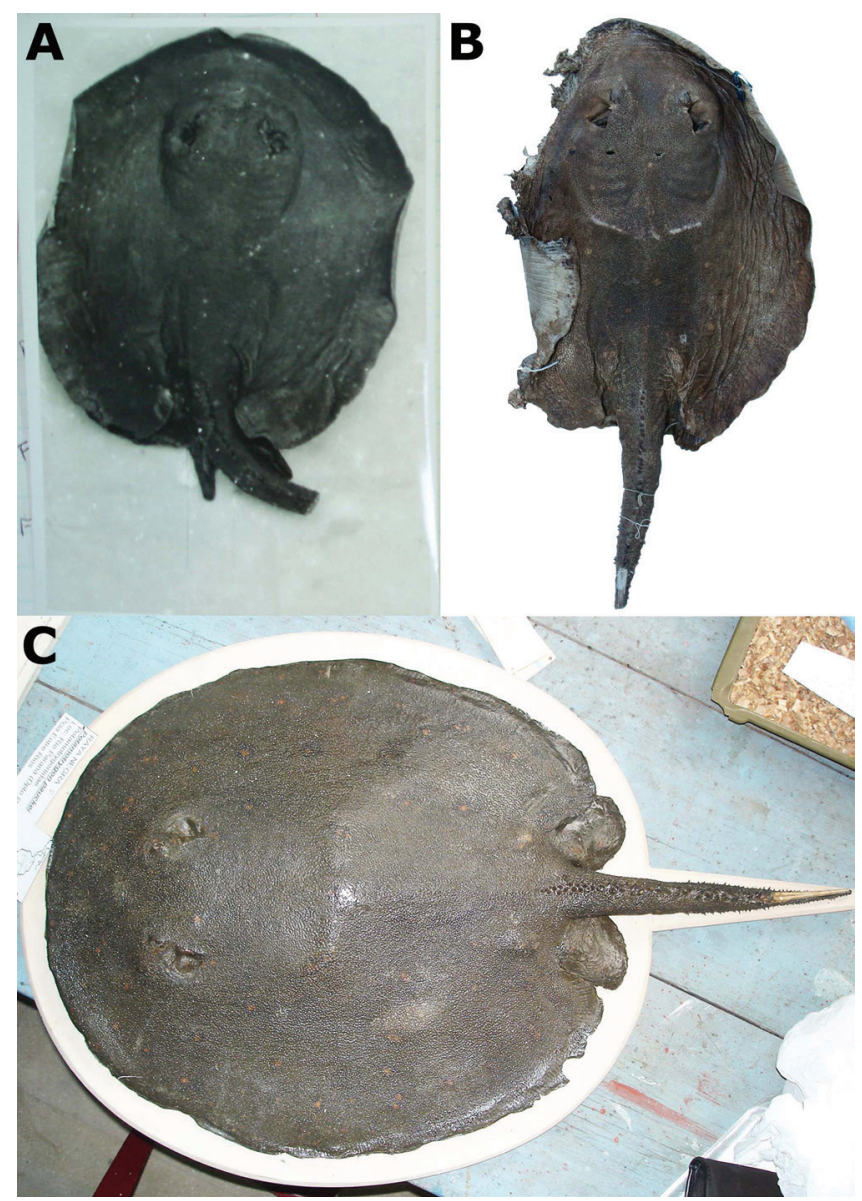

Fig. 21. An original photograph (a) found in Castex's archives of the first male specimen of $P$. pauckei published in Castex 1963 a (a specimen of $P$. amandae, sp. nov.); (b) MFA 232 a $P$. motoro specimen designated by Castex (1964) as lectotype of P. pauckei (this specimen was also analyzed by Rosa, 1985); (c) stuffed $P$. motoro specimen MFA 246, adult female, 495 mm DW. Specimen MFA 246 is still identified and exposed as $P$. pauckei in the Florentino Ameghino museum in Santa Fé, Argentina. conspecific with P. motoro (Fig. 7). This specimen was first published as Potamotrygon labratoris [sic] in a legend of a photograph in Castex (1963a, p. 55); however, in the original description, Castex et al. (1963) described the name in its currently accepted spelling P. labradori. We consider the name Potamotrygon labratoris as a nomen nudum, as Castex only provided a description of this species in a subsequent paper (Castex et al., 1963) and names originally published by indication, such as in a figure legend, after 1931 are unavailable (ICZN, 1999, Article 12.2.7).

Besides specimen MFA 231, some photographs, illustrations, and original notes made by Castex were found in the MFA that helped corroborate the status of this nominal species (Fig. 7c-d). Despite the specific pattern of dorsal disc coloration of $P$. labradori, which Castex et al. (1963, p. $119)$ identified as its principal diagnostic character, specimen MFA 231 does not present differences from P. motoro in other external diagnostic characters, such as ventral coloration, morphology and distribution of dermal denticles and spines, and tooth morphology and heterodonty in both jaws. Specimen MFA 231 is a specimen of $P$. motoro with a modified dorsal coloration presenting few and not so well-defined ocelli (in the original photographs, few ocelli in the posterior left margin of disc can be observed). We therefore corroborate that $P$. labradori is a junior synonym of $P$. motoro. Even though its

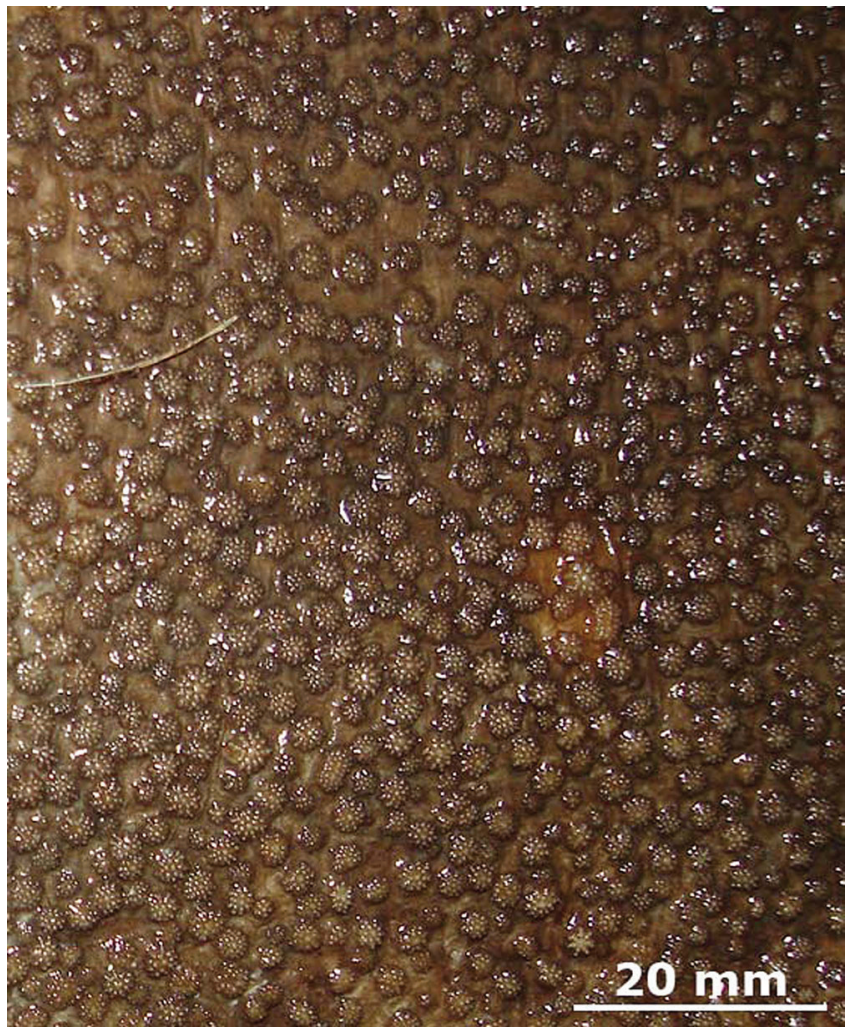

Fig. 22. Detail of dermal denticles in the central dorsal disc region of of MFA 232, a specimen of Potamotrygon motoro designated by Castex (1964) as lectotype of P. pauckei. 
state of conservation is precarious, morphometrics of MFA 231 are shown in Table 1.

A specimen later referred to the nominal species Potamotrygon pauckei first appeared as a photograph (male) with a cut tail in Castex (1963a). Although this indication does not constitute the original description (Fig. 21a), Castex used the name P. pauckei as a note in the "species section" of this paper (Castex, 1963a, p. 54). A footnote on page 54 of that work stated that he had access to more specimens, thus corroborating it as a separate species: "En momentos de entrar a prensa esta edición el Departarmento de Ciencias cuenta ya con ejemplares de juicio suficientes como para confirmar un nueva espécie "Pauckei" con lo que se poderia ya hablar de cinco espécies diversas" (Castex, 1963a).

In the subsequent, and more thorough, original description of $P$. pauckei Castex (1963c) cites six specimens of different sizes, two males and four females, all collected near the city of Santa Fé. Of the six specimens cited, Castex (1963b) describes only two: the first adult male collected and depicted in the picture published in Castex (1963a), and an adult female that was shown in two pictures in Castex (1963b). Regarding the male specimen, Castex only pointed out that it, by himself, already represented a possible new species, and does not go into details about it. However, concerning the adult female (Fig. 21b), Castex presented a more detailed description elaborating on morphometric proportions, distribution of enlarged, pointed spines, coloration, and distribution in the Colastiné river. Concerning the other four specimens of the original description, Castex (1963b) just mentions that they are similar to these other two.

In his other papers concerning P. pauckei (Castex, 1963c, 1963d, 1964, 1967a, 1967b, Castex \& Maciel, 1965, Castex \& Yagolkowski, 1970) Castex makes it clear that some specimens he had previously identified as this species actually represent $P$. motoro as in his papers on dermal denticles (1967a) and dentition (1967b), in which Castex showed typical characters of $P$. motoro as being diagnostic for P. pauckei. However, in the other papers cited above Castex mentioned characters that do not belong to $P$. motoro that he considered diagnostic for $P$. pauckei, such as dark dorsal and ventral coloration, a greater number of enlarged spines on tail and disc, and also the toxicity of these specimens, which according him, were more venemous than specimens of P. motoro (Castex, 1963d, 1964).

However, $P$. pauckei is clearly a junior synonym of $P$. motoro. When Castex (1964) designated a "holotype" [sic] for $P$. pauckei he chose the adult female syntype from the original description of this species (Castex, 1963b), MFA 232, which actually represents $P$. motoro (Fig. 21b, 22). Castex also designated an "allotype" [sic], MFA 245 in this same paper. When Rosa (1985) examinated both specimens, he identified them as $P$. motoro, and provided a photograph of the adult female MFA 232, the so-called "holotype" and the same female specimen of the original description (Castex, 1963b) (note that in Rosa's legend of this photograph, he mistakenly identified it as the male specimen, MFA 245; Rosa, 1985, p. 274). During a visit in 2006 to the Museu Florentino Ameghino, in Santa Fé, specimen MFA 232 was examined and, even though in a state of preservation slightly more deteriorated (Fig. 21b) than when seen by R. Rosa, we can clearly identify it as $P$. motoro, through dorsal and ventral coloration, dermal denticles (Fig. 22), spines on tail, and morphology of teeth in both jaws. Unfortunately, specimen MFA 245 could not be found.

In accordance with the ICZN (1999), when Castex (1964) designated one of the specimens of the original type series of $P$. pauckei as the "holotype" subsequent to the original description (Castex, 1963b), he in fact designated the lectotype from the syntypic series, and the nominal species $P$. pauckei should therefore be associated only with MFA 232 (Articles 74.5 and 74.6). When Castex designated this specimen (which we identify as $P$. motoro), all other five specimens cited in the original description (Castex, 1963b), including the adult male with a partially severed tail, automatically became paralectotypes (Articles 74.1.3 and 74.6).

The original description of Potamotrygon alba is restricted to a single paragraph in which few morphological characters are briefly described and discussed (Castex, 1963c, p. 55). The typeseries was composed solely of female specimens, two adults and one juvenile, and the type locality is "Asunción" (probably Paraguay River, in Asunción, Paraguay). In his description (Castex, 1963c), the author mentions the following characters as diagnostic: disc smooth dorsally, with a whitish coloration with some faint light pink and light yellow tones, tail without lateral rows of enlarged spines, just some dispersed spines being present. In this work, Castex noted similarities between specimens of $P$. alba and "type 1" of $P$. motoro of Devincenzi $\&$ Teague (1942) from the Uruguay River. A year later, Castex (1964) himself questioned the validity of $P$. alba, and cited its specimens as being a chromatic variation of $P$. motoro. In this work (1964, p. 38), Castex affirms that his description of the year before was incomplete, and also that the three specimens were destroyed in an "accident", but without further elaborating. However, Castex (1964) reinforced that the chromatic variation may have been due to albinism. Rosa (1985) cited this observation by Castex (that $P$. alba may be an albino variant of P. motoro), and did not place it in the synonymy of P. motoro, regarding it as a nomen dubium. Carvalho et al. (2003) placed $P$. alba in the synonymy of $P$. motoro and mentioned that the type-series may be lost. In the Florentino Ameghino museum, we could not find any specimen, note or photograph concerning $P$. alba. None of the diagnostic characters described by Castex (1963c) for P. alba correspond with those of P. motoro, however, and until more precise information from its type-specimen is made available, or from freshly captured topotypic specimens 
with similar external morphological characteristics, this nominal species should not be considered synonymous with $P$. motoro. Therefore, as previously concluded by Rosa (1985), P. alba is here considered a nomem dubium.

Further remarks on Potamotrygon motoro. In agreement with Castex (1963a), we observed a predominant disc color pattern in $P$. motoro in the Paraná-Paraguay basin, with just slight variation found in some specimens collected from near Cáceres, Mato Grosso (Brazil), and from Santa Fé (Argentina). These specimens present a reduced number of ocelli on dorsal disc, and some of these are arranged in groups of two or three smaller ocelli. As in typical P. motoro, however, ventral disc color in this material also presents darkers margins, and the background dorsal disc color is predominantly brown or gray, with tricolored ocelli distributed through the entire disc and on tail base (Fig. 5). This color variation was found in specimens independent of gender and size.

Adults of $P$. motoro range between 30 and $55 \mathrm{~cm}$ DL; however, some specimens from Argentina have been reported to reach $80 \mathrm{~cm} \mathrm{DL}$ (Castello, 1975), indicating that P. motoro is the largest species among the "ocellated" forms in the Paraná-Paraguay basin (other "ocellated" forms are described below). As in other potamotrygonid species, adult females reach greater sizes than adult males.

Taniuchi \& Ishihara (1990), in their study of potamotrygonid claspers, examined a specimen of $P$. motoro from the ParanáParaguay basin and reported an external "groove-like component" between the dorsal and ventral pseudosiphons. No adult or immature specimens examined in the present study presented this groove.

The lectotype of $P$. motoro (NMW 78655) was collected in the Guaporé River, near the city of Vila Bela da Santíssima Trindade, State of Mato Grosso, Brazil. Despite not being from the Paraná-Paraguay basin, the Guaporé River is located in a region called the "Guaporé-Paraguay divide," known to experience constant freshwater faunal exchanges between the Amazon and Paraná-Paraguay basins (Carvalho \& Alberts, 2011, p. 197-198). Futhermore, many Amazonian specimens of $P$. motoro were studied by Loboda (2010) and morphological differences between the populations of these two basins were not found. Loboda (2010) pointed out the great morphological similarity of $P$. motoro throughout its distribution in both basins, especially between populations of the upper Guaporé (Madeira) and upper Paraguay (Paraná-Paraguay) basins. This may suggest, as was expounded for bony fishes (Lima \& Ribeiro, 2011), a possible historical connection between these two South American basins (Loboda, 2010). Therefore, the type locality of the lectotype does not inhibit the application of the nominal species Potamotrygon motoro (Müller \& Henle, 1841) for specimens in the Paraná-Paraguay basin.

\section{Potamotrygon pantanensis, new species} Fig. 23-36

Holotype. MZUSP 110890, adult female, 323 mm DW, baia Sinhá Mariana, tributary of Cuiabá River, district of Barão de Melgaço, State of Mato Grosso, Brazil,, 24 Apr 2000, W. J. da Graça.

Paratypes. (8 specimens). MZUSP 110888, adult female, $336 \mathrm{~mm}$ DW, same data as holotype. MZUSP 110889, adult female, $325 \mathrm{~mm}$ DW, same data as holotype. MZUSP 110894, adult female, $317 \mathrm{~mm}$ DW, same data as holotype. MZUSP 110892, adult female, $300 \mathrm{~mm}$ DW, same data as holotype. MZUSP 110891 (adult male, $268 \mathrm{~mm}$ DW), same data as holotype. MZUSP 110901, adult female, $306 \mathrm{~mm}$ DW, Cuiabá River, district of Rosário do Oeste, State of Mato Grosso, Brazil, W. J. da Graça, 24 Apr 2000. MZUSP 110874, adult female, $297 \mathrm{~mm}$ DW, same data as previous. NUP 4179, adult male, $215 \mathrm{~mm}$ DW, Manso River, tributary of Cuiabá River, district of Chapada dos Guimarães, State of Mato Grosso, Brazil, W. J. da Graça, 16 Jan 2004.

Non-type specimens examined ( 8 specimens). MZUSP 110896, adult female, $328 \mathrm{~mm}$ DW, same data as holotype. MZUSP 110895, adult female, $328 \mathrm{~mm}$ DW, same data as holotype. MZUSP 110893, adult female, $306 \mathrm{~mm}$ DW, same data as holotype. MZUSP 110899, adult female, 289 mm DW, Cuiabá River, district of Rosário do Oeste, State of Mato Grosso, Brazil, W. J. da Graça, 24 Apr 2000. MZUSP 110898, juvenile female, $232 \mathrm{~mm}$ DW, same data as previous. NUP 3271, young female, 247 mm DW, Cuiabá River, district of Rosário do Oeste, State of Mato Grosso, Brazil, W. J. da Graça, 23 May 2000. MZUSP 110886, adult female, $334 \mathrm{~mm}$ DW, baia Chacororé, tributary of Cuiabá River, district of Barão de Melgaço, State of Mato Grosso, Brazil, W. J. da Graça, 21 Apr 2000. MZUSP 110897, adult female, without DW measurement as margins of disc were removed, same data as holotype.

Diagnosis. Potamotrygon pantanensis, sp. nov. is distinguished from congeners from the Paraná-Paraguay basin by presenting bicolored ocelli with diameter greater or equal to eye-diameter, and vermiculated markings with a beige, yellow or orange central area surrounded by a peripheral black ring, over a uniform brown dorsal disc background color (P. falkneri, P. histrix, P. schuhmacheri, and P. brachyura lack ocelli; P. motoro and $P$. amandae, sp. nov. have ocelli with three and two colors, respectively, and both lack vermiculations). The following characters in combination further distinguish P. pantanensis, sp. nov. from $P$. motoro and $P$. amandae, sp. nov.: a single, clearly demarcated gray color present on anterocentral ventral disc, transversed by a gray stripe over first pair of branchial slits (lacking in both $P$. motoro and $P$. amandae, sp. nov.); presence of minute, star-shaped dermal denticles only on central disc area, and two or three rows of minute, slender and curved enlarged spines on dorsal tail ( $P$. motoro with a single dorsal row of relatively large, tall and straight enlarged spines on dorsal tail, and $P$. amandae, sp. nov. with double or triple rows of small 
A

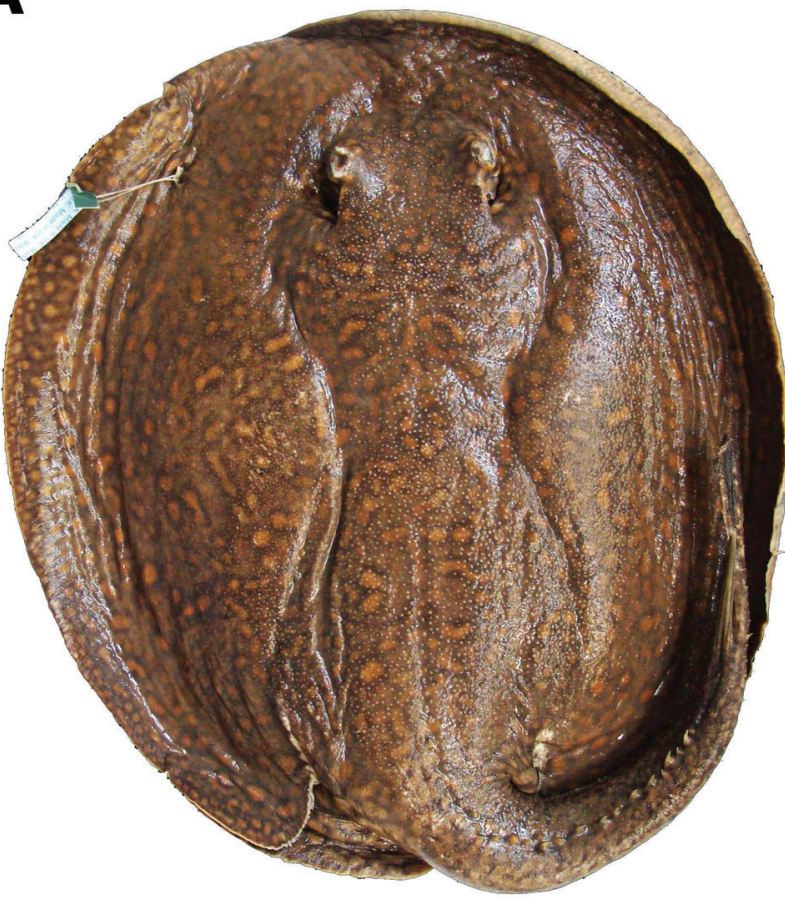

B

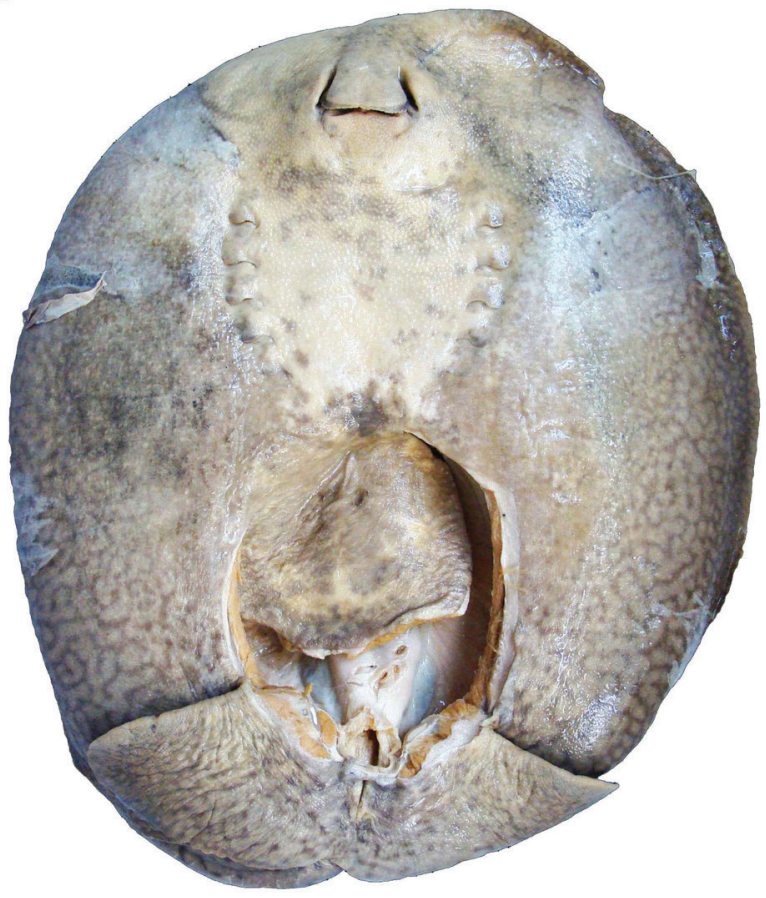

Fig. 23. Potamotrgon pantanensis, n. sp. Dorsal (a) and ventral (b) views of holotype, MZUSP 110890, adult female, 323 mm DW, Cuiabá River.

A

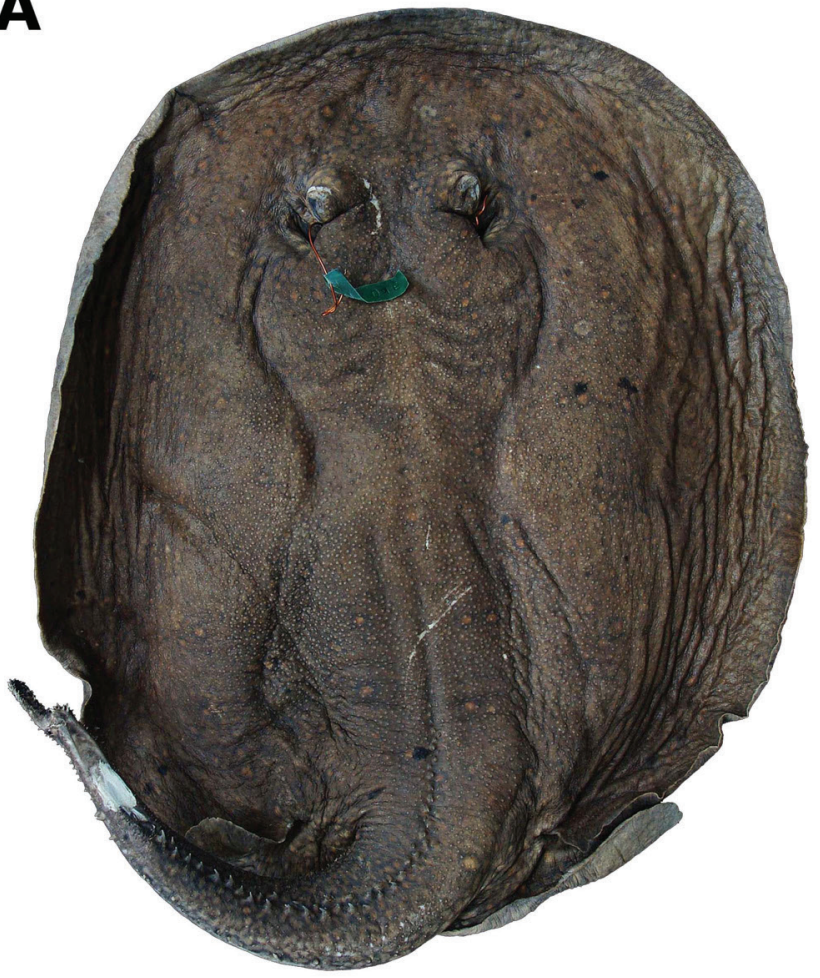

B

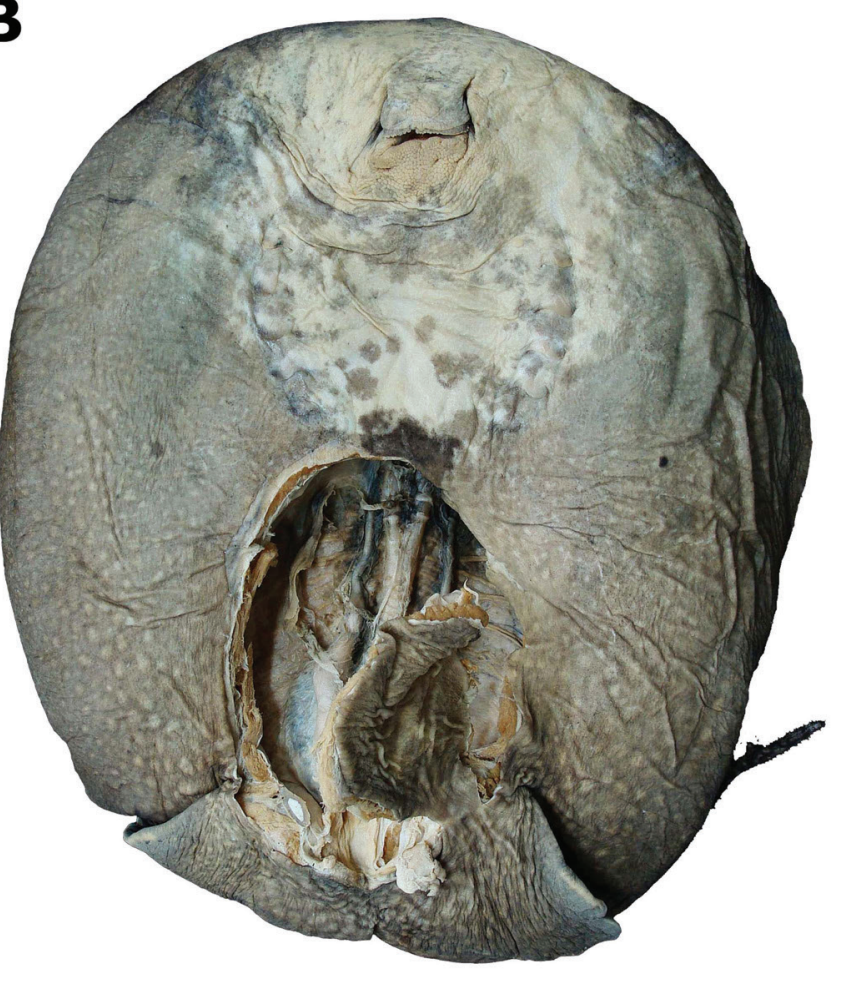

Fig. 24. Potamotrygon pantanensis, n. sp. Dorsal (a) and ventral (b) views of paratype, MZUSP 110888, adult female, $336 \mathrm{~mm}$ DW, from Cuiabá River. 
A

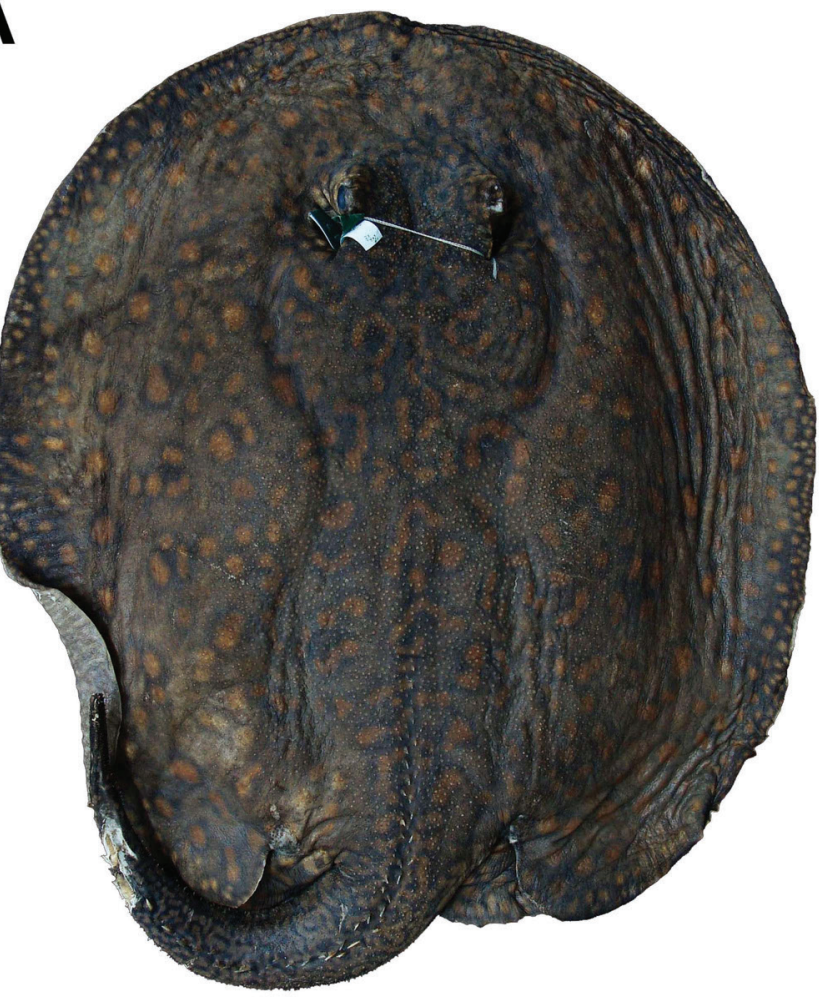

B

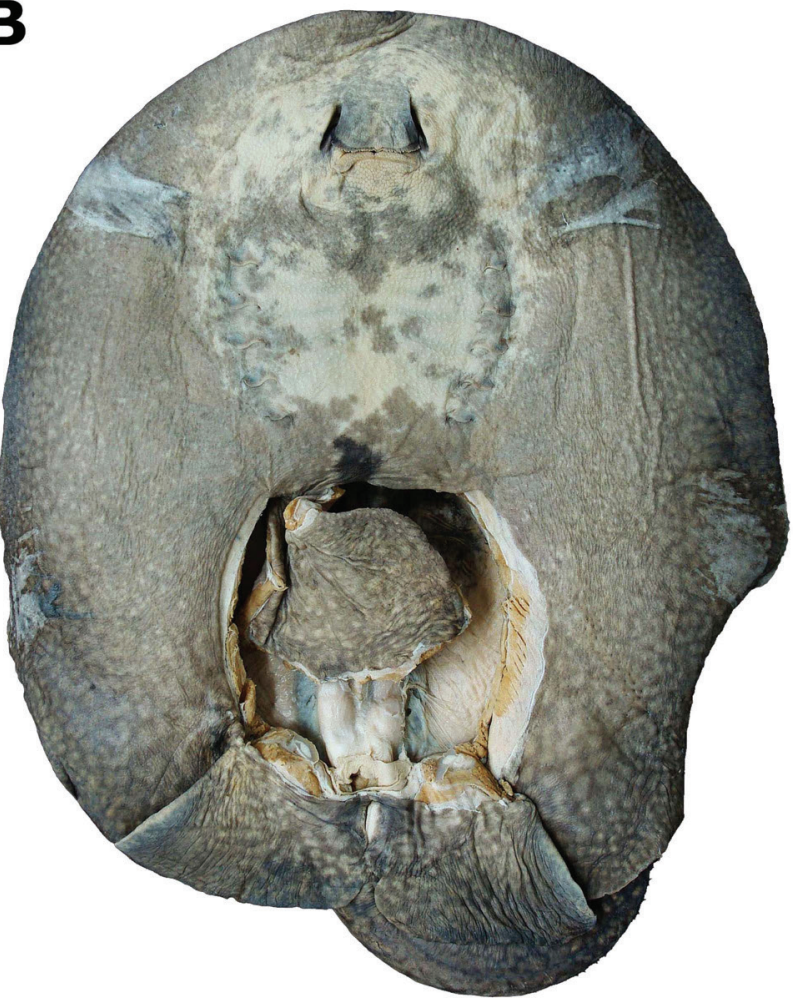

Fig. 25. Potamotrygon pantanensis, n. sp. Dorsal (a) and ventral (b) views of paratype, MZUSP 110889, adult female, $325 \mathrm{~mm}$ DW, from Cuiabá River.

A

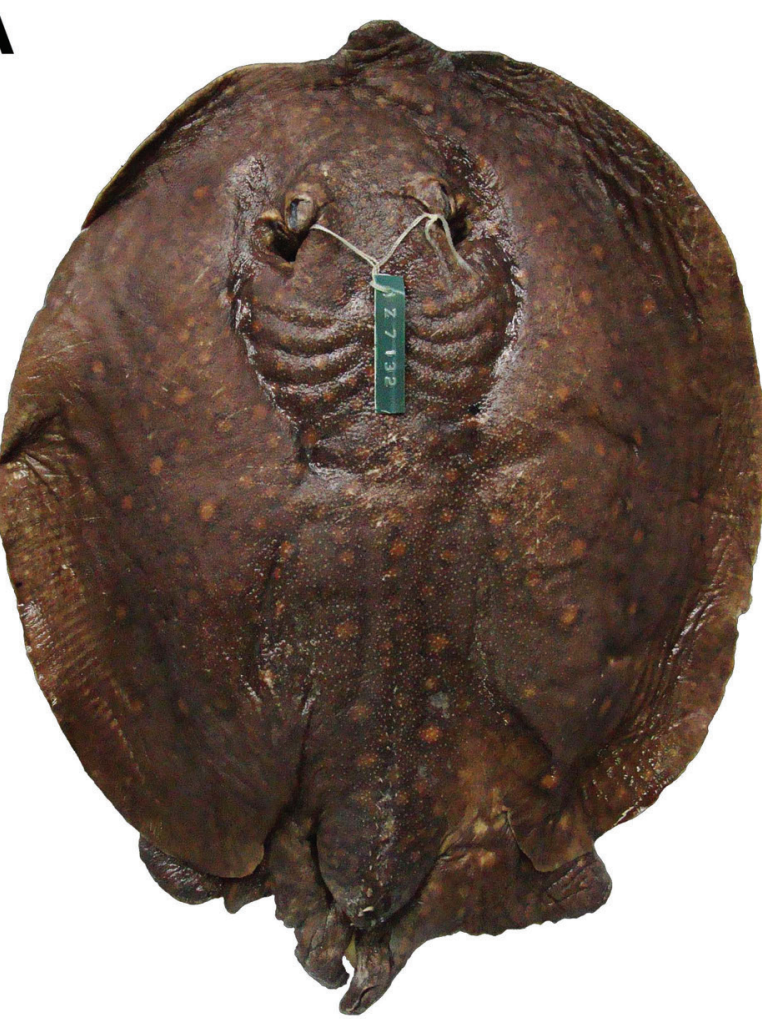

B

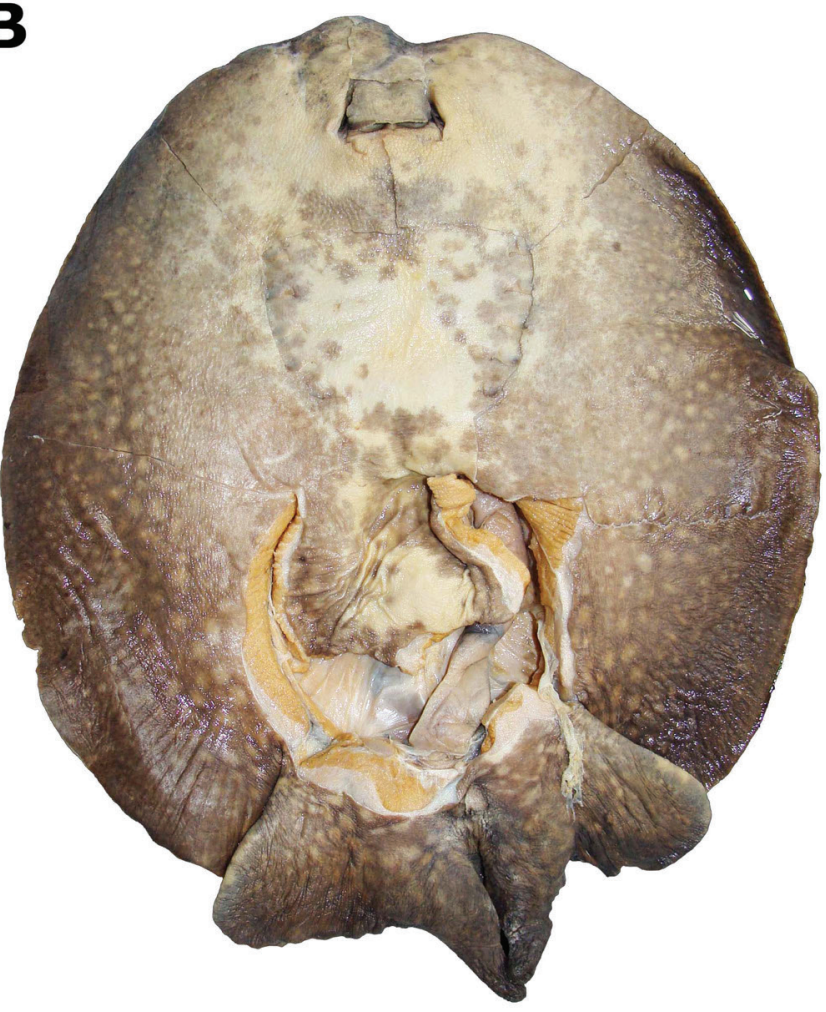

Fig. 26. Potamotrygon pantanesis, n. sp. Dorsal (a) and ventral (b) views of paratype, MZUSP 110891, adult male, $268 \mathrm{~mm}$ DW, from Cuiabá River. 
A

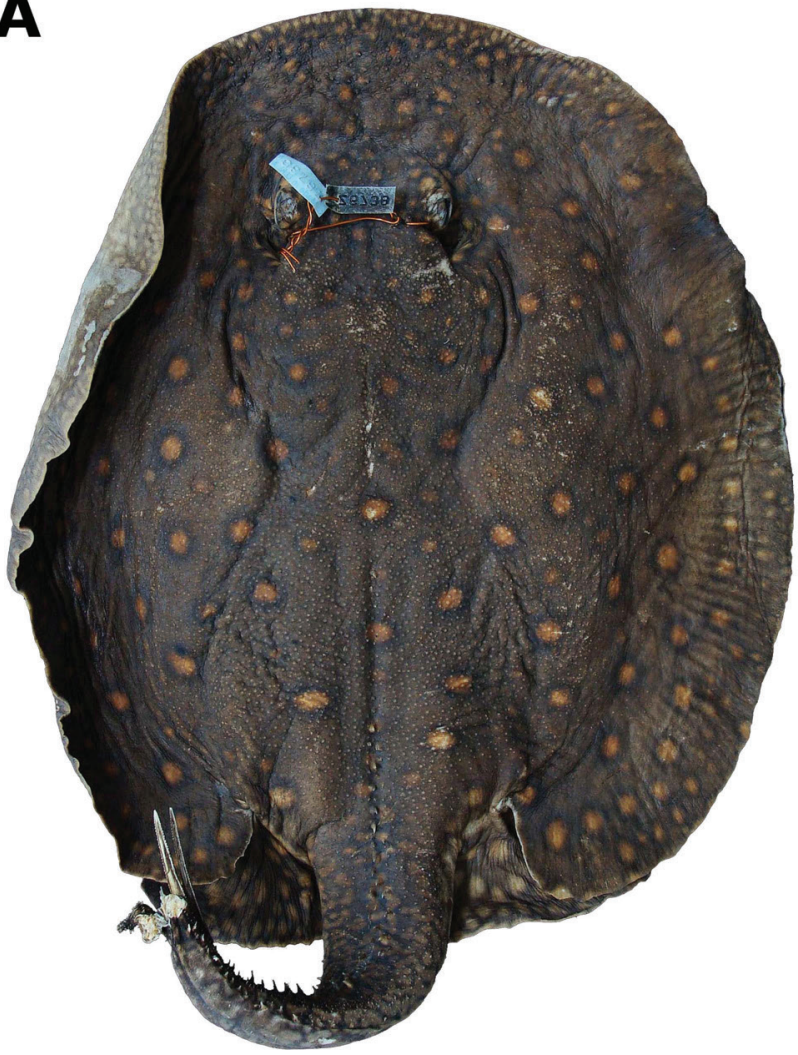

B

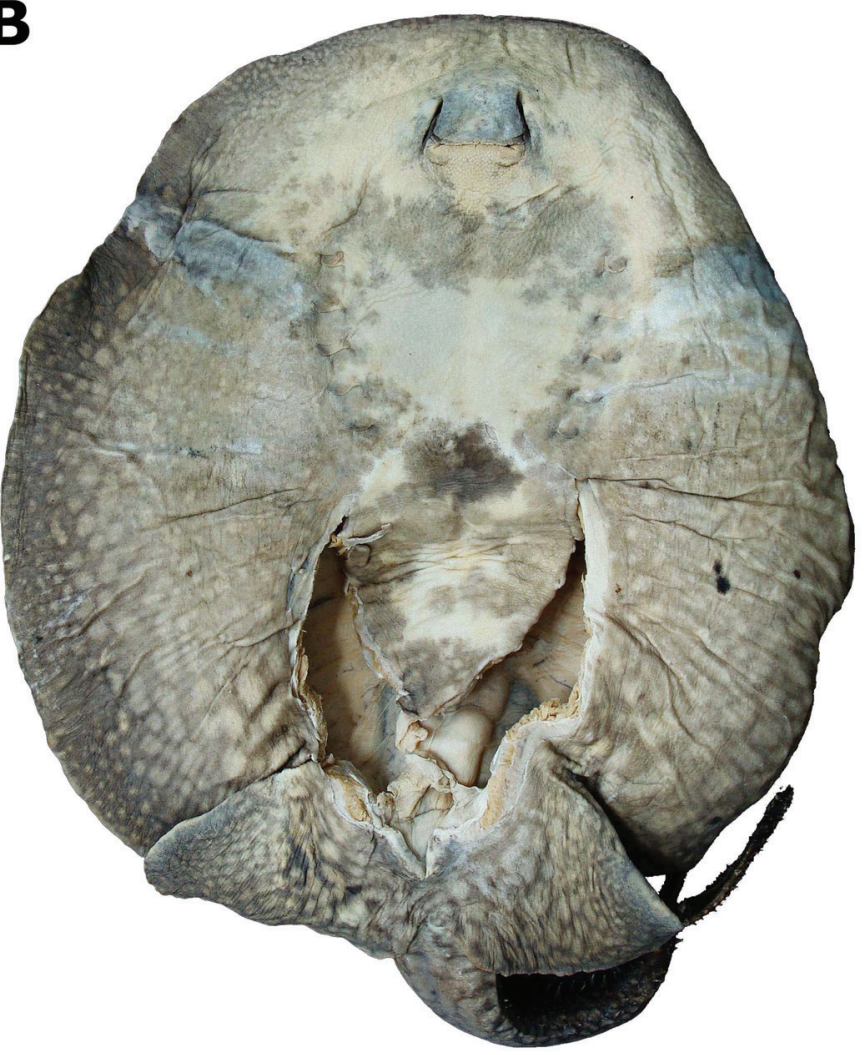

Fig. 27. Potamotrgon pantanensis, n. sp. Dorsal (a) and ventral (b) views of paratype, MZUSP 110901, adult female, 306 mm DW, from Cuiabá River.

A

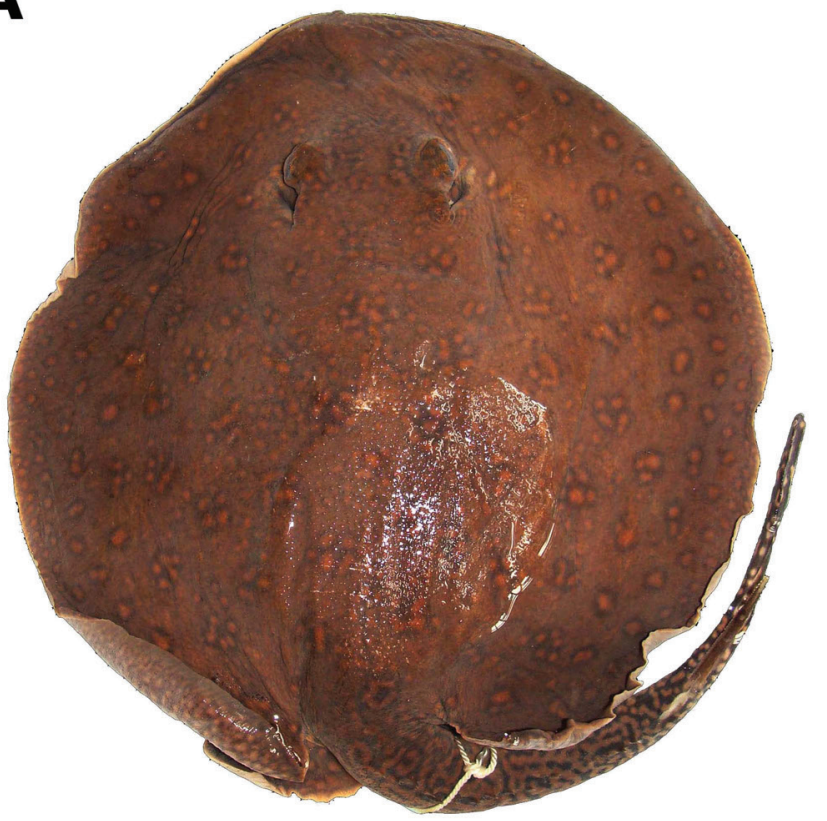

B

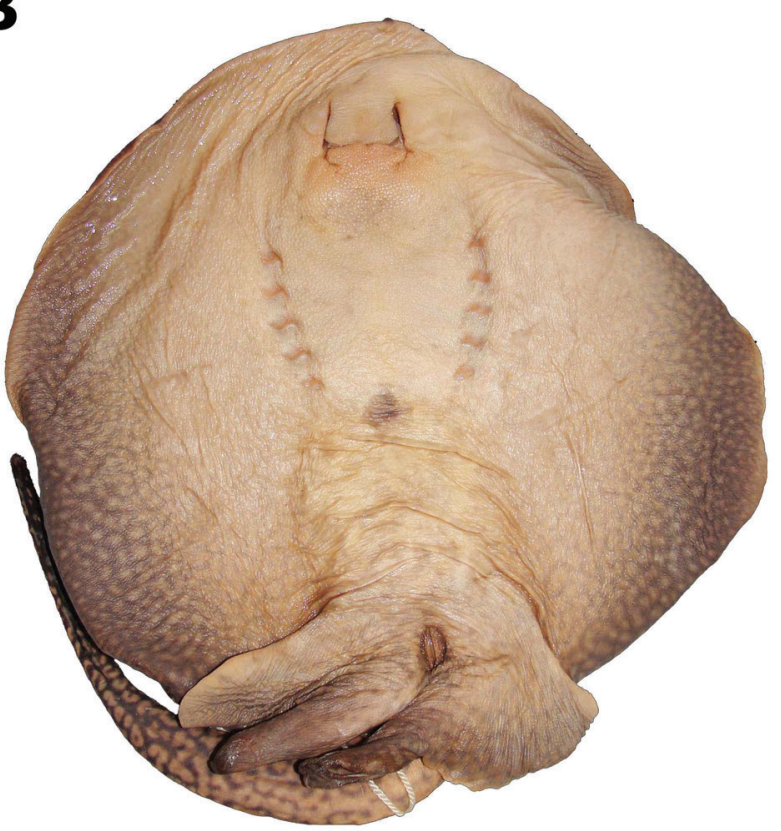

Fig. 28. Potamotrygon pantanensis, $\mathrm{n}$. sp. Dorsal (A) and ventral (B) views of paratype, NUP 4179, subadult male, $215 \mathrm{~mm}$ DW, from Manso River. 
and straight spines); dorsal pseudosiphon of clasper with dorsal flap broader than in P. motoro and P. amandae, sp. nov. (in P. pantanensis, sp. nov. this flap covers an area beyond the anterior margin of dorsal pseudosiphon, whereas in P. motoro and $P$. amandae, sp. nov. this flap is restricted to the dorsal pseudosiphon); total pectoral radials ranging from 87 to 95 (without mode), and tooth rows of lower jaw ranging from 30 to 31 (mode 31) (P. amandae, sp. nov. with 92 to 106 pectoral radials [without mode], and 23 to 33 lower tooth rows [mode 26]); a straight frontoparietal fontanelle with parallel margins (in P. motoro frontoparietal fontanelle with slightly curved and tapering margins, and $P$. amandae, sp. nov. with posterior portion of frontoparietal fontanelle more rounded); anterior angular cartilage much greater than posterior angular cartilage, more than twice its length, and relatively straight anteriorly (angular cartilages subequal in P. motoro and in P. amandae, sp. nov. anterior angular cartilage curved near articulation with Meckel's cartilage, with anterior margin very concave).

Description. Proportional measurements and counts are presented, respectively, in Tables 3 and 4 . All specimens were measured and formed the basis for the description of external morphology; internal morphology was investigated from radiographs of specimens MZUSP 110890, MZUSP 110891, MZUSP 110892, MZUSP 110895, and NUP 4179.

External morphology. Disc subcircular, slightly longer than broad, with disc length ranging from 102.9 to $117.1 \%$ DW. Head relatively more narrow than in P. motoro, with interorbital distance ranging from 12.1 to $15.4 \% \mathrm{DW}$, interspiracular distance between 16.4 to $21.7 \% \mathrm{DW}$, and internasal distance ranging from 7.8 to $8.9 \% \mathrm{DW}$. Mouth narrow, its width ranging from 7.3 to $9.8 \% \mathrm{DW}$, with five oral papillae on ventral oral epithelium (three central and two peripheral). Small, distinct

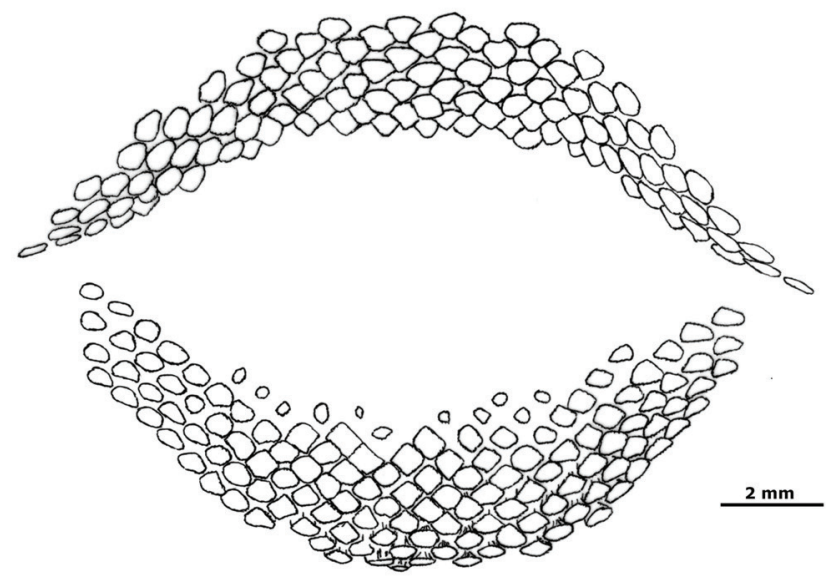

Fig. 29. Potamotrygon pantanensis, n. sp. Upper and lower jaws of an adult female paratype specimen, MZUSP 110892, $300 \mathrm{~mm}$ DW. rostral protuberance lacking. Eyes bulging dorsally, relatively large. Spiracles muscular and trapezoidal. Branchial basket about as long (range of length 16.5 to $18.5 \% \mathrm{DW}$ ) as distance between fifth pair of branchial slits (16.7 to $19.8 \%$ DW). Labial grooves developed on posterolateral mouth corners.

Teeth disposed in quincunx, very small and with same morphology in both jaws. Adult specimens without monognathic heterodonty in tooth rows (Fig. 29). Tooth rows and teeth in median rows of upper jaw, respectively, in 30 to 35 rows and 4 to 5 teeth, and in lower jaw, respectively, in 30 to 31 rows and 4 to 5 teeth.

Pelvic fins mostly covered dorsally by disc, with only posterior portion visible; pelvics subtriangular, with distal portion slightly rounded and posterior margin undulated. Anterior margins of pelvics oblique to midline, ranging from 19.5 to $26.8 \%$ DW. Tail thick and short (in comparison with P. motoro and $P$. amandae, sp. nov.), with ranges of distance of cloaca to

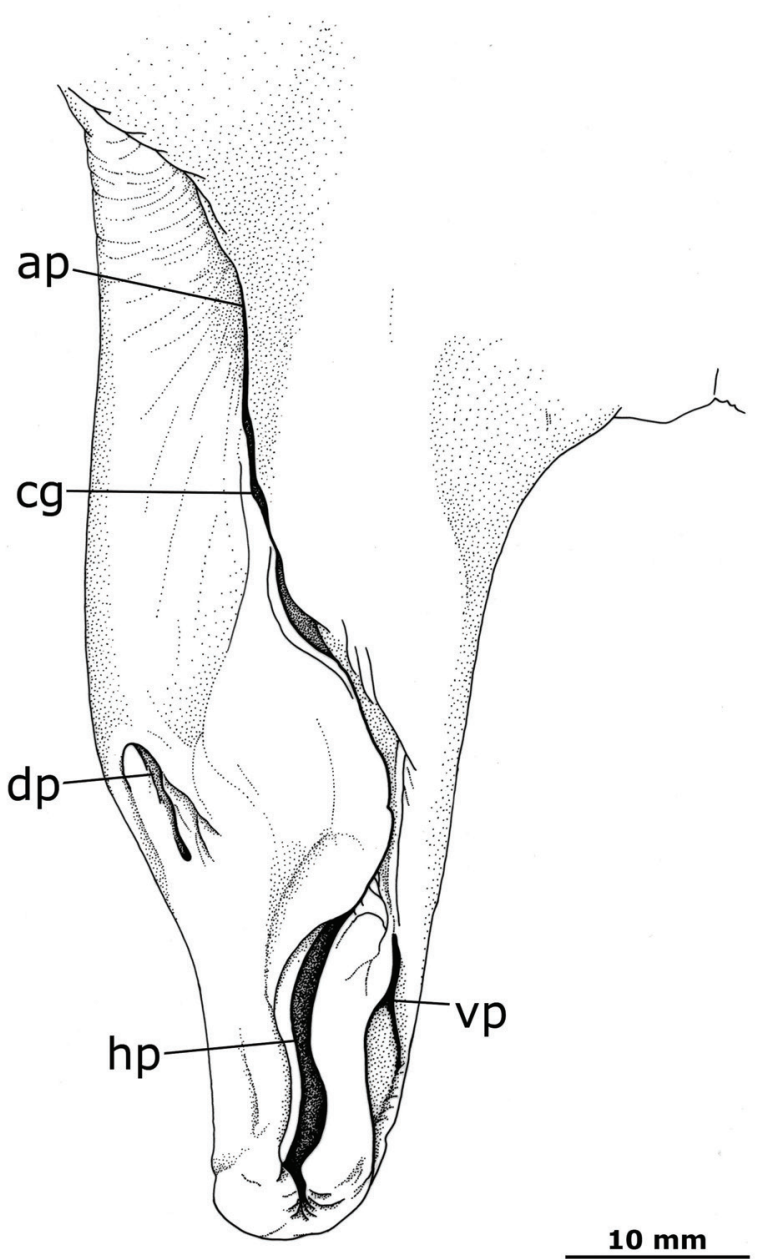

Fig. 30. Potamotrygon pantanensis, $n$. sp. Dorsal view of right clasper of an adult male, MZUSP 110891. Abbreviations: ap, apopyle; cg, clasper groove; dp, dorsal pseudosiphon; hp, hypopyle; vp, ventral pseudosiphon. 

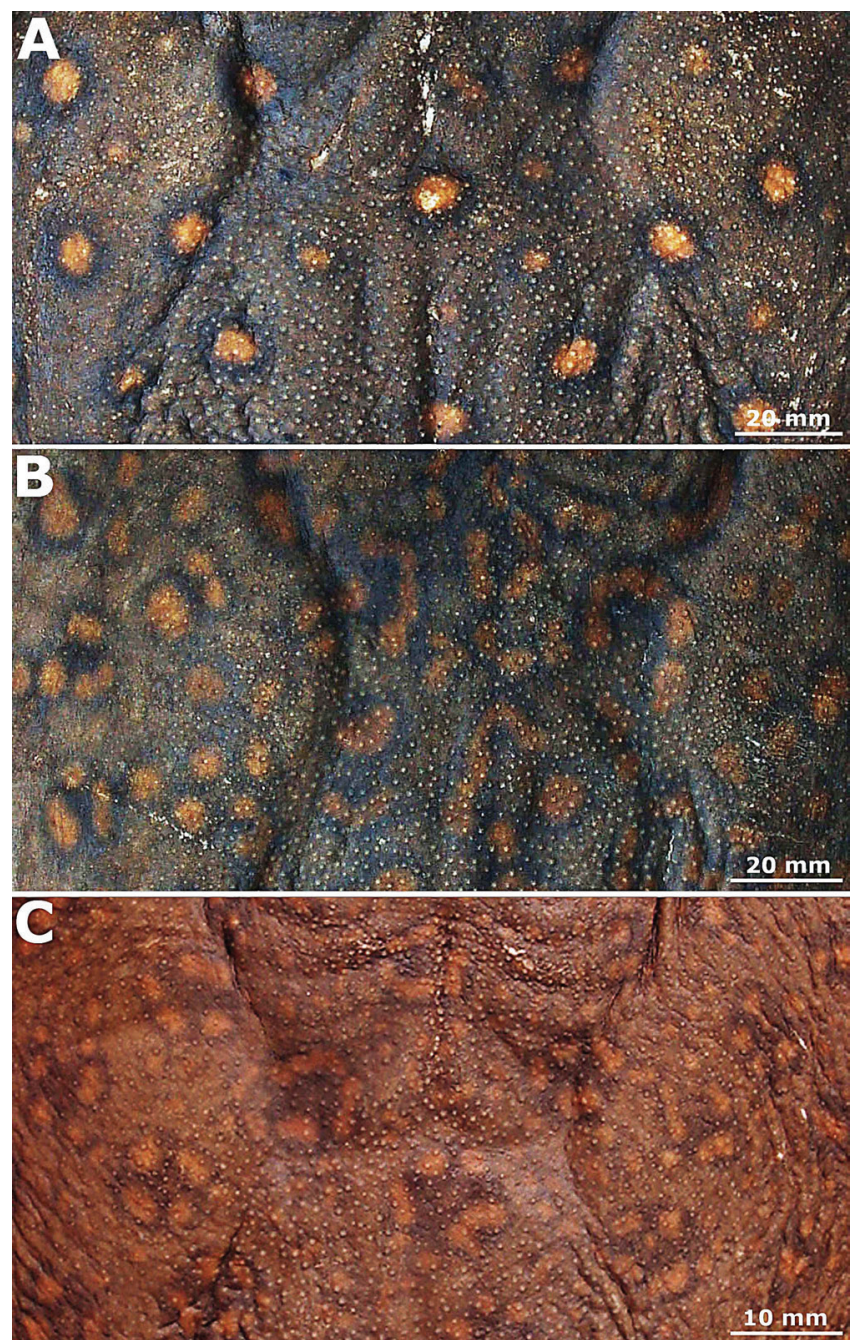

Fig. 31. Patterns of ocelli and spots in Potamotrygon pantanensis, n. sp.: (a) MZUSP 110901, (b) MZUSP 110889 and (c) MZUSP 110874, adult female, $297 \mathrm{~mm}$ DW.

tail tip and tail width, respectively, 61.9 to $91.2 \%$ DW and 11.2 to $15.5 \% \mathrm{DW}$; tail folds not as developed as in P. motoro. Clasper realtively short, straight and thick, with its posterior portion very tapered. Different to P. motoro and P. amandae, sp. nov., dorsal pseudosiphon anteriorly with a flap extending beyond its anterior limits and also covers lateral clasper portion in addition to anterior margin of pseudosiphon (Fig. 30). Range of internal length of claspers 24.3 to $27.9 \%$ DW and external length of claspers 13.1 to $14.4 \%$ DW (measured only in two adult males; Table 3 ).

Tail relatively smaller and more broad than $P$. motoro and $P$. amandae, sp. nov., with mean tail length $73.4 \%$ DW and mean tail width at base $13.2 \% \mathrm{DW}$. Dorsal and ventral tail folds present, with dorsal tail fold slightly more developed than ventral tail fold.

Coloration. In preservative, dorsal background coloration in females light or dark brown, and in males dark brown (Figs. 23-28, 31). Ocelli distributed over disc, some specimens also presenting vermiculations (Figs. 23a, 24a, 25a, 26a, 27a, 28a,
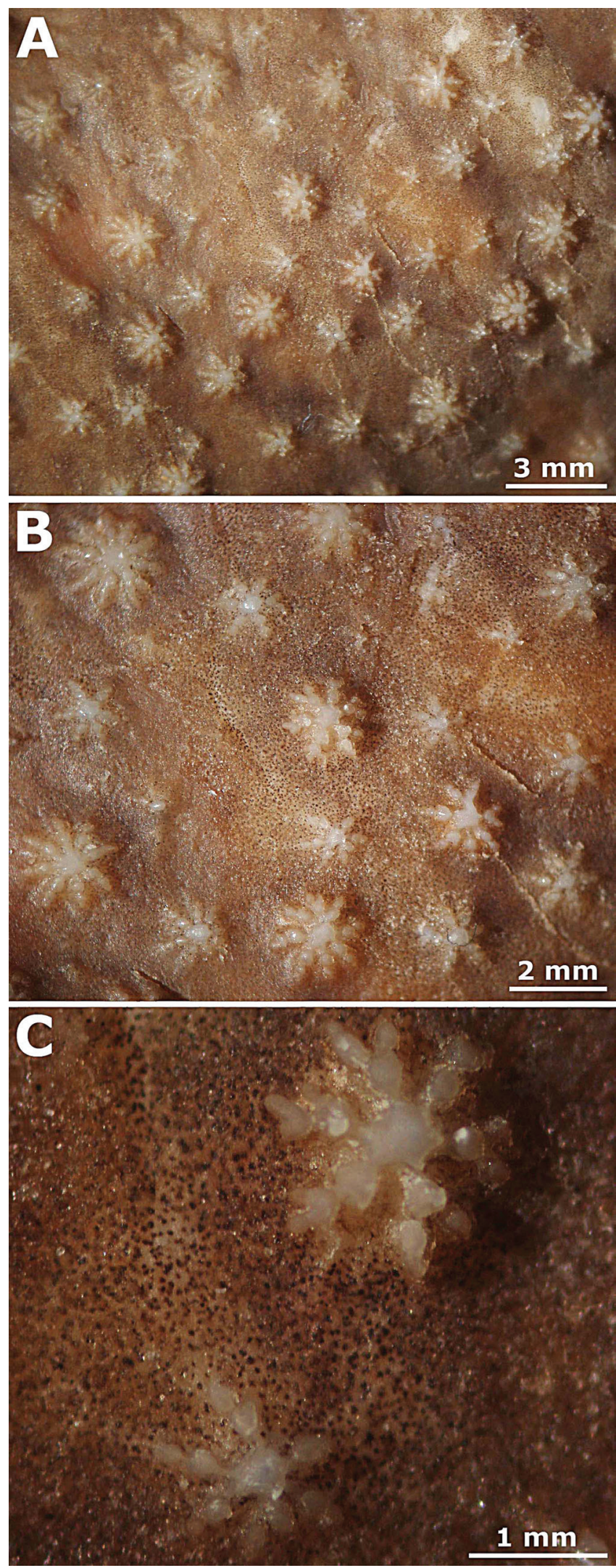

Fig. 32. Potamotrygon pantanensis, n. sp. Detail of dermal denticles in a non-type adult female specimen, MZUSP $110895,328 \mathrm{~mm}$ DW, showing two types of denticles present on dorsal disc. 

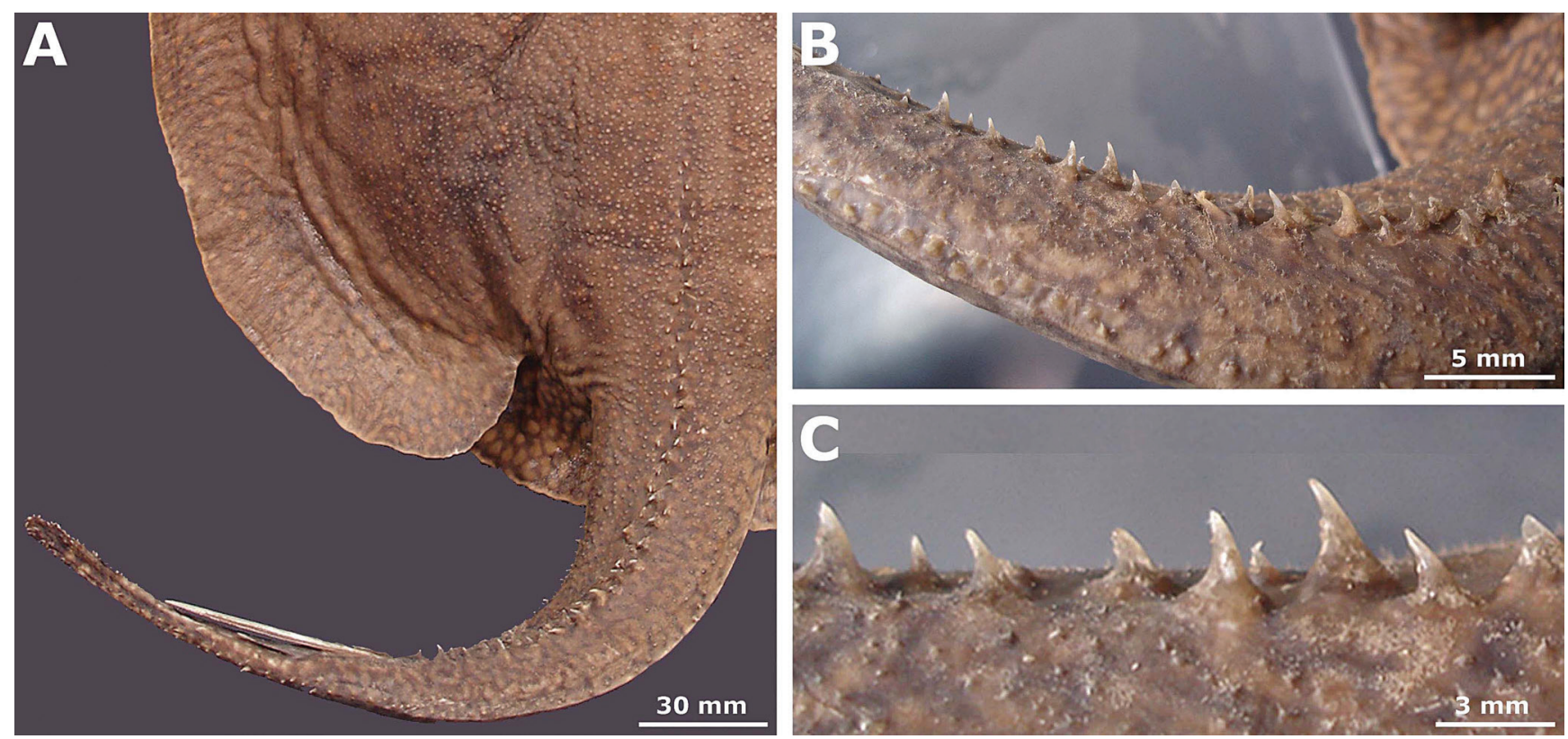

Fig. 33. Potamotrygon pantanensis, n. sp. MZUSP 110895: (a) Dorsal view of tail showing the entire dorsal row of enlarged pointed-spines, (b) showing the double rows and shape of pointed-spines, and (c) detail of some pointed-spines of dorsal rows.

and 31). Ocelli vary in length and shape. Specimens with ocelli only on dorsal disc at middisc region; ocelli greater or equal to eye-diameter, and smaller and more numerous on peripheral disc region. In some specimens vermiculations present on central disc region, and with ocelli only on disc margins. Some specimens present between central and marginal regions of disc intermediate-sized spots transitional between simple ocelli and vermiculations. Ocelli with two colors, central region orange, beige or yellow, with a peripheral black contour (Fig. 31). Dorsal coloration of pelvic fins similar to disc, presenting ocelli and spots weaker than those of disc. Dorsal coloration of tail, from its base to insertion of caudal sting, with a vermiculated bicolor pattern. Vermiculated spots brown surrounded by black contour. Vermiculations smaller at base of caudal sting.

Ventral coloration of disc with a predominantly whitish (sometimes yellowish or light beige) anterocentral region, with darker margins and posterior portion of disc (Figs. 23b, $24 \mathrm{~b}, 25 \mathrm{~b}, 26 \mathrm{~b}, 27 \mathrm{~b}, 28 \mathrm{~b})$. Whitish color of anterocentral disc also present on nostrils, mouth, and reaching anteriorly to disc margin; some specimens whitish also between branchial slits. Strip of darker color anterior to first pair of branchial slits sometimes present. Darker disc periphery sometimes with lighter spots, generally more concentrated on posterior disc. Ventral coloration of pelvic fins similar to outer disc margins, with more whitish spots. Ventral coloration of tail at base gray with some few black spots in most specimens. Vermicular pattern more concentrated near base of caudal sting; vermiculated spots small, forming several different patterns. Tip of tail black with small white spots, rounded or vermiculated.

Squamation. Dermal denticles principally on central region of dorsal disc; marginal disc and dorsal region of tail with few and dispersed denticles; denticles also present on lateral aspect of tail posterior to caudal sting. Dermal denticles very concentrated on central disc, head, scapular and pelvic girdle regions, and presenting a star-shaped morphology (morphologically similar to P. motoro) with dichotomous ridges on crown; some smaller denticles "V"-shape in dorsal view, with a small, blunt coronal plate and few coronal ridges (usually two) also occuring between larger star-shaped denticles (Fig. 32). Smaller denticles more numerous than star-shaped ones. Denticles on outer disc smaller than central disc denticles, some with star-shape, but with a pointed coronal plate and simple ridges (not dichotomous), and some presenting only a pointed coronal plate. Spiracle openings with trichotomous, pointed minute denticles. Few starshaped denticles on base of tail, most intermediate between star-shape and simply pointed. Denticles pointed on rest of tail. Generally two dorsal rows of enlarged pointed-spines present on tail, but three rows in some specimens (Fig. 33). Dorsal tail rows of pointed-spines originating from posterior to scapular girdle or from tail base; dorsal rows reach insertion of caudal sting posteriorly. Pointed-spines relatively small, curved and slender, varying from 32 to 77 (Table 4). Lateral row of pointed-spines on tail originating from tail base to origin of caudal sting. Lateral row generally single, sometimes double, but larger adults with two rows. Spines in lateral rows small, straight and posteriorly inclined. 
A
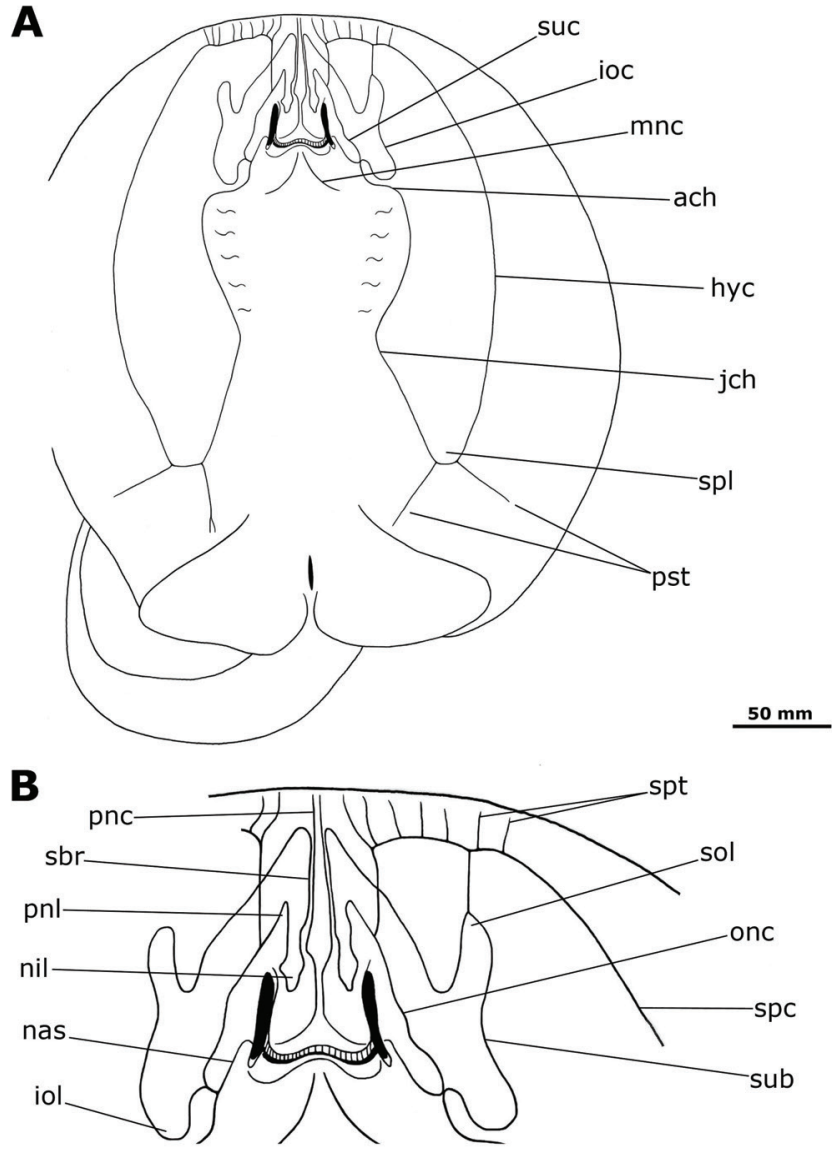

$20 \mathrm{~mm}$

Fig. 34. Potamotrygon pantanensis, n. sp. Ventral canals of lateral line system in an adult female non-type specimen, MZUSP 110899, 289 mm DW. Abbreviatons: hyc, hyomandibular canal; ioc, infraorbital canal; mnc, mandibular canal; nas, nasal canal; suc, supraorbital canal; ach, angular component of hyomandibular canal; iol, infraorbital loop; jch, jugular component of hyomandibular canal; nil, nasointernal loop; onc, orbitonasal component of supraorbital canal; pnc, prenasal component of nasal canal; pnl, prenasal loop; pst, posterior subpleural tubule; sbr, subrostral component of supraorbital canal; sol, suborbital loop; spc, subpleural component of hyomandibular canal; spl, subpleural loop; spt, subpleural tubules; sub, suborbital component of infraorbital canal.

Ventral lateral-line canals. Four adult specimens examined, three females (MZUSP 110886, 334 mm DW; MZUSP 110895, 328 mm DW; MZUSP 110899, 289 mm DW; Fig. 34) and one male (MZUSP 110891, $268 \mathrm{~mm}$ DW).

Hyomandibular canal (hyc) originates just anterior to, and connecting with, orbitonasal component of supraorbital canal (onc). Hyomandibular canal extends anteriorly in a straight fashion to anterior margin of disc, more so than in $P$. motoro. Few subpleural tubules (spt) present on subpleural component of hyomandibular canal (spc); central tubules curved toward anterior disc margin, sometimes subdivided.
Two females examined with two posterior subpleural tubules (pst) associated to subpleural loop ( $\mathrm{spl}$ ). Some specimens present small ramifications at distal portion of posterior subpleural tubules. Angular component of hyomandibular canal (ach) short and straight. Jugular component of hyomandibular canal (jch) without pronounced curve posterior to branchial basket, broadly arching lateral to branchial basket. Infraorbital canal (ioc) extends from junction with three other canals, the dorsal portion of hyomandibular canal, and portions of supraorbital (suc) and nasal (nas) canals. Lateral to this junction, infraorbital component extends slightly posteriorly to form rounded infraorbital loop (iol), and then anteriorly forming slender suborbital loop (sol). Suborbital component of infraorbital canal (sub) curved, somewhat "s"-shaped, forming lateral aspect of infraorbital canal. One female (MZUSP 110899) with a connection between suborbital component of infraorbital canal and anterior portion of hyomandibular canal (Fig. 34). Supraorbital canal (suc) extends anteromedially from junction with three other canals (hyomandibular, infraorbital, and nasal canals). Orbitonasal component (onc) of supraorbital canal not undulated, ascending toward anteromedial snout region, but curving posteriorly to delimit slender prenasal loop (pnl). Nasointernal loop (nil) extending posteriorly only very slightly, barely penetrating nasal flap. Subrostral component of supraorbital canal (sbr) extending anteriorly to connect with anterior portion of infraorbital canal near margin of disc. Nasal canal (nas) extends to mouth corners from junction of hyomandibular and infraorbital canals. Prenasal component of nasal canal (pnc) penetrating nasal curtain at posterior corners to extend anteromedially to anterior margin of disc. Different from P. motoro, P. pantanensis presents a connection between four major canals: infraorbital, supraorbital (orbitonasal component), nasal, and anteromedial portion of hyomandibular canals. Mandibular canal (mnc) short and extending posterolaterally from midline, reaching posteriorly almost to level of first gill slits.

Skeletal features. Potamotrygon pantanensis presents a neurocranium proportionally narrower than $P$. motoro (Figs. 35, 36). Precerebral fontanelle (PCF) wide, very circular and sharply delimited posteriorly by epiphysial bar (EPB). Frontoparietal fontanelle (FPF) narrow, extending posteriorly to level of postorbital process, and widening slightly posteriorly. Postorbital process (POP) seemingly not as developed as in $P$. motoro. Anterior angular cartilage (AAC) well-developed, almost half length of hyomandibula (HYO), whereas posterior angular cartilage (PAC) very reduced, less than half length of anterior angular cartilage. Meckel's cartilages (MC) smaller and less robust than in $P$. motoro, without a small concavity on dorsal margin near corner of mouth opening. Palatoquadrates (PQ) slender, presenting small dorsolateral projections (DLP), and with a small calcified ligament (CL) in between antimeres (Figs. 35). 
A

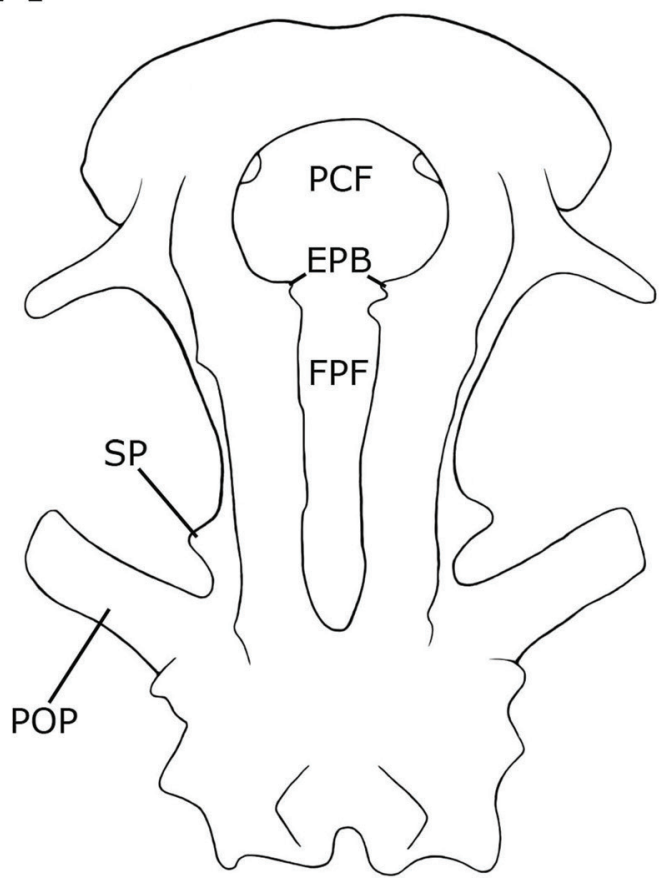

B

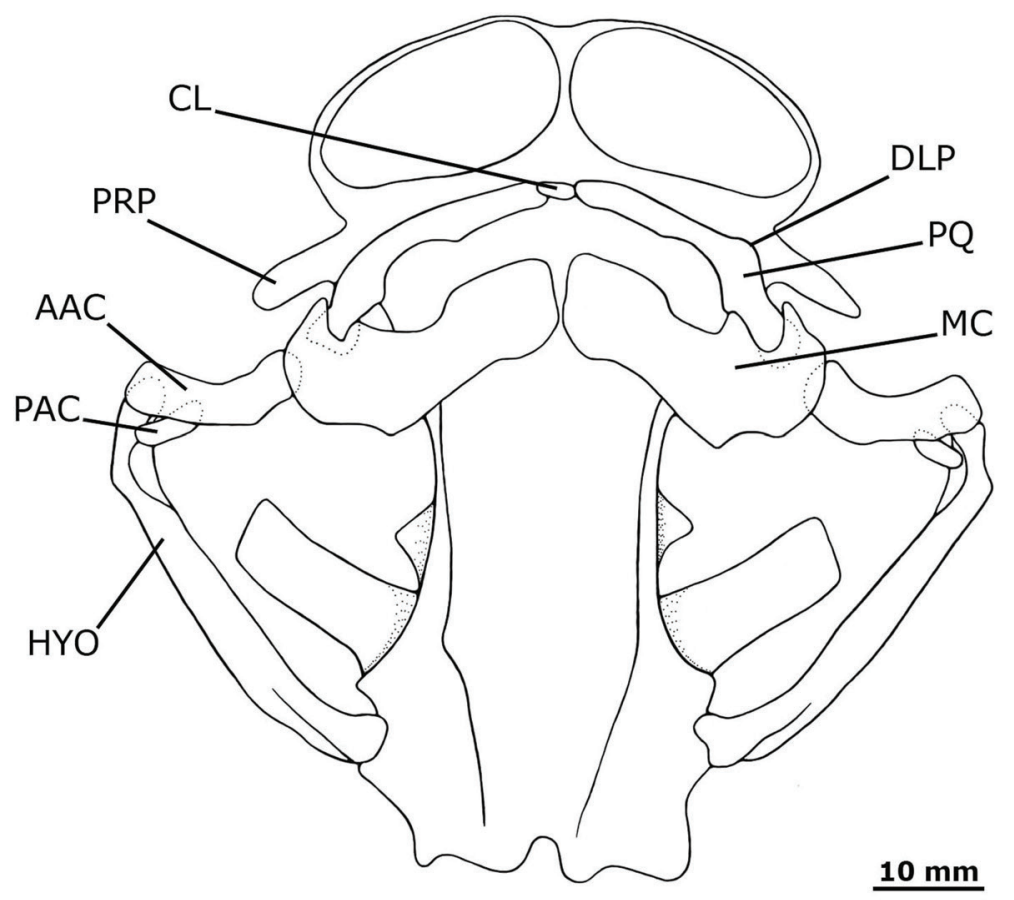

Fig. 35. Potamotrygon pantanensi, n. sp. Dorsal and ventral views of neurocranium and mandibular arch of an adult female, MZUSP 110895. Abbreviations: AAC, anterior angular cartilage; CL, calcified ligament; DLP, dorsolateral process; EPB, epiphysial bar; FPF, frontoparietal fontanelle; HYO, hyomandibula; MC, Meckel's cartilage; PAC, posterior angular cartilage; PCF, precerebral fontanelle; POP, postorbital process; PQ, palatoquadrate PRP, preorbital process; SP, supraorbital process.

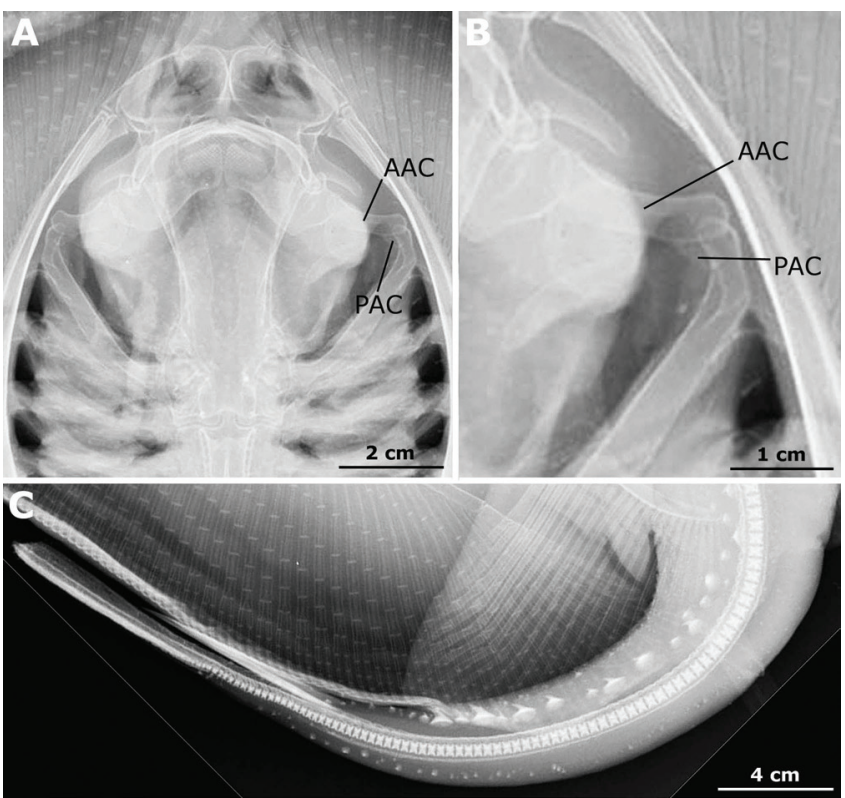

Fig. 36. Potamotrygon pantanensis, n. sp. Anatomical details from radiograph of holotype, MZUSP 110890. Abbreviations: AAC, anterior angular cartilage; PAC, posterior angular cartilage.

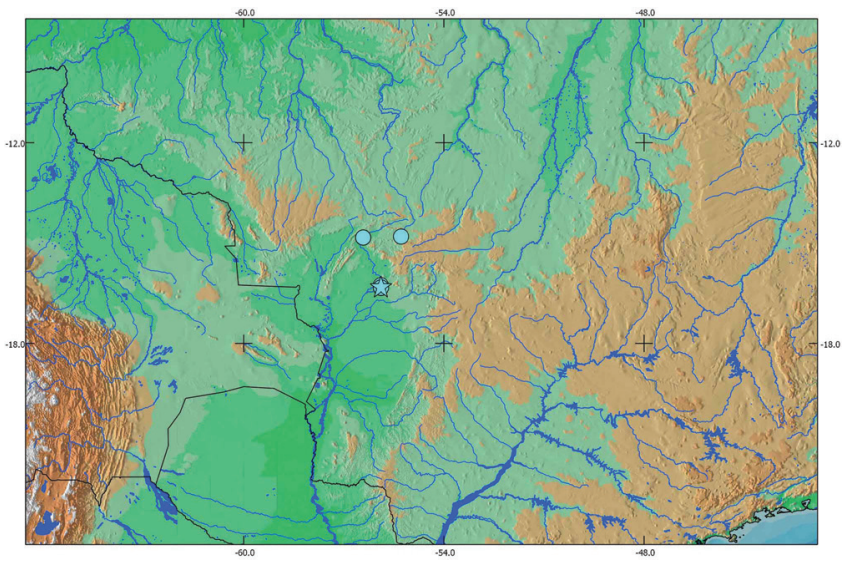

Fig. 37. Distribution of Potamotrygon pantanensis, n. sp. in the Paraná-Paraguay system. Blue circles show localities where specimens of $P$. pantanensis were obtained for this study. Blue star indicates Cuiabá River, type locality of $P$. pantanesis. 
Skeletal counts as follows. Range of number of vertebrae in P. pantanensis 118 to 125 , less than the other two species (P. motoro ranging between 116 to 133 and P. amandae 113 to 129). Mode and range of diplospondilic vertebrae, respectively, 90 and 89 to 100 ( $P$. motoro has 99 and 90 to 99 , and $P$. amandae, sp. nov. has 99 and 85 to 99 , respectively). Range of number of pectoral radials 87 to 95 , less than the other two species ( $P$. motoro with range from 86 to 101, and $P$. amandae, sp. nov. from 92 to 106). Propterygial and metapterygial radials ranges respectively 41 to 44 , and 31 to 36 in P. pantanensis (41 to 50, and 30 to 40 in P. motoro; and 42 to 51, and 35 to 40 in P. amandae, sp. nov.) (Tables 2, 4 and 6).

Geographic distribution. Specimens of P. pantanensis were collected only in the northern Pantanal region, in rivers located in Barão de Melgaço, Rosário do Oeste, and Chapada dos Guimarães, all in the state of Mato Grosso (Brazil) (Fig. 37).

Etymology. The species epithet pantanensis refers to the northern Pantanal region (Paraná-Paraguay basin) where this new species has been exclusively found to date.

Remarks. Sexual maturity of females occurs between 24 and $47 \mathrm{~cm} \mathrm{DL}$, whereas males sexually mature between 23 and $28 \mathrm{~cm} \mathrm{DL}$.

\section{Potamotrygon amandae, new species Figs. 38-52}

Potamotrygon pauckei: -Castex, 1963a: 54, 56, fig. 13, p. 56 [citation of one male specimen as legend to photograph]; -Castex, 1963c: 292 [citation of male specimen from Castex 1963a]; -Castex, 1963d: 27-28, 31, 44-46, 56 [morphological characters, toxicity, distribution]; -Castex, 1964: 30 [external morphology, coloration]; -Castex \& Maciel, 1965: 7-9, 14 [distribution and occurrence in rivers around Santa Fé, Argentina]; -Castex \& Yagolkowski, 1970: 3, 13-26, fig. 6, p. 24, fig. p. 25, fig. p. 26 [external morphology, dentition, denticles and spine morphology, coloration, measurements, distribution]; -Castello, 1975: 30-31 [citation of a female specimen].

Potamotrygon cf. motoro: -Graça \& Pavanelli, 2007: xi, 6, 9, $13,22,24,240$, fig. 2 , p. 24 [distribution, identification key, morphological measurements, coloration, tooth counts]. -Domingues \& Marques, 2007: 157, 167-168, 173 [new species of parasite described]; -Silva \& Goulart, 2007: 413-418, figs. $2-4$, p. 415 , fig. 5 , p. 416 , figs. $11-12$, p. 417, fig. 14, p. 418 [morphometric data].

Potamotrygon motoro: -Lonardoni et al., 2006: 195-200, fig. 2, p. 198 [feeding habits]; -Garrone-Neto et al., 2007: 206-208, fig. 3, p. 207 [occurrence in upper Paraná River];
-Silva \& Uieda, 2007: 221-225, fig. 1a, p. 222 [feeding habits]; -Lacerda et al., 2008: 115, 117, 121 [parasites]; -Garrone-Neto \& Sazima, 2009a: 113-115, fig. 2, p. 115 [foraging habits]; -Garrone-Neto \& Sazima, 2009b: 499500, fig. 1, p. 500 [foraging behavior]; -Maniglia, 2010: 6-7, 10-12, 14, 16, 19-38, fig. 1, p. 16, fig. 2, p. 20, fig. 3 , p. 22 , fig. 4 , p. 23 , fig. 5 , p. 25 , fig. 6 , p. 26 , fig. 7 , p. 28 , fig. 8 , p. 28 , fig. 9 , p. 30 , fig. 10 , p. 31 , fig. 11 , p. 32 , fig. 12 , p. 33 , fig. 13 , p. 34 [molecular data].

Potamotrygon aff. motoro: -Cruz et al. 2011: 201-205, 207, fig. 2, p. 203, fig. 3, p. 204, fig. 6, p. 207 [karyotype].

Holotype. MZUSP 110910, adult female, $341 \mathrm{~mm}$ DW, Paraguai River, subdistrict of Albuquerque, district of Corumbá, State of Mato Grosso do Sul, Brazil, 19²41'S 57³8’W, 11 Dec 2003, F. P. L. Marques, F. Reyda \& W. Santana.

Paratypes. (12 specimens). MZUSP 110904, adult male, $312 \mathrm{~mm}$ DW, Paraná River, district of Porto Primavera, State of São Paulo, Brazil, 22 $47^{\prime}$ 'S 52 $96^{\prime}$ 'W, B. A. de Oliveira \& G.C. Evagenlista, 06 Apr 2004. MZUSP 111921, adult female, 298 mm DW, Paraná River, subdistrict of Jupiá, district of Três Lagoas, State of Mato Grosso do Sul, Brazil, 2079'S 516'ㄴ'W, F. P. L. Marques, F. Reyda, J. Caira \& W. Santana, 17 Dec 2003. MZUSP 110906, adult female, 294 mm DW, Paraguai River, subdistrict of Albuquerque, district of Corumbá, $19^{\circ} 41^{\prime}$ S $57^{\circ} 38^{\prime}$ W, F. P. L. Marques, F. Reyda \& W. Santana, 08 Dec 2003. MZUSP 110909, adult female, 290 mm DW, Paraguai River, subdistrict of Albuquerque, district of Corumbá, $19^{\circ} 41^{\prime}$ S $57^{\circ} 38^{\prime}$ W, F. P. L. Marques, F. Reyda \& W. Santana, 10 Dec 2003. MZUSP 110907, adult female, 270 mm DW, Paraguai River, subdistrict of Albuquerque, district of Corumbá, 19² $41^{\prime} \mathrm{S} 57^{\circ} 38^{\prime} \mathrm{W}$, F. P. L. Marques, F. Reyda \& W. Santana, 08 Dec 2003. MZUSP 111916, adult male, 259 mm DW, Paraná River, subdistrict of Jupiá, district of Três Lagoas, State of Mato Grosso do Sul, Brazil, 2079'S $51^{\circ} 65^{\prime}$ W, F. P. L. Marques, F. Reyda, J. Caira \& W. Santana, 15 Dec 2003. MZUSP 111920, adult male, 255 mm DW, Paraná River, subdistrict of Jupiá, district of Três Lagoas, State of Mato Grosso do Sul, Brazil, 2079'S $51^{\circ} 65^{\prime}$ W, F. P. L. Marques, F. Reyda, J. Caira \& W. Santana, 17 Dec 2003. MZUSP 110913, adult female, $254 \mathrm{~mm}$ DW, Paraguai River, subdistrict of Albuquerque, district of Corumbá, $19^{\circ} 41^{\prime}$ 'S $57^{\circ} 38^{\prime}$ W, F. P. L. Marques, F. Reyda, J. Caira \& W. Santana, 12 Dec 2003. MZUSP 111919, adult female, $236 \mathrm{~mm}$ DW, Paraná River, subdistrict of Jupiá, district of Três Lagoas, State of Mato Grosso do Sul, Brazil, 2079'S 51ํ6' W, F. P. L. Marques, F. Reyda, J. Caira \& W. Santana, 16 Dec 2003. MZUSP 111917, young male, 218 mm DW, Paraná River, subdistrict of Jupiá, district of Três Lagoas, State of Mato Grosso do Sul, Brazil, 2079'S $51^{\circ} 65^{\prime}$ W, F. P. L. Marques, F. Reyda, J. Caira \& W. Santana, 15 Dec 2003. MZUSP 111925, juvenile male, $195 \mathrm{~mm}$ DW, Paraná River, subdistrict of Jupiá, district of Três Lagoas, $20^{\circ} 79^{\prime}$ S $51^{\circ} 65^{\prime}$ W, F. P. L. Marques, F. Reyda, J. Caira \& W. Santana, 17 Dec 2003. MZUSP 111923, juvenile female, $194 \mathrm{~mm}$ DW, same data as previous specimen. 
A

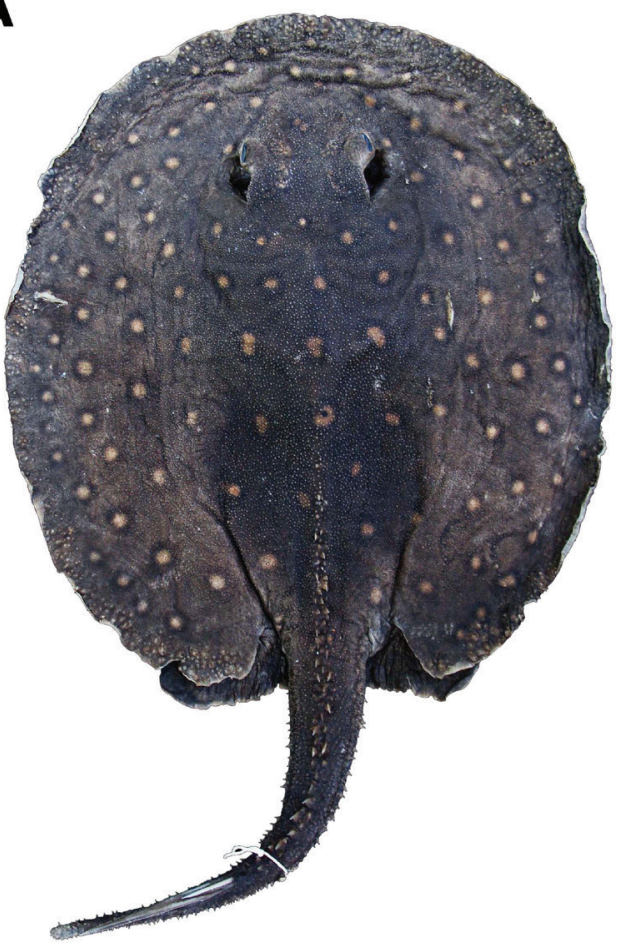

B

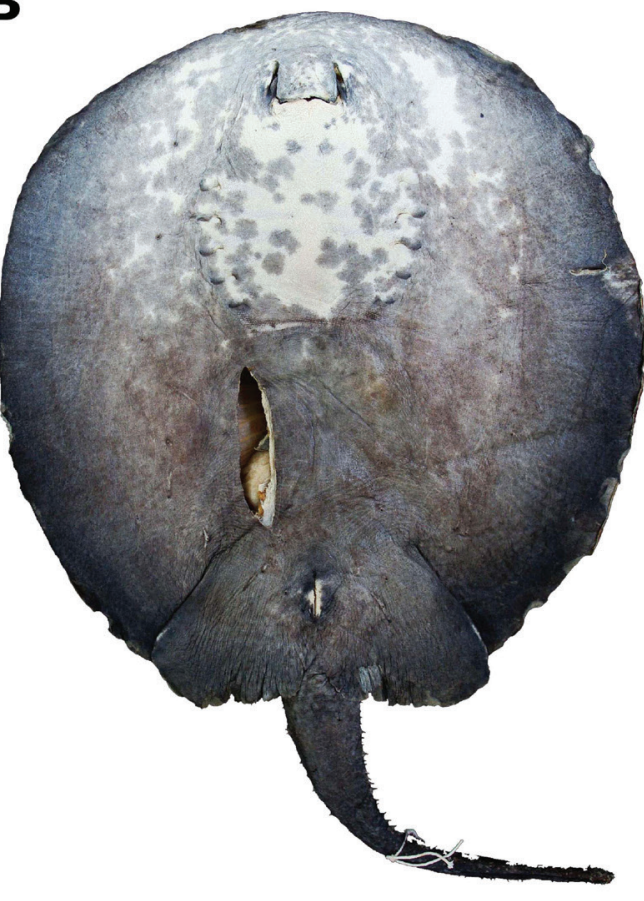

Fig. 38. Potamotrygon amandae, n. sp. Dorsal (a) and ventral (b) views of holotype, MZUSP 110910, adult female, 341 mm DW, Paraguay River.

A

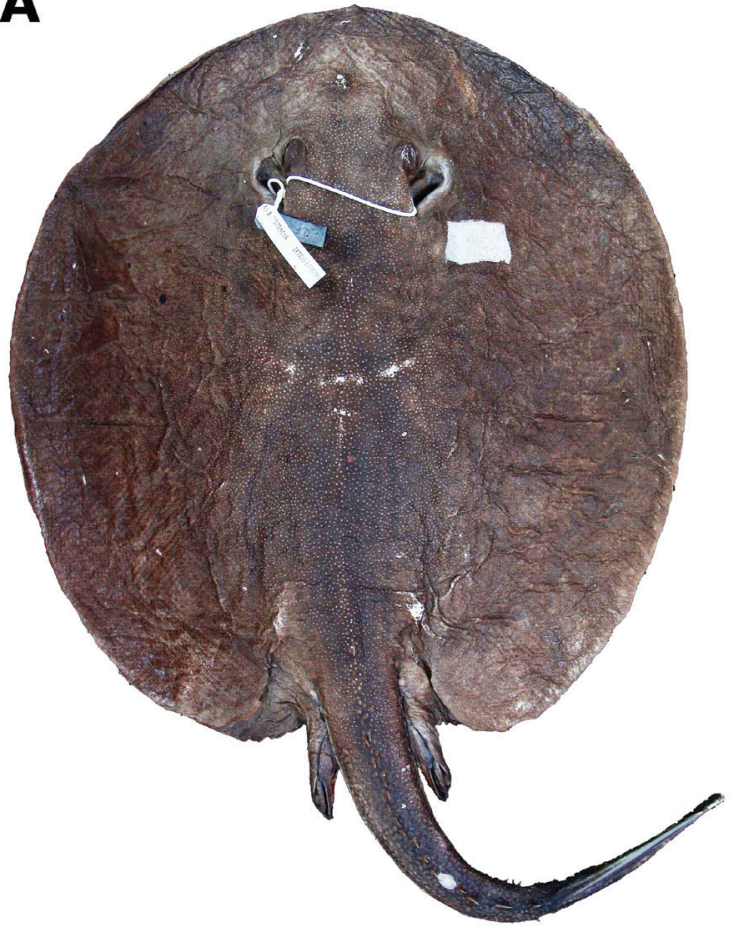

B

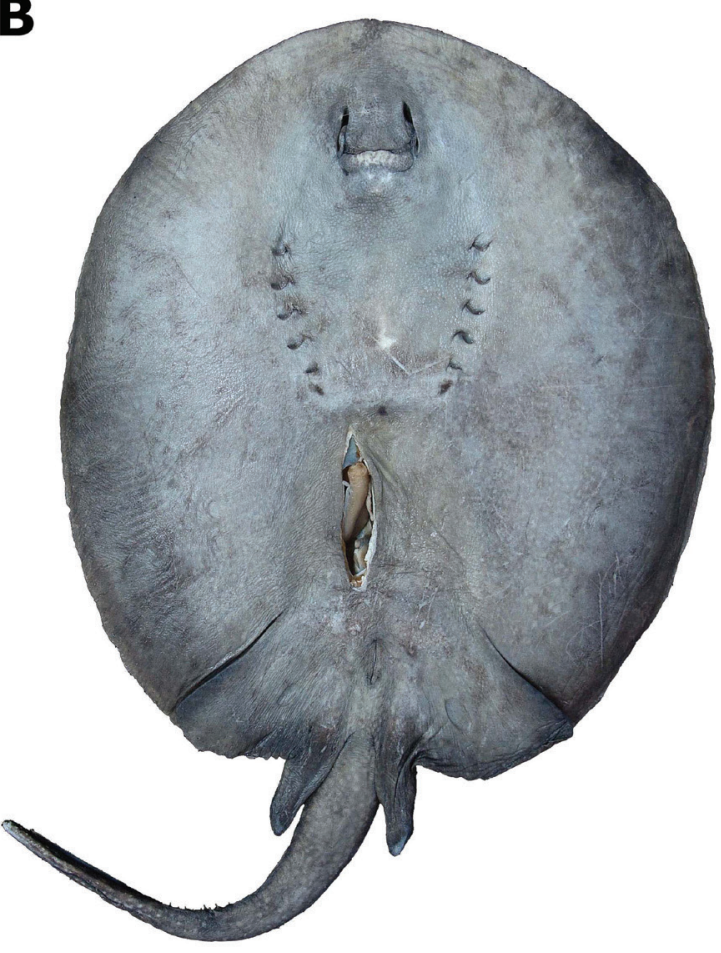

Fig. 39. Potamotrygon amandae, n. sp. Dorsal (a) and ventral (b) views of paratype, MZUSP 110904, adult male, 312 mm DW, from Paraná River. 
A

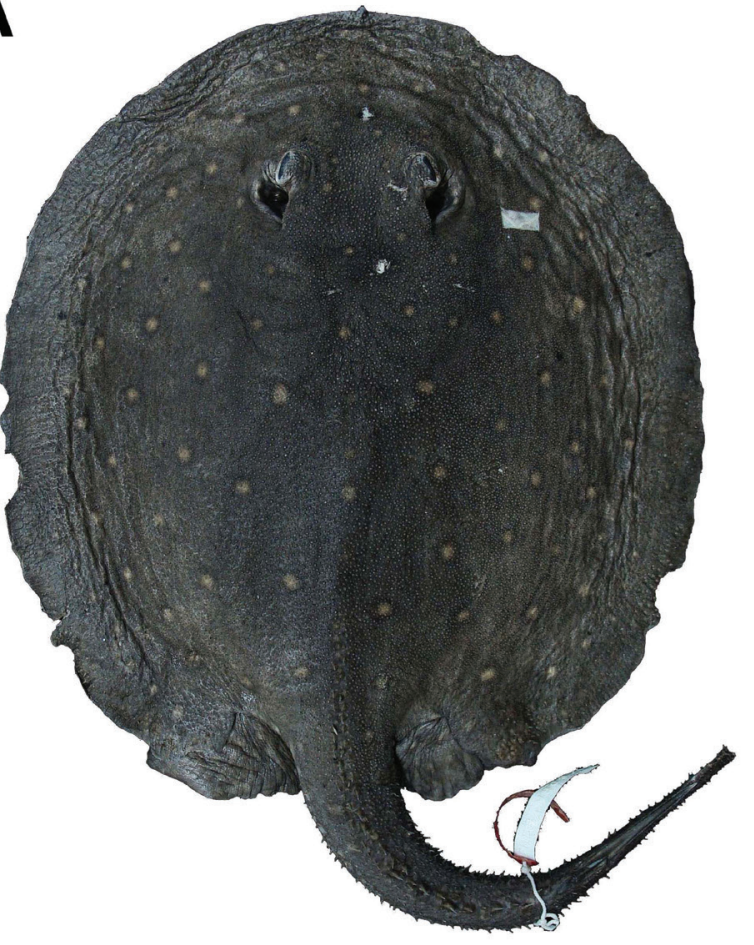

B

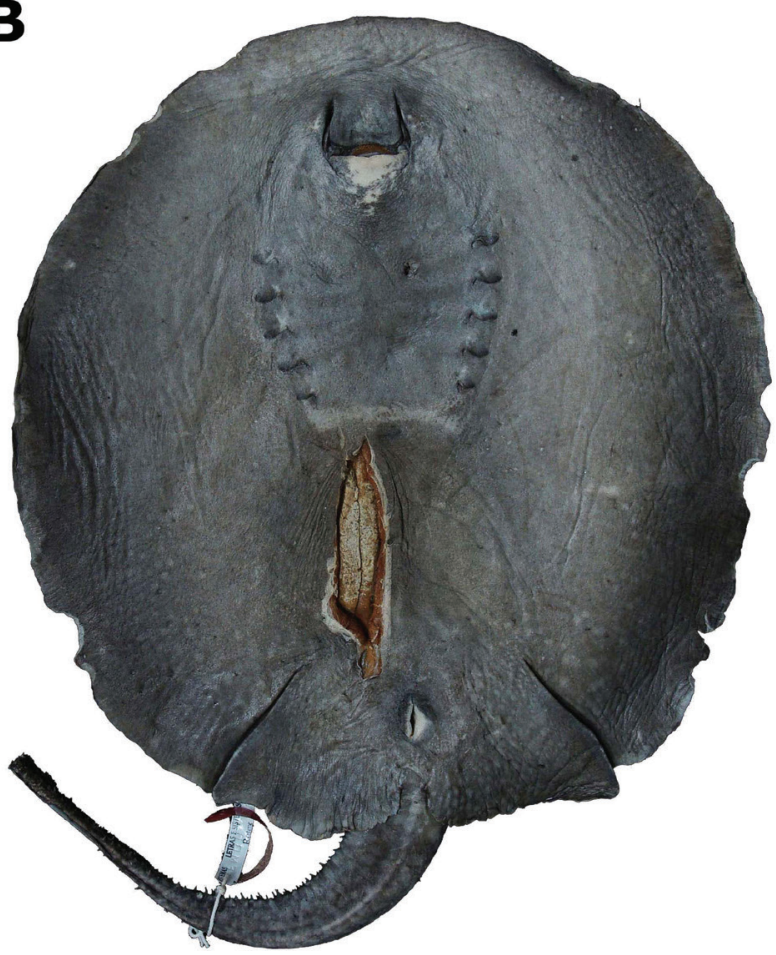

Fig. 40. Potamotrygon amandae, n. sp. Dorsal (a) and ventral (b) views of paratype, MZUSP 110906, adult female, $294 \mathrm{~mm}$ DW, from Paraguay River.

A

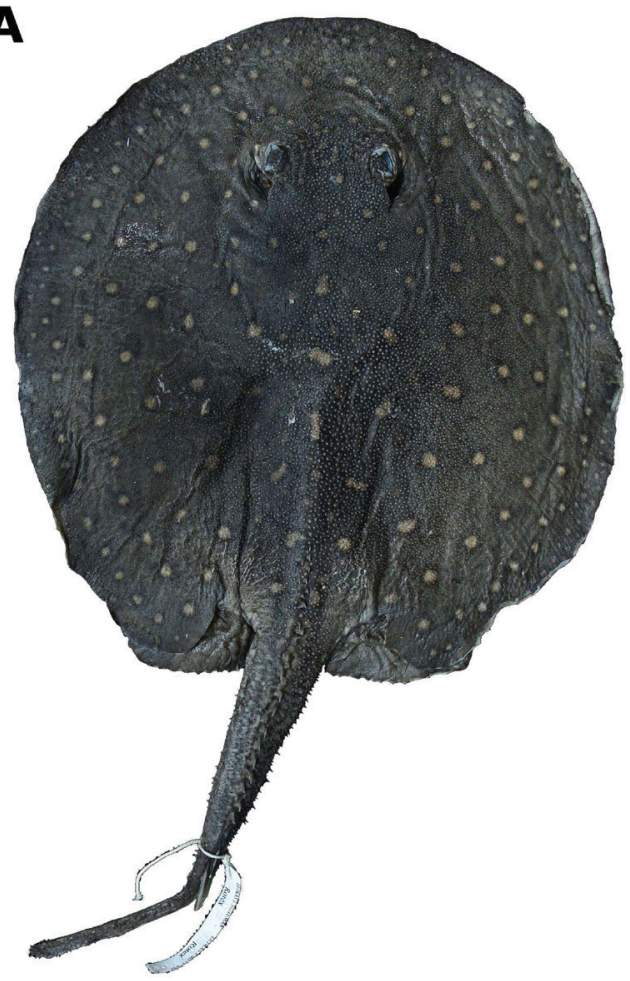

B

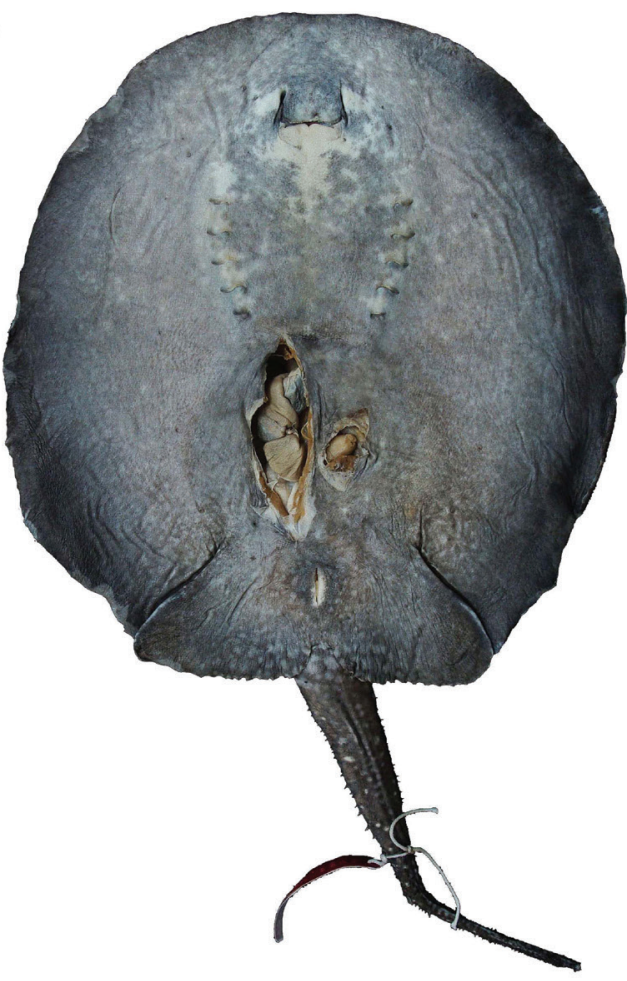

Fig. 41. Potamotrygon amandae, n. sp. Dorsal (a) and ventral (b) views of paratype, MZUSP 110907, adult female, $270 \mathrm{~mm}$ DW, from Paraguay River. 
Table 3. Measurements of specimens of Potamotyrgon pantanensis analyzed in this study, including the holotype (A) MZUSP 110890. Mean $(x)$ and Standard Deviation (SD) are expressed as proportions of disc width (\% DW), and range is expressed in millimeters $(\mathrm{mm})$ and proportion of disc width $(\% \mathrm{DW})$. Clasper measurements were taken only from adult specimens.

\begin{tabular}{|c|c|c|c|c|c|c|c|}
\hline \multirow[t]{2}{*}{ MEASUREMENTS } & \multicolumn{2}{|c|}{$\mathbf{A}$} & \multirow[t]{2}{*}{$\mathbf{n}$} & \multicolumn{2}{|c|}{ Range } & \multirow{2}{*}{$\begin{array}{c}x \\
\% \mathrm{DW}\end{array}$} & \multirow{2}{*}{$\begin{array}{c}\text { SD } \\
\% \mathrm{DW}\end{array}$} \\
\hline & $\mathrm{mm}$ & $\% \mathrm{DW}$ & & $\mathrm{mm}$ & $\% \mathrm{DW}$ & & \\
\hline Disc width & 323 & & 15 & $215-336$ & & & \\
\hline Disc length & 350 & 108.4 & 15 & $235-368$ & $102.9-117.1$ & 109.5 & 4.1 \\
\hline Total length & 533 & 165.0 & 13 & $407-664$ & $150.3-189.3$ & 164.9 & 9.9 \\
\hline Interorbital distance & 45 & 13.9 & 15 & $26-60$ & $12.1-15.4$ & 13.7 & 0.8 \\
\hline Interspiracular distance & 66 & 20.4 & 15 & $43-83$ & $16.4-21.7$ & 19.9 & 1.1 \\
\hline Preorbital distance & 64 & 19.8 & 14 & $45-85$ & $19.8-25.6$ & 22.3 & 1.5 \\
\hline Eye diameter & 15 & 4.6 & 15 & $12-17$ & $3.9-5.6$ & 4.5 & 0.5 \\
\hline Spriracular length & 31 & 9.6 & 14 & $20-41$ & $7.6-9.6$ & 8.7 & 0.6 \\
\hline Prenasal distance & 44 & 13.6 & 14 & $31-68$ & $11.6-15.4$ & 14.0 & 1.3 \\
\hline Preoral distance & 62 & 19.2 & 14 & $46-92$ & $17.9-22.5$ & 20.1 & 1.3 \\
\hline Internasal distance & 28 & 8.7 & 15 & $17-32$ & $7.8-8.9$ & 8.2 & 0.4 \\
\hline Mouth width & 28 & 8.7 & 15 & $17-39$ & $7.3-9.8$ & 8.4 & 0.8 \\
\hline Space between $1^{\text {st }}$ branchial slits & 86 & 26.6 & 15 & $54-113$ & $25.1-26.6$ & 25.9 & 0.5 \\
\hline Space between $5^{\text {th }}$ branchial slits & 59 & 18.3 & 15 & $36-75$ & $16.7-19.8$ & 18.2 & 0.9 \\
\hline Branchial basket length & 54 & 16.7 & 15 & $36-74$ & $16.5-18.5$ & 17.3 & 0.7 \\
\hline Length ant. margin of pelvic fin & 75 & 23.2 & 15 & $53-90$ & $19.5-26.8$ & 22.7 & 2.2 \\
\hline Pelvic fins width & 180 & 55.7 & 15 & $123-256$ & $54.9-65.7$ & 60.6 & 3.5 \\
\hline Length ext. margin of clasper & - & - & 2 & $31-35$ & $13.1-14.4$ & 13.7 & 1.0 \\
\hline Length int. margin of clasper & - & - & 2 & $60-65$ & $24.3-27.9$ & 26.1 & 2.6 \\
\hline Cloaca to tip tail & 200 & 61.9 & 12 & $196-280$ & $61.9-91.2$ & 73.4 & 8.1 \\
\hline Tail width between pectoral insertions & 39 & 12.1 & 15 & $24-54$ & $11.2-15.5$ & 13.2 & 1.2 \\
\hline Snout to cloaca & 310 & 96.0 & 15 & $181-376$ & $84.2-96.6$ & 92.3 & 4.4 \\
\hline Distance between pectoral axil and posterior margin of pelvic fin & 65 & 20.1 & 15 & $32-70$ & $10.5-21.5$ & 16.4 & 3.5 \\
\hline Cloaca to serrated-spine & 155 & 48.0 & 13 & $105-194$ & $39.6-53.6$ & 46.5 & 4.0 \\
\hline Caudal sting length & - & - & 5 & $41-59$ & $16.3-19.4$ & 18.4 & 1.3 \\
\hline Caudal sting width & - & - & 5 & $4-5$ & $1.3-2.3$ & 1.7 & 0.4 \\
\hline Dorsal pseudosiphon & - & - & 0 & - & - & - & - \\
\hline Ventral pseudosiphon & - & - & 0 & - & - & - & - \\
\hline
\end{tabular}

Non-type specimens examined: Brazil. State of Mato Grosso: (22 specimens). MZUSP 111911, adult female, 274 mm DW, Mutum River, tributary of Cuiabá River, district of Barão de Melgaço, F. P. L. Marques \& M. Cardoso, 08 Jul 2006. MZUSP 111914, adult male, $268 \mathrm{~mm}$ DW, same data as previous. MZUSP 111913, adult male, 245 $\mathrm{mm}$ DW, same data as previous. MZUSP 111912, adult male, $232 \mathrm{~mm}$ DW, same data as previous. MZUSP 110916, adult female, $275 \mathrm{~mm}$ DW, baia Sinhá Mariana, tributary of Cuiabá River, district of Barão de Melgaço, W. J. da Graça, 22 Set 2003. State of Mato Grosso do Sul: MZUSP 110915, adult female, 322 mm DW, Paraguai River, subdistrict of Albuquerque, district of Corumbá, 19²41'S 57 38' W, F. P. L. Marques, F. Reyda, J. Caira \& W. Santana, 13 Dec 2003. MZUSP 110905, adult female, $319 \mathrm{~mm}$ DW, Paraguai River, subdistrict of Albuquerque, district of Corumbá, $19^{\circ} 41^{\prime}$ 'S 57 $38^{\circ}$ 'W, F. P. L. Marques, F. Reyda \& W. Santana, 05 Dec 2003. MZUSP 110914, adult female, $253 \mathrm{~mm}$ DW, Paraguai River, subdistrict of Albuquerque, district of
Corumbá, $19^{\circ} 41^{\prime}$ 'S 573'' W, F. P. L. Marques, F. Reyda, J. Caira \& W. Santana, 12 Dec 2003. MZUSP 110912, adult female, $227 \mathrm{~mm}$ DW, same data as previous. MZUSP 111918, adult female, $254 \mathrm{~mm}$ DW, Paraná River, subdistrict of Jupiá, district of Três Lagoas, 2079'S $51^{\circ}$ 65’W, F. P. L. Marques, F. Reyda, J. Caira \& W. Santana, 16 Dec 2003. MZUSP 111140, adult female, 254 mm DW, Paraná River, subdistrict of Jupiá, district of Três Lagoas, $20^{\circ} 79^{\prime}$ 'S 51 ${ }^{\circ} 65^{\prime}$ W, F. P. L. Marques, F. Reyda, J. Caira \& W. Santana, 17 Dec 2003. MZUSP 111926, juvenile female, $228 \mathrm{~mm}$ DW, Paraná River, subdistrict of Jupiá, district of Três Lagoas, $20^{\circ} 79^{\prime}$ 'S $51^{\circ} 65^{\prime}$ W, F. P. L. Marques, F. Reyda, J. Caira \& W. Santana, 18 Dec 2003. MZUSP 111922, juvenile female, 226 $\mathrm{mm}$ DW, same data as previous. MZUSP 111136 young female, 226 mm DW, Paraná River, subdistrict of Jupiá, district of Três Lagoas, $20^{\circ} 79^{\prime}$ S $51^{\circ} 65^{\prime}$ W, F. P. L. Marques, F. Reyda, J. Caira \& W. Santana, 17 Dec 2003. MZUSP 111924, young female, 210 mm DW, Paraná River, subdistrict of Jupiá, district of Três Lagoas, State of Mato 
A

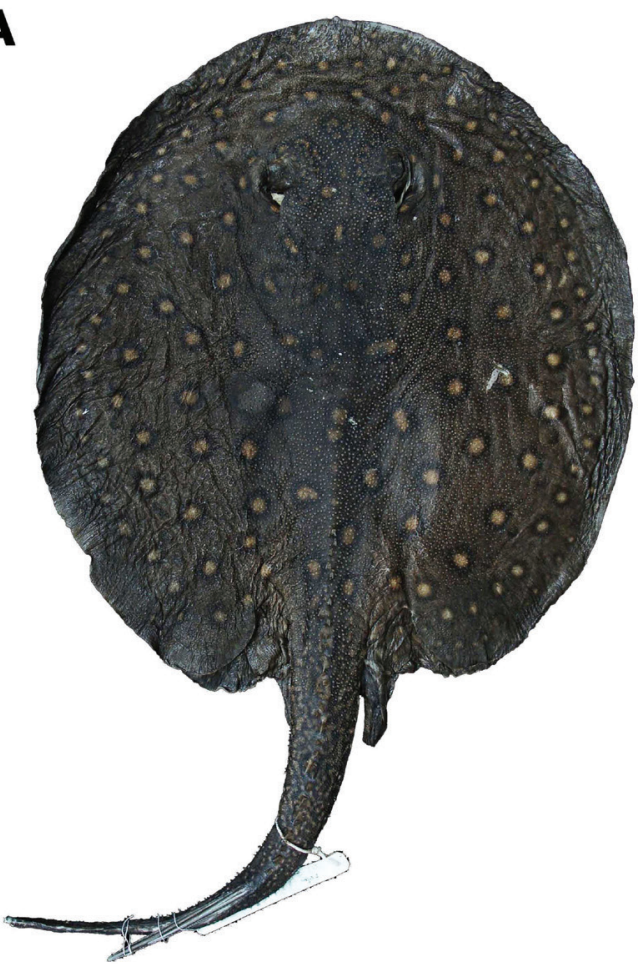

B

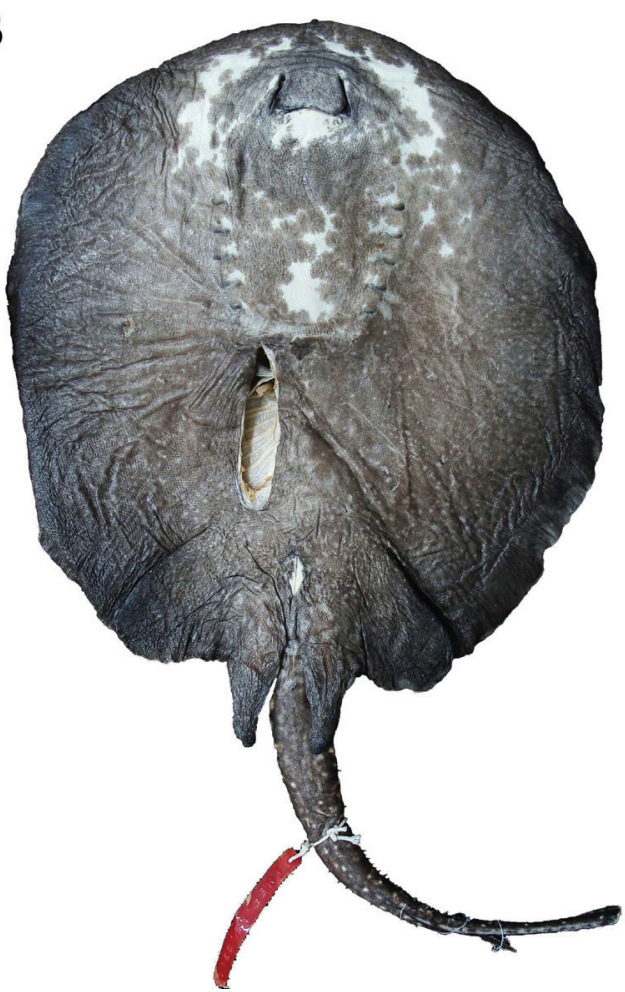

Fig. 42. Potamotrygon amandae, n. sp. Dorsal (a) and ventral (b) views of paratype, MZUSP 111916, adult male, $259 \mathrm{~mm}$ DW, from Paraná River.

Grosso do Sul, Brazil, 2079'S 51ํ5'W, F. P. L. Marques, F. Reyda, J. Caira \& W. Santana, 15 Dec 2003. State of Paraná: NUP 4379, adult female, 264 mm DW, São Francisco Verdadeiro River, tributary of Paraná River, district of Pato Bragado. NUP 4396, adult female, $243 \mathrm{~mm}$ DW, same data as previous. NUP 4420, juvenile female, 230 mm DW, São Francisco Falso River, tributary of Paraná River, district of Santa Helena. State of São Paulo: MZUSP 110903, adult male, 311 mm DW, Paraná River, district of Porto Primavera, 22 $2^{\circ} 7^{\prime} \mathrm{S}$ $52^{\circ} 96^{\prime}$ W, B.A. de Olibeira \& C.G. Evangelista, 05 Apr 2004. Paraná River basin, without specific locality: MZUSP 111148, adult male, $280 \mathrm{~mm}$ DW. MZUSP 111149, adult female, $256 \mathrm{~mm}$ DW. MZUSP 111150, juvenile male, $215 \mathrm{~mm}$ DW.
A
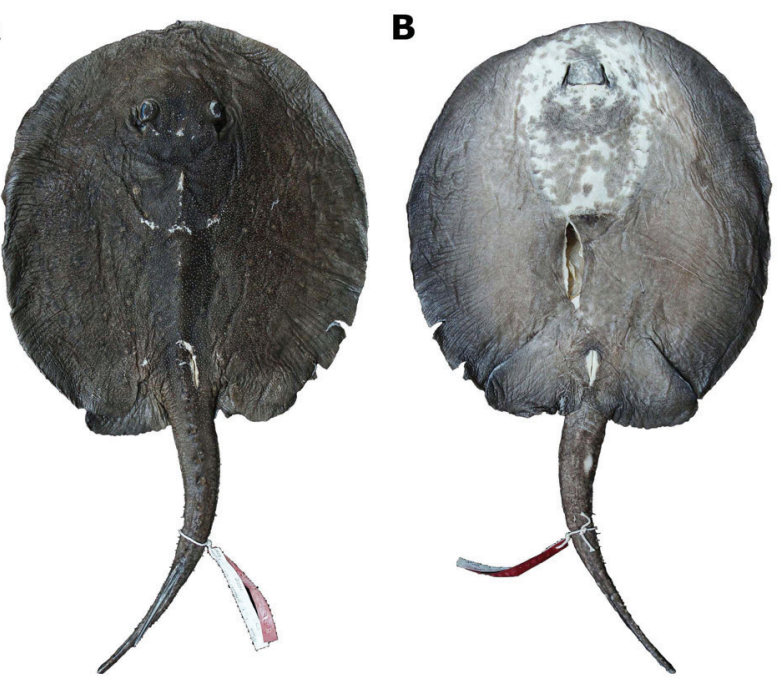

Fig. 43. Potamotrygon amandae, n. sp. Dorsal (a) and ventral (b) views of paratype, MZUSP 111919, adult female, $236 \mathrm{~mm}$ DW, from Paraná River.
A
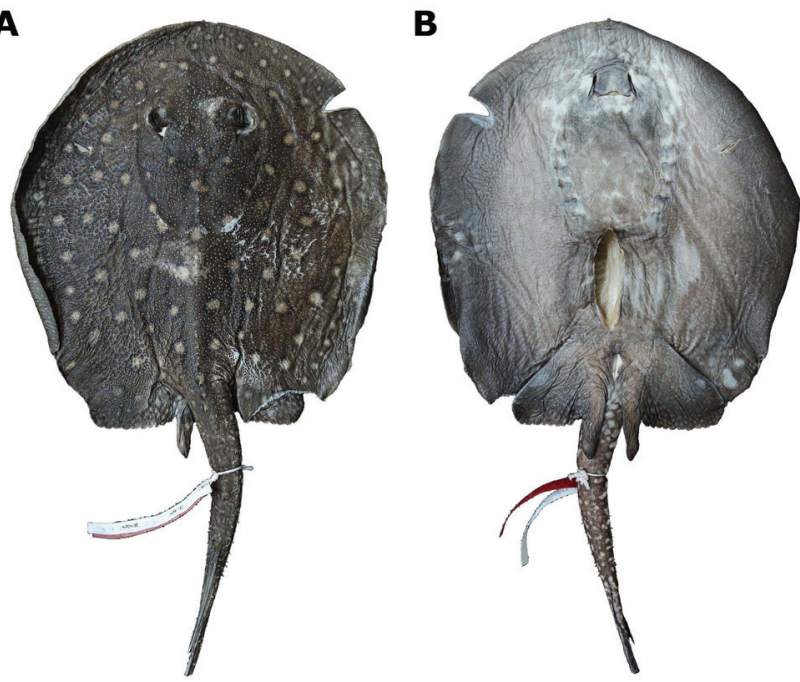

Fig. 44. Potamotrygon amandae, n. sp. Dorsal (a) and ventral (b) views of paratype, MZUSP 111917, immature male, 218 $\mathrm{mm}$ DW, from Paraná River. 


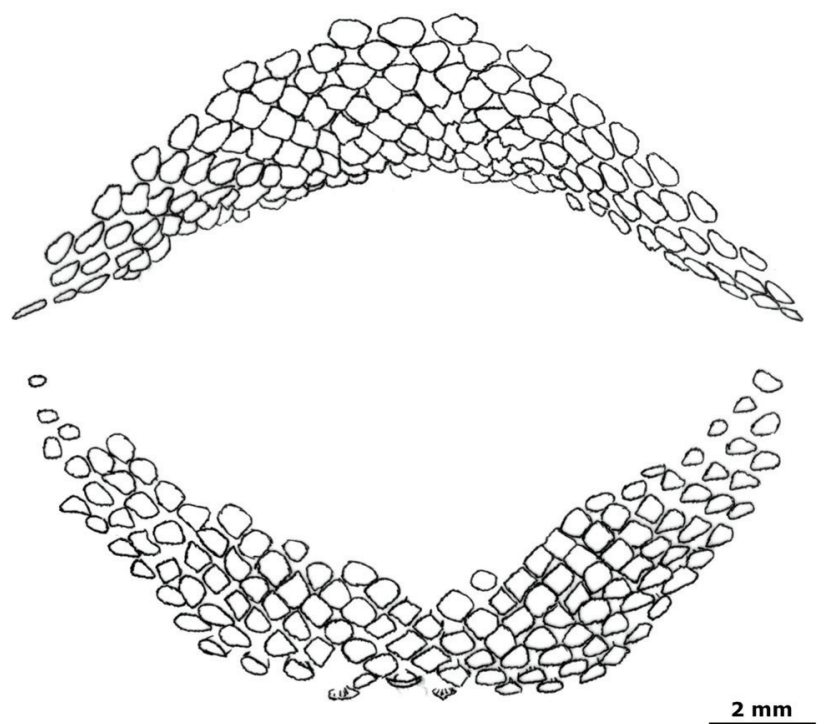

Fig. 45. Potamotrygon amandae, n. sp. Upper and lower jaws of a non-type adult female specimen, MZUSP 110916, $275 \mathrm{~mm}$ DW.

Table 4. Meristic data taken from specimens of Potamotrygon pantanensis, including the holotype (A) MZUSP 110890.

\begin{tabular}{lcccc}
\hline & A & n & Range & Mode \\
\hline & & & & \\
Precaudal vertebrae & 36 & 5 & $36-49$ & 36 \\
Caudal vertebrae & 82 & 4 & $76-85$ & - \\
Total vertebrae & 118 & 4 & $118-$ & - \\
& & & 125 & \\
Diplospondylic vertebrae & 90 & 4 & $89-100$ & 90 \\
Propterygial radials & 43 & 5 & $41-44$ & 43 \\
Mesopterygial radials & 16 & 5 & $14-16$ & 16 \\
Metapterygial radials & 33 & 5 & $31-36$ & 33 \\
Total pectoral radials & 92 & 5 & $87-95$ & - \\
Pelvic radials & 21 & 5 & $17-24$ & - \\
Tooth rows of upper jaw & - & 3 & $30-35$ & - \\
Tooth rows of lower jaw & - & 3 & $30-31$ & 31 \\
Symphysis of upper jaw & - & 3 & $4-5$ & 4 \\
Symphysis of lower jaw & - & 3 & $4-5$ & 5 \\
Enlarged dorsal pointed-spines & 33 & 14 & $32-77$ & 60
\end{tabular}

Diagnosis. Potamotrygon amandae, sp. nov. differs from congeners in the Paraná-Paraguay basin, except $P$. motoro and P. pantanensis, due to its predominantly grayish or dark brown dorsal background color usually with bicolored ocelli on dorsal disc (P. falkneri, P. histrix, P. schuhmacheri, and P. brachyura lack ocelli; some specimens of $P$. amandae, sp. nov. lack ocelli and have a uniform dark brown or gray dorsal color). A combination of characters differentiates $P$. amandae, sp. nov. from $P$. motoro

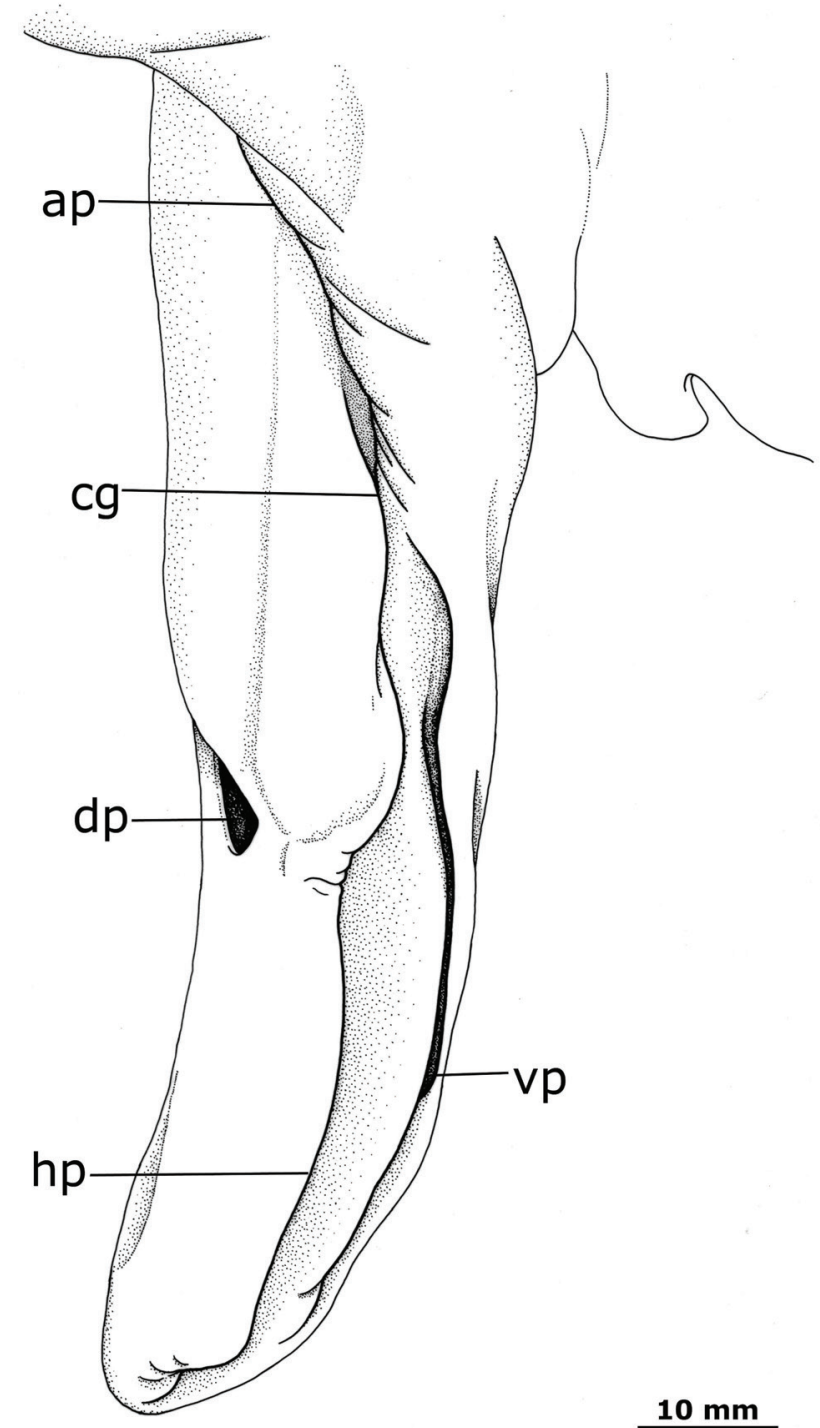

Fig. 46. Potamotrygon amandae, n. sp. Dorsal view of right clasper of an adult male, MZUSP 111148, adult male, 280 mm DW. Abbreviations: ap, apopyle; cg, clasper groove; dp, dorsal pseudosiphon; hp, hypopyle; vp, ventral pseudosiphon.

and $P$. pantanensis: dorsal background predominantly grayish or dark brown ( $P$. motoro with dorsal disc background color gray, dark gray, olive, olivaceous brown, or dark brown, and $P$. pantanensis with dorsal disc background brown); ocelli, when present, with two colors, with a whitish, light gray or light yellow central area surrounded by a black peripheral ring (P. motoro presents tricolored ocelli with a peripheral dark ring, yellowish or orange center and with an intermediate band, and P. pantanensis presents bicolored ocelli with a beige, orange or dark yellow central area surrounded by a peripheral black ring); ventral disc coloration grayish, covering almost all of ventral disc (ventral color predominantly whitish over central disc in $P$. motoro and $P$. pantanensis); dermal denticles differ from $P$. motoro due to their smaller size and without developed coronal plates in P. amandae, 

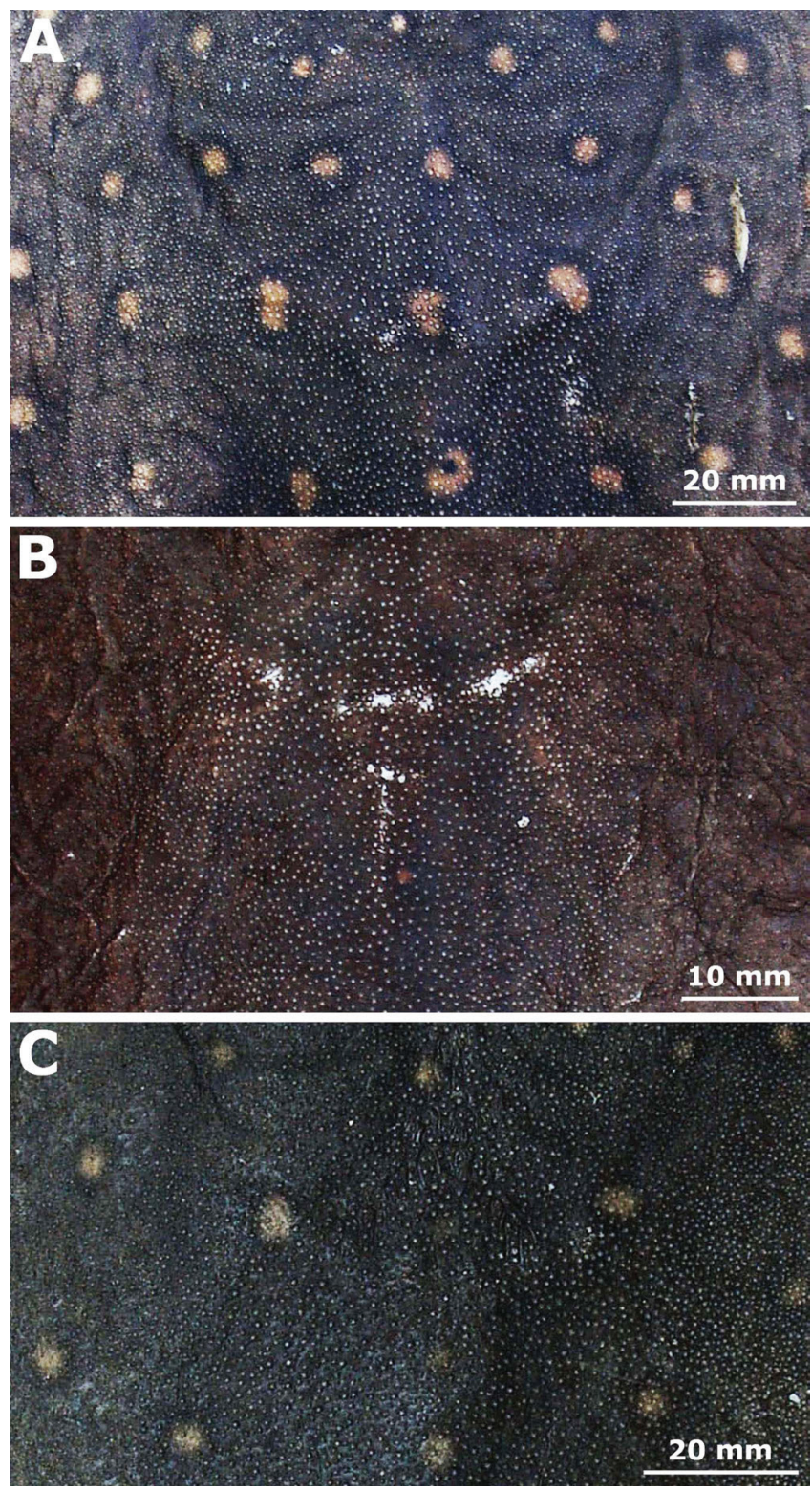

Fig. 47. Patterns of ocelli and spots in specimens of $P$. amandae, n. sp.: (a) holotype MZUSP 110910, (b) MZUSP 110904 and (c) MZUSP 110906.

sp. nov., and from $P$. pantanensis due to their distribution over almost entire dorsal side of disc (in P. motoro and P. pantanensis, dermal denticles do not cover almost entire dorsal disc); greater spiracular length compared to $P$. motoro and P. pantanensis, with mean $10.1 \%$ DW (ranging from 8.2 to $12.8 \% \mathrm{DW}$ ), whereas in P. motoro spiracular mean length is $8.0 \% \mathrm{DW}$ (ranging from 6.7 to $9.8 \% \mathrm{DW}$ ), and in $P$. pantanensis mean spiraclular length is $8.7 \%$ DW (ranging from 7.6 to $9.6 \% \mathrm{DW}$ ); relatively longer tail, with tail length averaging $82.1 \% \mathrm{DW}$, whereas mean tail length is $78.5 \% \mathrm{DW}$ in $P$. motoro and $73.4 \% \mathrm{DW}$ in P. pantanensis; tail relatively more slender in $P$. amandae, sp. nov., with mean tail width $11.0 \% \mathrm{DW}$ (ranging from 7.2 to $13.6 \% \mathrm{DW}$ ), whereas in P. motoro and P. pantanensis mean tail width is, respectively,
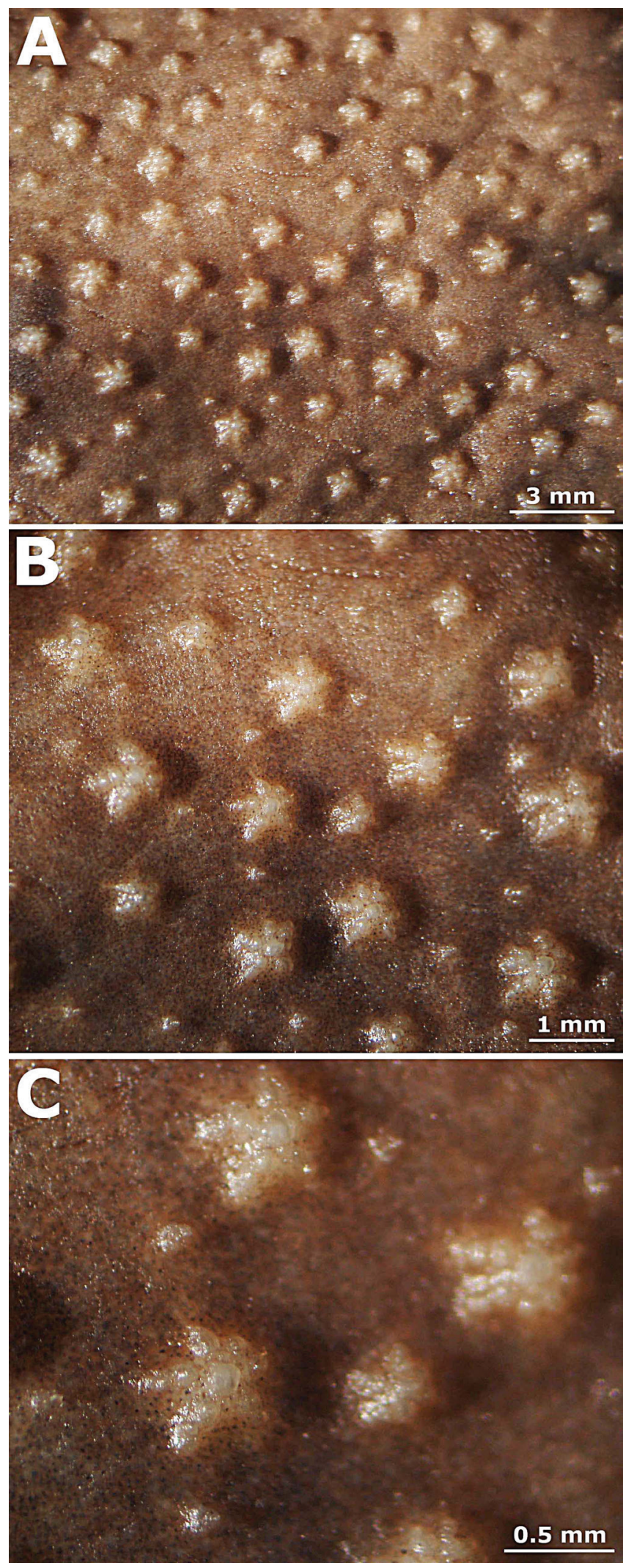

Fig. 48. Potamotrygon amandae, n. sp. Detail of dermal denticles present in a non-type juvenile male specimen, MZUSP 111150, $215 \mathrm{~mm}$ DW, showing the two morphological types of denticles, with star-shaped and pointed crowns. 

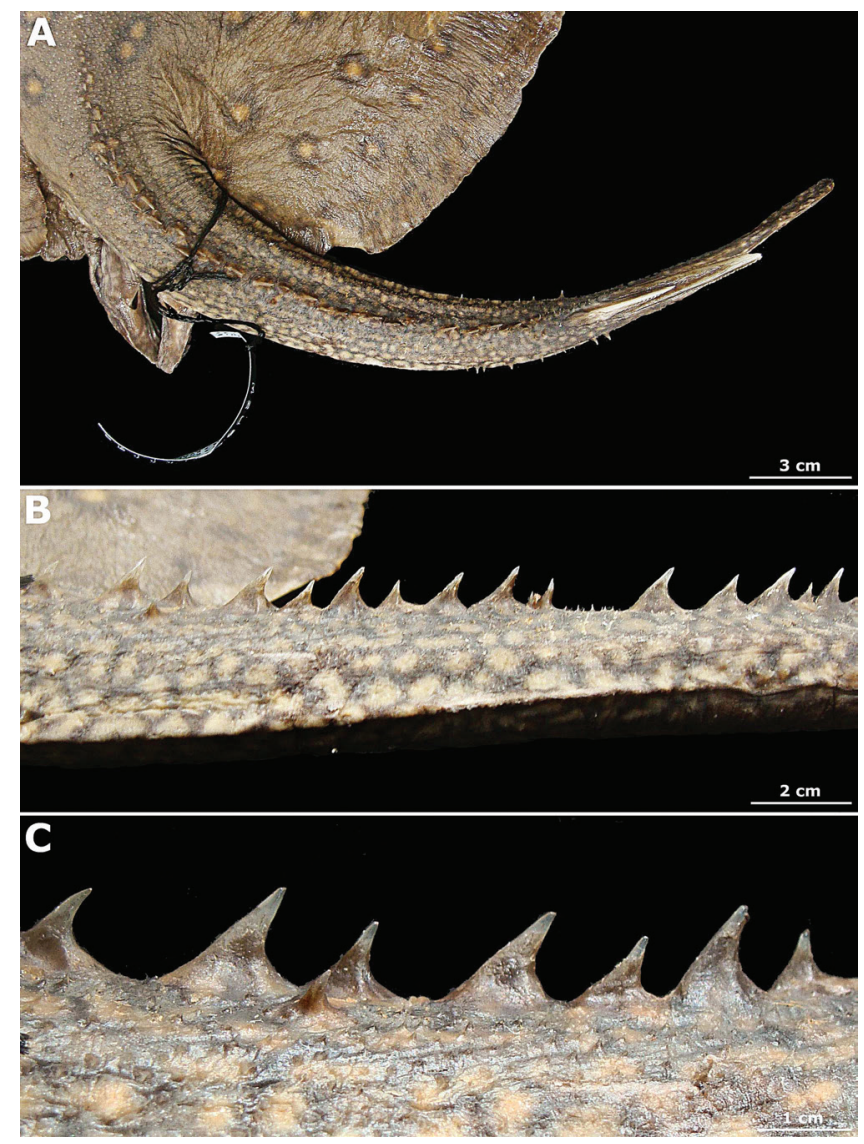

Fig. 49. Potamotrygon amandae, n. sp. MZUSP 111148: (a) Dorsal view of tail showing the entire dorsal rows of enlarged pointed spines, (b) showing the rows and format of pointed spines, and (c) detail of some pointed spines of dorsal rows.

$13.4 \% \mathrm{DW}$ and $13.2 \% \mathrm{DW}$ (ranging from 10.5 to $14.8 \%$ and 11.2 to $15.5 \%$ DW, respectively); frontoparietal fontanelle of neurocranium constricted at midlength (unconstricted in $P$. motoro and $P$. pantanensis), and postorbital process clearly more developed than in P. motoro and P. pantanensis; anterior angular cartilage with its medial portion at articulation with Meckel's cartilages highly curved ("J"-shaped), and much greater than posterior angular cartilage (both angular cartilages subequal in $P$. motoro, and $P$. pantanensis with anterior angular cartilage rather straight, not "J"-shaped).

Description. Proportional morphometrics and counts are presented, respectively, in Tables 5 and 6.

External morphology. Disc subcircular, longer than broad, with disc length ranging from 105.5 to $121.4 \% \mathrm{DW}$, similar to P. motoro. Head narrow with interorbital distance 11.5 to $16.9 \% \mathrm{DW}$, interspiracular distance 17.4 to $21.4 \% \mathrm{DW}$, and internasal distance 6.6 to $9.6 \%$ DW. Mouth narrow, its width ranging from 7.0 to $11.7 \% \mathrm{DW}$, and with five papillae on ventral oral epithelium (three central and two

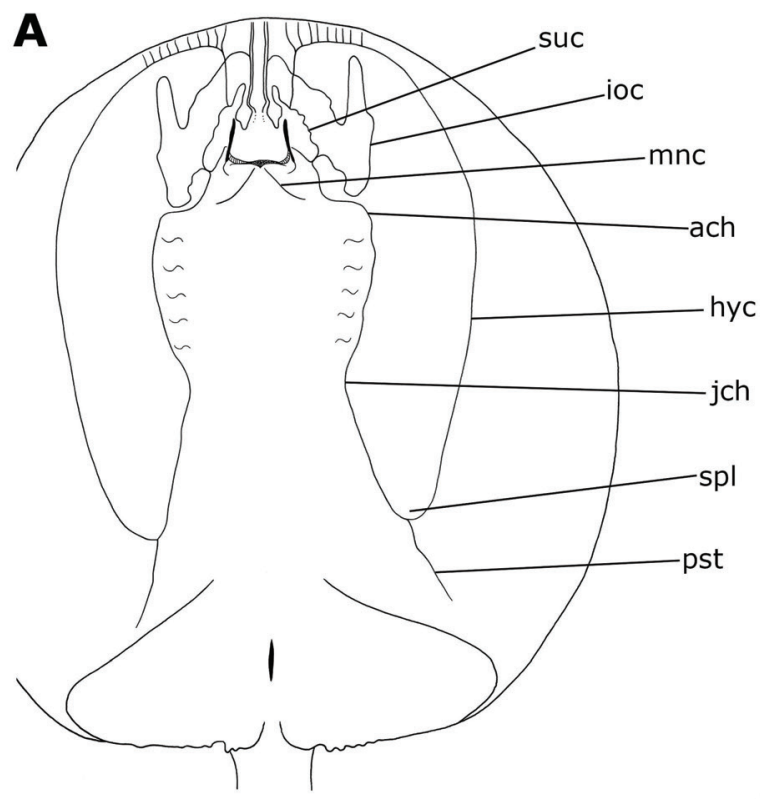

$3 \mathrm{~cm}$

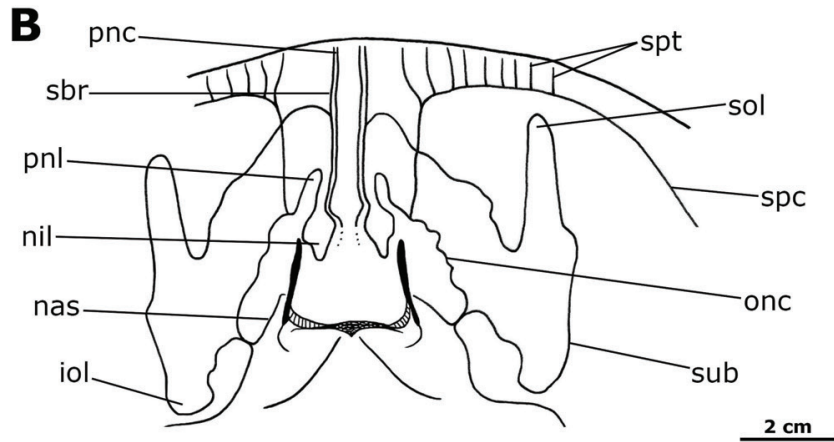

Fig. 50. Potamotrygon amandae, n. sp. Ventral canals of lateral line system in a non-type adult female specimen, MZUSP 111140, 254 mm DW. Abbreviations: hyc, hyomandibular canal; ioc, infraorbital canal; mnc, mandibular canal; nas, nasal canal; suc, supraorbital canal; ach, angular component of hyomandibular canal; iol, infraorbital loop; jch, jugular component of hyomandibular canal; nil, nasointernal loop; onc, orbitonasal component of supraorbital canal; pnc, prenasal component of nasal canal; pnl, prenasal loop; pst, posterior subpleural tubule; sbr, subrostral component of supraorbital canal; sol, suborbital loop; spc, subpleural component of hyomandibular canal; spl, subpleural loop; spt, subpleural tubules; sub, suborbital component of infraorbital canal.

peripheral). Small, distinct rostral protuberance lacking. Eyes bulging dorsally, relatively large. Spiracles muscular, trapezoidal and large, with mean spiracular length $10.1 \%$ DW, ranging from 8.2 to $12.8 \%$ DW. Branchial basket narrow, with mean distances between first gills slits and fifth gill slits, respectively, 25.4\% DW and 17.9 DW; branchial basket mean length $17.3 \% \mathrm{DW}$, similar to $P$. pantanensis. Potamotrygon amandae presents well-developed labial grooves on posterolateral corners of mouth. 

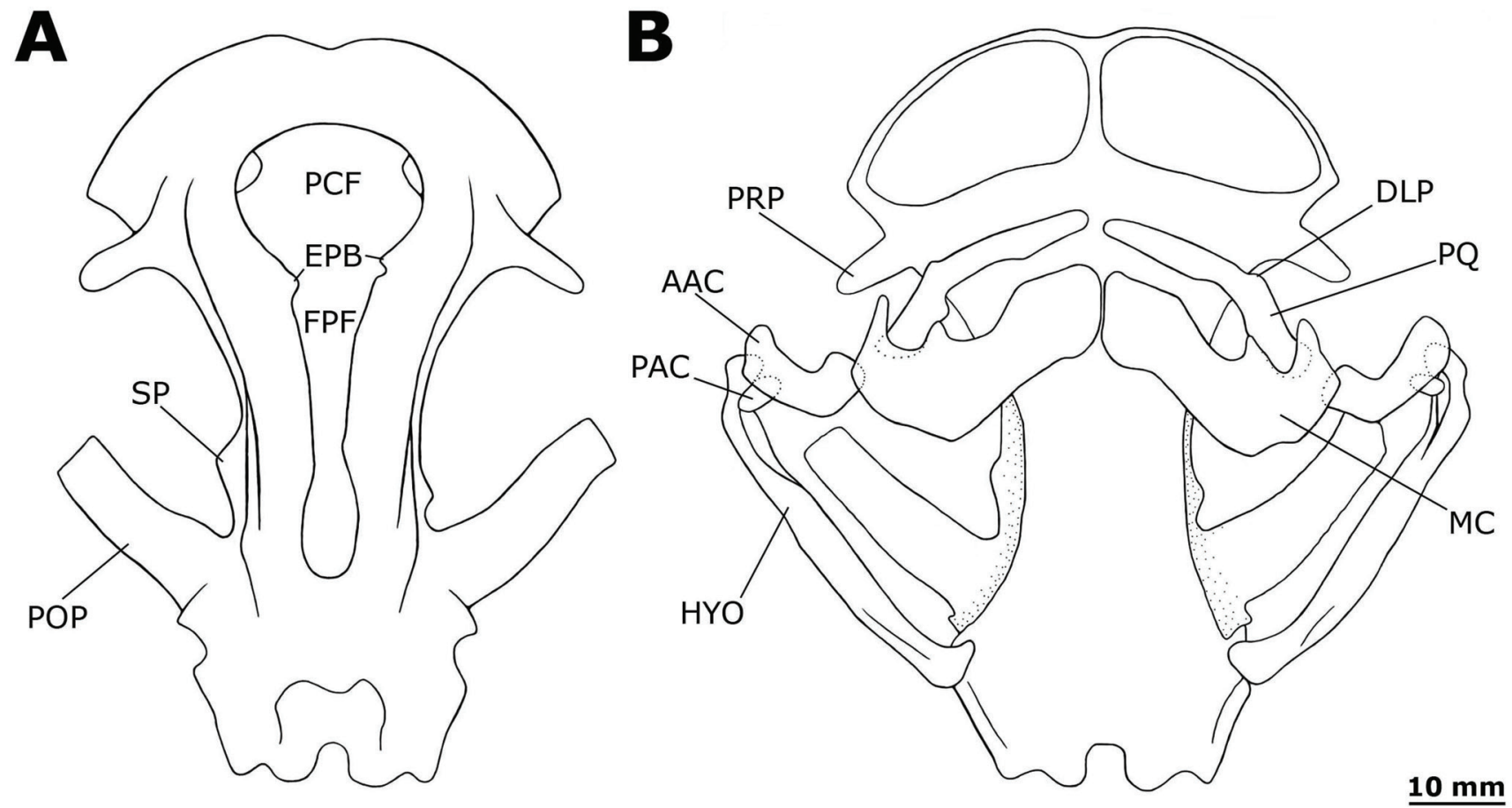

Fig. 51. Potamotrygon amandae, n. sp. Dorsal and ventral views of neurocranium and mandibular arch (in ventral view) of a non-type adult male specimen, MZUSP 111148, 280 mm DW. Abbreviations: AAC, anterior angular cartilage; CL, calcified ligament; DLP, dorsolateral process; EPB, epiphysial bar; FPF, frontoparietal fontanelle; HYO, hyomandibula; MC, Meckel's cartilage; PAC, posterior angular cartilage; PCF, precerebral fontanelle; POP, postorbital process; PQ, palatoquadrate PRP, preorbital process; $\mathbf{S P}$, supraorbital process.

Teeth in quincunx, individual teeth smaller than in $P$. motoro, without monognathic heterodonty (Fig. 45). Contrary to $P$. motoro, more tooth rows present on upper jaw compared to lower jaw; tooth row count 26-37/23-33; teeth in median rows of upper and lower jaws 6-8/4-13 (Table 6).

Pelvic fins dorsally covered by disc, with only posterior margins extending beyond disc. Pelvic fins triangular, with distal portion slightly rounded; anterior margins range between 18.6 to $27.2 \%$ DW. Clasper long and slightly curved; dorsal pseudosiphon drop-shaped (Fig. 46). Clasper relatively small, with mean and range of internal length in mature adult males, respectively, $25.6 \% \mathrm{DW}$ and 23.2 to $26.7 \% \mathrm{DW}$, and mean and range of external length, respectively, $12.3 \% \mathrm{DW}$ and 10.0 to $13.9 \%$ DW (Table 5).
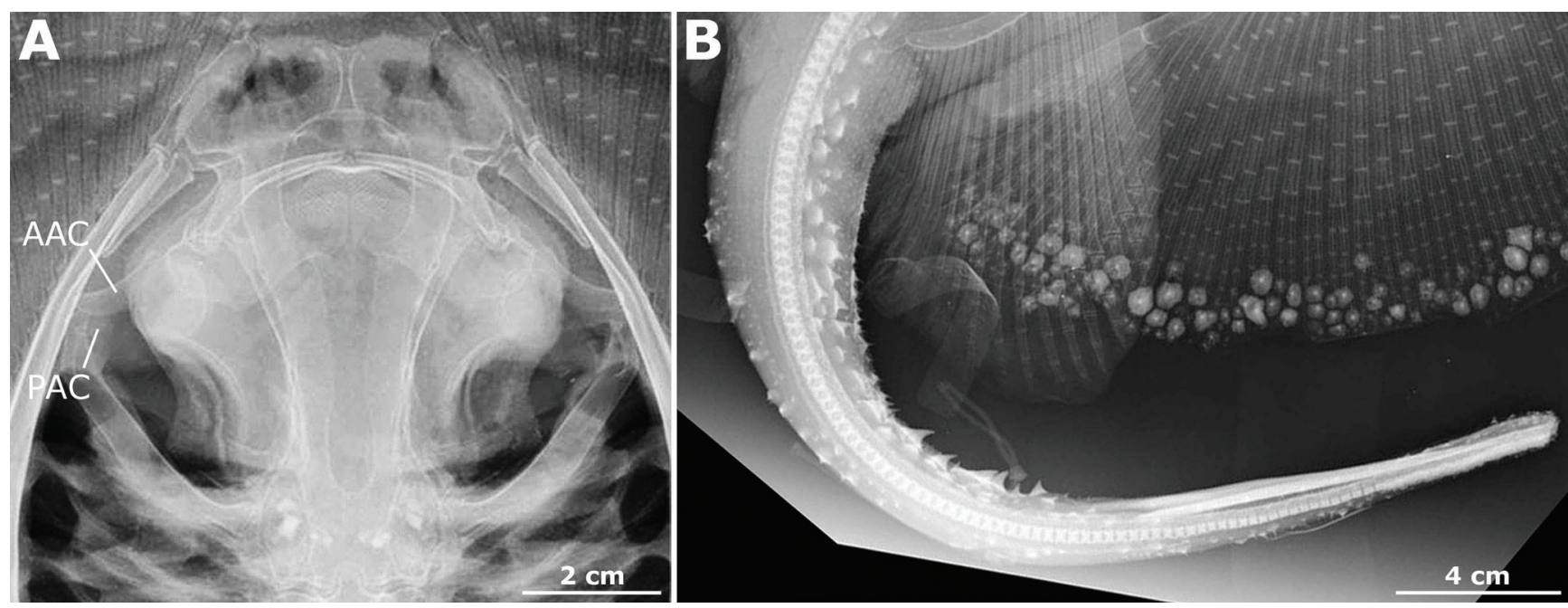

Fig. 52. Potamotrygon amandae, n. sp. Anatomical details from radiograph of holotype, MZUSP 110910. Abbreviations: AAC, anterior angular cartilage; PAC, posterior angular cartilage. 
Table 5. Measurements of specimens of Potamotyrgon amandae analyzed in this study, including the holotype (A) MZUSP 110910. Mean (x) and Standard Deviation (SD) are expressed in proportions of disc width (\% DW), and range is expressed in millimeters $(\mathrm{mm})$ and proportions of disc width $(\% \mathrm{DW})$. Clasper measurements were taken only from adult specimens.

\begin{tabular}{|c|c|c|c|c|c|c|c|}
\hline & \multicolumn{2}{|c|}{$\mathbf{A}$} & \multirow[t]{2}{*}{$\mathbf{n}$} & \multicolumn{2}{|c|}{ Range } & \multirow{2}{*}{$\begin{array}{c}x \\
\% \mathrm{DW}\end{array}$} & \multirow{2}{*}{$\begin{array}{c}\text { SD } \\
\% \mathrm{DW}\end{array}$} \\
\hline & $\mathrm{mm}$ & $\% \mathrm{DW}$ & & $\mathrm{mm}$ & $\% \mathrm{DW}$ & & \\
\hline Disc width & 341 & & 37 & $192-341$ & & & \\
\hline Disc length & 380 & 111.4 & 37 & $208-380$ & $105.5-121.4$ & 110.3 & 3.0 \\
\hline Total length & 592 & 173.6 & 32 & $356-592$ & $138.2-199.6$ & 177.7 & 13.4 \\
\hline Interorbital distance & 51 & 15.0 & 37 & $26-51$ & $11.5-16.9$ & 14.8 & 1.2 \\
\hline Interspiracular distance & 62 & 18.2 & 37 & $37-62$ & $17.2-21.4$ & 19.2 & 1.3 \\
\hline Preorbital distance & 80 & 23.5 & 35 & $47-85$ & $21.1-26.5$ & 23.4 & 1.3 \\
\hline Eye diameter & 15 & 4.4 & 37 & $11-16$ & $3.8-6.9$ & 4.9 & 0.6 \\
\hline Spriracular length & 29 & 8.5 & 37 & $13-34$ & $8.2-12.8$ & 10.1 & 1.0 \\
\hline Prenasal distance & 51 & 15.0 & 37 & $26-51$ & $11.8-16.8$ & 14.0 & 1.2 \\
\hline Preoral distance & 71 & 20.8 & 37 & $37-71$ & $16.5-23.1$ & 20.2 & 1.5 \\
\hline Internasal distance & 26 & 7.6 & 37 & $14-28$ & $6.6-9.6$ & 7.9 & 0.7 \\
\hline Mouth width & 28 & 8.2 & 37 & $15-30$ & $7.0-11.7$ & 8.8 & 1.1 \\
\hline Space between $1^{\text {st }}$ branchial slits & 86 & 25.2 & 37 & $47-86$ & $22.9-29.5$ & 25.4 & 1.6 \\
\hline Space between $5^{\text {th }}$ branchial slits & 64 & 18.8 & 37 & $32-64$ & $16.6-20.9$ & 17.9 & 1.1 \\
\hline Branchial basket length & 58 & 17.0 & 37 & $32-58$ & $16.1-20.0$ & 17.3 & 1.0 \\
\hline Length ant. margin of pelvic fin & 91 & 26.7 & 37 & $40-91$ & $18.6-27.2$ & 23.1 & 2.0 \\
\hline Pelvic fins width & 180 & 52.8 & 37 & $100-192$ & $48.0-64.6$ & 57.8 & 3.9 \\
\hline Length ext. margin of clasper & - & - & 9 & $26-40$ & $10.0-13.9$ & 12.3 & 1.2 \\
\hline Length int. margin of clasper & - & - & 9 & $57-83$ & $23.2-26.7$ & 25.6 & 1.0 \\
\hline Cloaca to tip tail & 256 & 75.1 & 32 & $163-270$ & $54.5-102.3$ & 82.1 & 11.5 \\
\hline Tail width between pectoral insertions & 45 & 13.2 & 37 & $16-45$ & $7.2-13.6$ & 11.0 & 1.4 \\
\hline Snout to cloaca & 312 & 91.5 & 37 & $168-312$ & $84.0-114.6$ & 89.8 & 4.7 \\
\hline Distance between pectoral axil and posterior margin of pelvic fin & 40 & 11.7 & 37 & $18-60$ & $8.4-20.7$ & 13.1 & 2.2 \\
\hline Cloaca to serrated-spine & 149 & 43.7 & 33 & $80-164$ & $38.6-56.8$ & 45.6 & 4.8 \\
\hline Caudal sting length & 81 & 23.8 & 29 & $38-81$ & $13.9-28.8$ & 22.1 & 3.5 \\
\hline Caudal sting width & 8 & 2.3 & 31 & $3-8$ & $1.3-2.9$ & 1.9 & 0.3 \\
\hline Dorsal pseudosiphon & - & - & 8 & $7-12$ & $2.3-5.2$ & 3.1 & 0.8 \\
\hline Ventral pseudosiphon & - & - & 8 & $21-26$ & $7.1-10.3$ & 9.0 & 1.0 \\
\hline
\end{tabular}

Tail long and relatively more slender in comparison with P. motoro and P. pantanensis, with range and mean of distance between cloaca and caudal extremity, respectively, 54.5 to $102.3 \% \mathrm{DW}$ and $82.3 \% \mathrm{DW}$; tail width ranging from 7.2 to $13.6 \%$ DW. Dorsal and ventral tail folds relatively well-developed.

Coloration. Dorsal disc coloration somewhat variable, generally with a dark background color, and with bicolor ocelli distributed throughout entire disc (Figs. 38a, 39a, 40a, 41a, 42a, 43a, 44a). Bicolor ocelli present a whitish rounded central region surrounded by a black peripheral ring (Fig. 47). Background color on dorsal disc light gray, dark gray, light brown, or dark brown. Three patterns of dorsal disc coloration predominant in P. amandae: specimens with only ocelli, specimens with ocelli and small spots, and specimens without ocelli or spots (Figs. 38a, 39a, 40a, 41a, 42a, 43a, 44a, 47). In specimens only with ocelli, most ocelli concentrated on central region of disc, their diameter greater than ocelli on disc margins, with some central ocelli reaching eye-diameter in size. Ocelli either poorly or well-defined. Ocelli with bicolor pattern generally with central region light gray, light beige or light yellow surrounded by black ring; some specimens with tricolored ocelli (with an additional intermediate brownish band). Specimens with ocelli and spots present spots more numerous on central disc, and ocelli concentrated on disc margins. Spots with vermiculate or "U" format (Fig. 46a). Spots and ocelli poorly or well-defined, and both composed of two bands of colors with central region whitish, light gray, light beige, beige, or dark beige or brown surrounded by a black peripheral ring. In specimens without ocelli or spots, only few indistinct, brownish spots, hidden by 
Table 6. Meristic data taken from specimens of Potamotrygon amandae, including the holotype (A) MZUSP 110910. Mode of enlarged dorsal pointed-spines presents two predominant values.

\begin{tabular}{lllll}
\hline & A & $\mathrm{n}$ & Range & Mode \\
\hline & & & & \\
Precaudal vertebrae & 31 & 7 & $31-47$ & 39 \\
Caudal vertebrae & 88 & 7 & $73-88$ & 88 \\
Total vertebrae & 119 & 7 & $113-129$ & - \\
Diplospondylic vertebrae & 85 & 7 & $85-99$ & 99 \\
Propterygial radials & 46 & 7 & $42-51$ & 43 \\
Mesopterygial radials & 13 & 7 & $12-17$ & 13 \\
Metapterygial radials & 36 & 7 & $35-40$ & 40 \\
Total pectoral radials & 95 & 7 & $92-106$ & 95 \\
Pelvic radials & 23 & 7 & $18-23$ & 19 \\
Tooth rows of upper jaw & - & 4 & $26-37$ & 31 \\
Tooth rows of lower jaw & - & 4 & $23-33$ & 26 \\
Symphysis of upper jaw & - & 4 & $6-8$ & 8 \\
Symphysis of lower jaw & - & 4 & $4-13$ & - \\
Enlarged dorsal pointed-spines & 70 & 33 & $11-70$ & 15,18 \\
\hline
\end{tabular}

general backgound color, present around eyes and spiracles (Figs. 38a, 46b). Dorsal coloration of pelvic fins similar to dorsal disc, but less intense; number of bicolor ocelli and spots from few, near pelvic insertion, to numerous on entire surface of pelvic fin. Dorsal color of tail in specimens without ocelli and spots with uniform coloration on entire tail, from base to tip. Specimens with dorsal disc ocelli with many spots on tail. Specimens with dorsal disc ocelli and spots with many small spots on dorsal tail, alternating with darker backgound to resemble a striped pattern posterior to caudal sting. Freshly collected specimens with more intensely colored ocelli.

Ventral disc coloration with three distinct regions (Figs. 38b, 39b, 40b, 41b, 42b, 43b, 44b). Anterocentral ventral disc and snout area predominantly whitish on most specimens (surrounding mouth and nostrils and between, and anterior to, branchial slits). Most of ventral disc, except anterocentral and marginal regions, predominantly light gray, gray, or light brown, with whitish, small rounded spots. Disc margins, usually posterior to level of mouth, predominantly dark gray, brown or dark brown, also with scattered whitish spots. Ventral color of pelvic fins with light gray, gray, or light brown background, with whitish, small rounded spots; margins of pelvic fins similar to ventral disc margins. Ventral coloration of tail with round or vermiculate whitish or light gray spots from base to tip, on a grayish or brownish background.

Squamation. Dermal denticles distributed over entire dorsal disc and tail. Central region of disc with two predominant

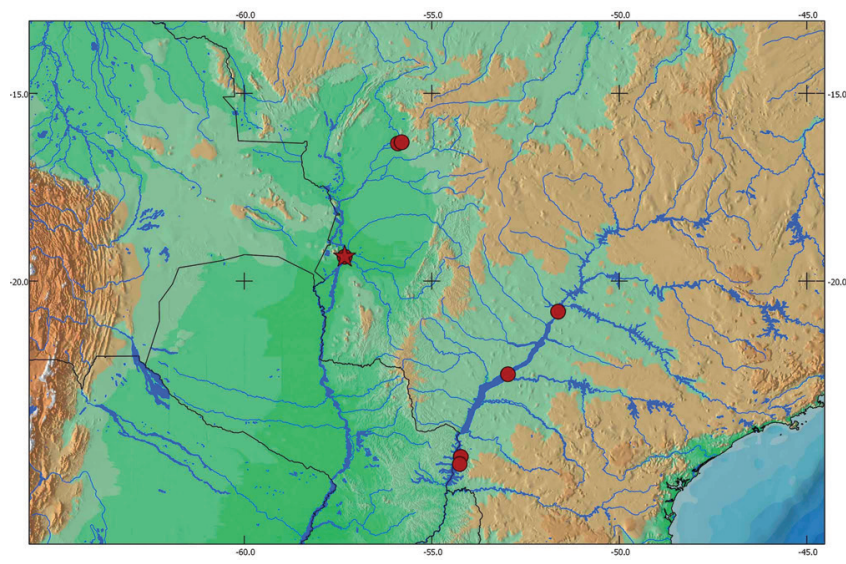

Fig. 53. Distribution of Potamotrygon amandae, n. sp. in the Paraná-Paraguay system. Red circles show localities where specimens of $P$. amandae were obtained for this study. Red star indicates Paraguay River, type locality of $P$. amandae.

types of dermal denticles, one larger with a star-shaped crown, and another very small with a pointed crown. Star-shaped denticles in P. amandae differ from P. motoro in presenting few developed coronal ridges and a taller and more pointed crown; pointed denticles present a pointed coronal plate surrounded by tiny pointed coronal ridges (Fig. 48). Marginal region of disc with only pointed denticles with a relatively smaller diameter and only a pointed coronal plate; denticles greater in size on posterior and anterior disc. Between central and marginal disc regions, denticles with intermediate morphology between star-shaped and pointed. Denticles with pointed, trichotomous crown surrounding spiracles. Distribution, concentration and size of dermal denticles varies slightly among specimens, with some presenting more developed and concentrated denticles on dorsal disc but most with more denticles on head and anterior disc margin. Denticles with pointed crowns posterior to tail base, and relatively large near caudal sting. Dorsal row of pointed-spines on tail unique, with some specimens presenting double and even triple rows (Fig. 49). Rows generally originate anterior to tail origin on disc, but in some specimens even more anteriorly. Morphology of dorsal tail spines varies slightly between specimens, with majority presenting higher, more slender and straight spines, and more curved and lower spines in others (Fig. 49). Number of spines in dorsal rows varies from 11 to 70 in specimens analyzed (Table 6). One or two lateral rows of pointed-spines on tail with spines morphologically similar to those on dorsal tail.

Ventral lateral-line canals. Description based on three adult specimens, two females (MZUSP 110916, $275 \mathrm{~mm}$ DW; MZUSP 111140, $254 \mathrm{~mm}$ DW), and one male (MZUSP 110903, 311 mm DW) (Fig. 50). 
Hyomandibular canal (hyc) connects with orbitonasal component of supraorbital canal (onc) anterior to nostrils, as in P. pantanensis; orbitonasal component not as straight as in $P$. pantanensis, with undulations that resemble $P$. motoro. Number of subpleural tubules (spt) in the subpleural component of hyomandibular canal (spc) in P. amandae greater than in P. pantanensis and less than in P. motoro; anteriormost tubules relatively more curved. Subpleural loop (spl) presents an elongate and unique posterior subpleural tubule (pst) without ramifications. Jugular component of hyomandibular canal (jch) without pronounced curve at level of branchial basket as in $P$. motoro, and with slight undulations close to gill basket (absent in P. motoro and P. pantanensis). Jugular component connects anteriorly with angular component of hyomandibular canal (ach), itself connecting anteriorly with nasal canal (nas) as in P. motoro. Angular component short and straight, but little more developed than in P. pantanensis. Infraorbital canal (ioc) extends from junction with supraorbital canal (suc), as in P. motoro, and extends laterally as a broad curve, sometimes with undulations. Infraorbital canal with a straight external segment extending to anterior portion of disc, forming the infraorbital loop (iol). Suborbital component of infraorbital canal (sub) greater than in P. pantanensis and smaller than in P. motoro, and slightly undulated (straight in P. pantanensis and P. motoro). Suborbital loop (sol) rather straight as in P. pantanensis, but more developed, and greater than infraorbital loop, not deflecting anteromedially as in P. motoro. Ascending portion of suborbital component of infraorbital canal slightly undulated, such as in P. motoro, and extends to ascending portion of subrostral component of supraorbital canal (sbr). Supraorbital canal (suc), as in P. motoro, extends from junction with infraorbital canal. Orbitonasal component of supraorbital canal (onc) with several small undulations. Prenasal loop (pnl) smaller and more narrow than in $P$. motoro and $P$. pantanensis, but nasointernal loop (nil) more broad than in $P$. pantanensis and P. motoro. Subrostral component of supraorbital canal (sbr) extends anteroposteriorly in parallel and closely adjacent to prenasal component of nasal canal (pnc), reaching anterior disc margin. Infraorbital canal intersects subrostral component just anterior to its midlength. As in P. motoro, nasal canal (nas) extends anteromedially from connection with final portion of hyomandibular canal; however, different from P. pantanensis and P. motoro, prenasal component of nasal canal (pnc) appears just anterior to anterior margin of nostrils on nasal curtain. Contrary to $P$. pantanensis and more similar to P. motoro, P. amandae presents a considerable distance between intersection of final portion of hyomandibular canal and anterior portion of nasal canal with infraorbital and supraorbital canals. Mandibular canal (mnc) as in $P$. pantanensis, relatively shorter and more straight than in P. motoro.
Skeletal features. Skeleton generally similar to P. pantanensis, differing principally in dorsal fontanelle size and shape from P. motoro (Figs. 51, 52). Fontanelle similar to P. pantanensis, however frontoparietal fontanelle (FPF) in P. amandae more slender, constricted at its midlength, and more oval posteriorly. Supraorbital process (SP) less developed than in P. motoro and $P$. pantanensis, and postorbital process (POP) greater proportionally than in $P$. pantanensis. Jaws similar to $P$. pantanensis, with the principal difference that in $P$. amandae the anterior angular cartilage (AAC) curved medially where it articulates to Meckel's cartilages (MC), presenting a "J"shape (Fig. 51).

Geographic distribution. Specimens of $P$. amandae were collected from many localities throughout the Paraná-Paraguay basin: northern Pantanal, southern Pantanal, Paraná River at the border between São Paulo and Mato Grosso do Sul States, and along the border between Brazil (Paraná State) and Paraguay. Specimens of $P$. amandae examined in the Florentino Ameghino museum are from the region of Santa Fé, Argentina. The species has recently been collected in the lower Tietê River (an afluent of the Paraná River in São Paulo State; Garrone-Neto et al., 2007), a result of a recent increase in its range; its presence in the Tietê River is a consequence of the formation of the Itaipu reservoir, which previously contained the Sete Quedas waterfall system, a natural barrier impeding the presence of stingrays farther up the Paraná River (Fig. 53).

Etymology. The specific name posthumously honors biologist Amanda Lucas Gimeno, who was an undergraduate colleague of the first author.

Remarks. Despite being a new species, $P$. amandae has been known for some time, however its similarities with $P$. motoro and $P$. histrix probably confounded authors who recognized it as a hybrid because of some of its intermediate characteristics (mainly dorsal coloration; Castex \& Yagolkowski, 1970). The first author that probably studied a specimen of $P$. amandae was Castex (1963a, 1963c, 1963d, 1964, Castex \& Maciel, 1965, Castex \& Yagolkowski, 1970), albeit misidentified as P. pauckei. Some specimens (MFA 300, MFA 315 and MFA 316), identified as $P$. pauckei in the Florentino Ameghino museum and examined by us, are actually specimens of P. amandae. Nevertheless, the nominal species $P$. pauckei cannot be applied to specimens we have described as $P$. amandae because, as explained above (see remarks for $P$. motoro), even though the type-series of $P$. pauckei probably originally included one specimen of $P$. amandae, P. pauckei is a junior synonym of $P$. motoro [when Castex (1964) subsequently designated one of the specimens of original type-series of P. pauckei as "holotype", which counts as a lectotype designation, he fixed this nominal species to MFA 
Table 7. Measurements of Potamotyrgon histrix. Three specimens were examined for this study: (A) MS 0415, (B) MS 0442, and (C) MS 0443. Mean ( $x$ ) and Standard Deviation (SD) are expressed as proportions of disc width (\% DW), and range is expressed in millimeters $(\mathrm{mm})$ and proportions of disc width $(\% \mathrm{DW})$. Clasper measurements were taken only from adult specimens.

\begin{tabular}{|c|c|c|c|c|c|c|c|c|c|c|}
\hline & \multicolumn{2}{|c|}{$\mathbf{A}$} & \multicolumn{2}{|c|}{ B } & \multicolumn{2}{|c|}{$\mathbf{C}$} & \multicolumn{2}{|c|}{ Range } & \multirow{2}{*}{$\begin{array}{c}x \\
\text { \%DW }\end{array}$} & \multirow{2}{*}{$\begin{array}{l}\text { SD } \\
\% \mathrm{DV}\end{array}$} \\
\hline & $\mathrm{mm}$ & $\% \mathrm{DW}$ & $\mathrm{mm}$ & $\% \mathrm{DW}$ & $\mathrm{mm}$ & $\% \mathrm{DW}$ & $\mathrm{mm}$ & $\% \mathrm{DW}$ & & \\
\hline Disc width & 278 & & 217 & & 202 & & $202-278$ & & & \\
\hline Disc length & 295 & 106.1 & 226 & 104.1 & 215 & 106.4 & $215-295$ & $104.1-106.4$ & 105.6 & 1.2 \\
\hline Total length & 458 & 164.7 & 367 & 169.1 & 330 & 163.4 & $330-458$ & $163.4-169.7$ & 165.7 & 3.0 \\
\hline Interorbital distance & 52 & 18.7 & 44 & 20.3 & 38 & 18.8 & $38-52$ & $18.7-20.3$ & 19.3 & 0.9 \\
\hline Interspiracular distance & 56 & 20.1 & 43 & 19.8 & 43 & 21.3 & $43-56$ & $19.8-21.3$ & 20.4 & 0.8 \\
\hline Eye diameter & 8 & 2.9 & 8 & 3.7 & 8 & 4.0 & $\ldots$ & $2.9-4.0$ & 3.5 & 0.6 \\
\hline Spriracular length & 16 & 5.8 & 12 & 5.5 & 7 & 3.5 & $7-16$ & $3.5-5.8$ & 4.9 & 1.3 \\
\hline Prenasal distance & 40 & 14.4 & 23 & 10.6 & 23 & 11.4 & $23-40$ & $10.6-14.4$ & 12.1 & 2.0 \\
\hline Preoral distance & 59 & 21.2 & 41 & 18.9 & 40 & 19.8 & $40-59$ & $18.9-21.2$ & 20.0 & 1.2 \\
\hline Internasal distance & 29 & 10.4 & 18 & 8.3 & 21 & 10.4 & $18-29$ & $8.3-10.4$ & 9.7 & 1.2 \\
\hline Mouth width & 19 & 6.8 & 19 & 8.8 & 19 & 9.4 & $\ldots$ & $6.8-9.4$ & 8.3 & 1.3 \\
\hline Space between $1^{\text {st }}$ branchial slits & 75 & 27.0 & 55 & 25.3 & 56 & 27.7 & $55-75$ & $25.3-27.7$ & 26.7 & 1.2 \\
\hline Space between $5^{\text {th }}$ branchial slits & 59 & 21.2 & 40 & 18.4 & 42 & 20.8 & $40-59$ & $18.4-21.2$ & 20.1 & 1.5 \\
\hline Branchial basket length & 54 & 19.4 & 40 & 18.4 & 39 & 19.3 & $39-54$ & $18.4-19.4$ & 19.1 & 0.5 \\
\hline Length ant. margin of pelvic fin & 62 & 22.3 & 49 & 22.6 & 32 & 15.8 & $32-62$ & $15.8-22.6$ & 20.2 & 3.8 \\
\hline Pelvic fins width & 137 & 49.3 & 124 & 57.1 & 112 & 55.4 & $112-137$ & $49.3-57.1$ & 54.0 & 4.1 \\
\hline Length ext. margin of clasper & - & - & - & - & 32 & 15.8 & - & - & 15.8 & - \\
\hline Length int. margin of clasper & - & - & - & - & 50 & 24.8 & - & - & 24.8 & - \\
\hline Cloaca to tip tail & 221 & 79.5 & 173 & 79.7 & 146 & 72.3 & $146-221$ & $72.3-79.7$ & 77.2 & 4.2 \\
\hline Tail width between pectoral insertions & 30 & 10.8 & 24 & 11.1 & 22 & 10.9 & $22-30$ & $10.8-11.1$ & 10.9 & 0.1 \\
\hline Snout to cloaca & 235 & 84.5 & 184 & 84.8 & 179 & 88.6 & $179-235$ & $84.5-88.6$ & 86.0 & 2.3 \\
\hline $\begin{array}{l}\text { Distance between pectoral axil and posterior } \\
\text { margin of pelvic fin }\end{array}$ & 31 & 11.2 & 21 & 9.7 & 26 & 12.9 & $21-31$ & $9.7-12.9$ & 11.2 & 1.6 \\
\hline Serrated-spine length & 73 & 26.3 & 51 & 23.5 & 52 & 25.7 & $51-73$ & $23.5-26.3$ & 25.2 & 1.5 \\
\hline Serrated-spine width & 5 & 1.8 & 5 & 2.3 & 4 & 2.0 & $4-5$ & $1.8-2.3$ & 2.0 & 0.3 \\
\hline Cloaca to serrated-spine & 116 & 41.7 & 92 & 42.4 & 82 & 40.6 & $82-116$ & $40.6-42.4$ & 41.6 & 0.9 \\
\hline
\end{tabular}

232, which is a specimen of P. motoro (Articles 74.5 e 74.6 of the ICZN; see remarks for $P$. motoro above)].

Some specimens of $P$. amandae have a dorsal disc color similar to many specimens of $P$. histrix. Despite ocelli being present in the former species and absent in the latter, both species share a predominantly gray background as the principal coloration on dorsal and ventral surfaces of disc, pelvic fins and tail. Other morphological features that are similar between these two species are the high concentration of dermal denticles on the center of disc, dorsal rows of enlarged and pointed spines on tail, and the morphology of these spines. However, besides the dorsal coloration usually presenting whitish ocelli (diagnostic for P. amandae) and gray, drak gray to purple, small vermiculate spots (diagnostic for $P$. histrix), morphometrics of some specimens of $P$. histrix helps separate these two species: mean interorbital distance (19.3\%
DW) and range ( $18.7 \%$ to $20.3 \%$ DW), mean spiracular length $(4.9 \% \mathrm{DW})$ and range (3.5 to $5.8 \% \mathrm{DW})$, and mean prenasal distance $(12.1 \% \mathrm{DW})$ and range (10.6 to $11.8 \% \mathrm{DW})$ are the principal distinctions; more measurements are presented in Tables 5 and 7. Futhermore, characters of $P$. histrix, such morphology of dermal denticles, ventral lateral-line canals, and skeletal componets show significant differences between these two species (Silveira \& Carvalho, pers. obs.).

Similar to other potamotrygonid species (e.g., Potamotrygon falkneri; Silva \& Carvalho, 2011a, 2011b), P. amandae presents a variable pattern of dorsal disc coloration. Within the brown and gray patterns, the variation can be composed of ocelli, small, vermiculated marks or the total absence of specific dorsal patterns. Some of these variations are present in specimens that have been collected together in the same locations in the Paraná-Paraguay basin, and therefore cannot be applied in a consistent manner to separate 
putative sub-groups within $P$. amandae. Adult males of $P$. amandae also mature at relatively smaller sizes, between 20 and $35 \mathrm{~cm} \mathrm{DW.}$

\section{Acknowledgments}

Sincere thanks are owed to Carla Pavanneli and Weferson Júnio da Graça for access to material and for lending specimens from NUPELIA(UEM), and especially to Weferson for hospitality in Maringá. José Lima de Figueiredo for his great assistance during visits to MZUSP, and thanks are also due to Oswaldo Oyakama, Flávio Lima, José Luis Birindelli, and Michel Gianetti. We are very grateful to Fernando Marques (IBUSP) and his collaborators for specimens collected and donated to MZUSP and for the opportunity given to the first author to participle in a collecting trip in July 2006. Gustavo Chiaramonte and Francisco Firpo (MACN) and Andres Pautasso (MFA) are thanked for greatly aiding the first author in Buenos Aires and Santa Fé. Gilmar de Oliveira (Seção de Radiologia, Hospital Central da Faculdade de Medicina de Ribeirão Preto) is sincerely thanked for taking radiographs of many specimens of Potamotrygon and for always receiving us so kindly. Hugo Hidalgo, Reinaldo Silva and Silvana Unruh (Faculdade de Medicina Veterinária e Zootecnia, USP, São Paulo) also thanked for radiographs. Special thanks to Ernst Mikschi and Helmut Wellendorf for photographs and radiographs of NMW specimens, and to Peter Bartsch for photos and radiographs of the ZMB typespecimen. We are grateful to Thomas Püttker and Rachel Giacoia for translating German texts (note that any mistakes in the translations are our own). We thank Ulisses L. Gomes (UERJ) and Flavio A. Bockmann (LIRP-USP) for discussions and advice related to this project. Previous members of LIRP are acknowledged for support, especially Aléssio Datovo for help in clearing and staining specimens. Thanks are also due to Wilson S. Junior who made the external clasper illustrations. This project was undertaken with funds to TSL and MRC from the Fundação de Amparo à Pesquisa do Estado de São Paulo (FAPESP 05/53120-8, 11/23420-0, and 02/06459-0, 10/51193-5, respectively), and from the Conselho Nacional de Desenvolvimento Científico e Tecnológico (CNPq) to MRC (303061/2008-1, 304615/2011-0).

\section{Literature Cited}

Achenbach, G. M. \& S. V. M. Achenbach. 1976. Notas acerca de algunas especies de raya fluvial (Batoidei, Potamotrygonidae) que freqüentam el sistema hidrográfico del Paraná médio em el Departamento La Capital (Santa Fe - Argentina). Comunicaciones del Museu Provincial de Ciencias Naturales Florentino Ameghino, 8: 1-34.

Bigelow, H. B. \& W. C. Schroeder. 1953. The Fishes of the Western North Atlantic, Part II. Sawfishes, Skates and Rays and Chimaeroids. Memoir of Sears Foundation for Marine Research. 2: XV, 1-588.
Brooks, D. R. \& J. F. R. Amato. 1992. Cestodes parasites in Potamotrygon motoro (Müller \& Henle) (Chondrichthyes: Potamotrygonidae) from southwestern Brazil, including Rhinebothroides mclennanae sp. n. (Tetraphyllidea: Phyllobothriidae) and a revised host-parasite checklist for helminthes inhabiting Neotropical freshwater stingrays. Journal of Parasitology, 78: 393-398.

Carvalho, M. R. de \& N. R. Lovejoy. 2011. Morphology and phylogenetic relationships of a remarkable new genus and two new species of Neotropical freshwater stingrays from the Amazon basin (Chondrichthyes: Potamotrygonidae). Zootaxa, 2776: 13-48.

Carvalho, M. R. de, N. R. Lovejoy \& R. S. Rosa. 2003. Family Potamotrygonidae (river stingrays). Pp. 22-29. In: Reis, R. E., L. R. Malabarba \& C. Ferraris (Eds.). Checklist of the Freshwater Fishes of South and Central America, Porto Alegre, Edipucrs.

Carvalho, M. R. de, J. G. Maisey \& L. Grande. 2004. Freshwater stingrays of the Green River Formation of Wyoming (Early Eocene), with the description of a new genus and species and an analysis of its phylogenetic relationships (Chondrichthyes: Myliobatiformes). Bulletin of the American Museum of Natural History, 284: 1-136.

Carvalho, M. R. de, M. H. Sabaj Perez \& N. R. Lovejoy. 2011. Potamotrygon tigrina, a new species of freshwater stingray from the upper Amazon basin, closely related to Potamotrygon schroederi Fernandez-Yépez, 1958 (Chondrichthyes: Potamotrygonidae). Zootaxa 2827: 1-30.

Carvalho, T. P. \& J. S. Albert. 2011. The Amazon-Paraguay Divide. Pp. 193-202. In: Albert, J. S. \& R. E. Reis (Eds.). Historical biogeography of neotropical freshwaters fishes. University of California Press.

Castello, H.P. 1975. Hunting for freshwater stingrays. Tropical Fish Hobbyist, 23: 19-34.

Castex, M. N. 1963a. La raya fluvial. Notas histórico-geográficas. Publicación del departamento de Ciencias Colegio de la Inmaculada Concépcion. Santa Fé. Libreria y Editorial Castellví S.A.: 1-120.

Castex, M. N. 1963b. Observaciones sobre la raya de rio Potamotrygon motoro (Muller y Henle). Comunicaciones del Museo Argentino de Ciencias Naturales "Bernadino Rivadavia" e Instituto Nacional de Investigacion de Las Ciencias Naturales, Hidrobiologia, 1(2): 7-14.

Castex, M. N. 1963c. Uma nueva especie de raya fluvial Potamotrygon pauckei. Notas distintivas. Boletín de la Academia Nacional de Ciencias, 43: 289-294.

Castex, M. N. 1963d. El gênero Potamotrygon en el Paraná médio. Anales del Museo Provincial de Ciencias Naturales "Florentino Ameghino", 11(1): 1-87.

Castex, M. N. 1964. Estado actual de los estudios sobre la raya fluvial neotropical. Cicuentenario del Museo Provincial de Ciencias Naturales "Florentino Ameghino": 9-49.

Castex, M. N. 1967a. Observaciones em torno a las formaciones estelares que recubren el dorso de algunas espécies de raya de água dulce (Chondrichthyes, Potamotrygonidae). Physis, 26: 485-491.

Castex, M. N. 1967b. Notas sobre los dientes de las espécies del genero Potamotrygon Garman, 1877 (Chondrichthyes: Potamotrygonidae). Physis, 26: 493-496.

Castex, M. N. \& I. Maciel. 1965. Notas sobre la família Potamotrygonidae Garman, 1913. Dirección General de Recursos Naturales, Publicacion Tecnica, 14: 1-23.

Castex, M. N. \& H. P. Castello. 1969. Nuevas sinonímias para el genero monotípico Disceus Garman, 1877 (Potamotyrgonidae) y observaciones sistemáticas a la família Paratrygonidae Fowler 1948 (dubit.). Instituto Latinoamericano de Fisiología de la Reproducción, Acta Scientifica, 7: 1-43. 
Castex, M. N. \& D. R. Yagolkowski. 1970. Notas sobre dos species de raya de agua dulce (Chondrichthyes, Potamotrygonidae): a. Redescripción de P. schroederi, Yepéz 1957. B. Designación de dos parátipos de $P$. pauckei, Castex 1963 y descripción de los mismos. Instituto Latinoamericano de Fisiología de la Reproducción, Acta Scientifica, 9: 1-27.

Castex. M. N., I. Maciel \& G. M. Achenbach. 1963. Acerca de la raya fluvial Potamotrygon labradori. Neotropica, 9: 117-121.

Compagno, L. J. V. 1977. Phyletic relationships of living sharks and rays. American Zoologist 17: 303-322.

Compagno, L. J. V. \& S. D. Cook. 1995. The exploitation and conservation of freshwater elasmobranchs: status of taxa and prospects for the future. Pp. 62-90. The Biology of Freshwater Elasmobranchs, a Symposium to Honor Thomas B. Thorson. Journal of Aquariculture \& Aquatic Sciences. Vol. VII.

Deynat, P. P. \& B. Séret. 1996. Le revêment cutané des raies (Chondrichthyes, Elasmobranchii, Batoidea). I: Morphologie et arrangement des denticules cutanés. Annales des Sciences Naturalles, Zoologie 17: 65-83.

Devincenzi, G. J. \& G. W. Teague. 1942. Ictiofauna del Rio Uruguay médio. Anales del Museo de Historia Nacional de Montevideo, (Ser. 2) 5: 1-100.

Dingerkus, G. J. \& L. D. Uhler. 1977. Enzymes clearing of alcian blue stained whole small vertebrae for demonstration of cartilage. Stain Technology, 52 (4): 229-232.

Fowler, H. W. 1951. Os peixes de água doce do Brasil. Arquivos de Zoologia do Estado de São Paulo, 6: 8.

Garman, S. 1877. On the pelvis and external sexual organs of selachians, with special references to new genera Potamotrygon and Disceus (with descriptions). Proceedings of the Boston Society of Natural History, 19: 197-215.

Garman, S. 1888. On the lateral canal system of the Selachia and Holocephala. Bulletin of the Museum of Comparative Zoölogy at Harvard College, 17: 57-119.

Garman, S. 1913. The Plagiostoma (sharks, skates and rays). Memoirs of the Museum of Comparative Zoölogy, 36: 1-515.

Garrone Neto, D., V. Haddad, M. J. A. Vilela \& V. S. Ueida. 2007. Registro de ocorrência de duas espécies de potamotrigonídeos na região do Alto Rio Paraná e algumas considerações sobre sua biologia. Biota Neotropica 7: 205-208.

Garrone-Neto \& Sazima, 2009a. Stirring, charging, and picking: hunting tactics of potamotrygonid rays in the upper Paraná River. Scientific Note. Neotropical Ichthyology, 7(1): 113-116.

Garrone-Neto \& Sazima, 2009b. The more stirring the better: cichlid fishes associate with foraging potamotrygonid rays. Scientific Note. Neotropical Ichthyology, 7(3): 499-501.

Günther, A. 1870. Catalogue of the fishes in the British Museum, Vol. 8. London: British Museum (Natural History): 1-549.

Ishihara, H. \& T. Taniuchi. 1995. A strange potamotrygonid ray (Chondrichthyes: Potamotrygonidae) from the Orinoco river system. The Biology of Freshwater Elasmobranchs, a Symposium to Honor Thomas B. Thorson. Journal of Aquariculture \& Aquatic Sciences: 91-97.

Loboda, T. S. 2010. Revisão taxonômica e morfológica de Potamotyrgon motoro (Müller \& Henle, 1841) na bacia Amazônica (Chondrichthyes: Myliobatiformes: Potamotrygonidae). Unpublished M.Sc.Dissertation, Instituto de Biociências da Universidade de São Paulo, São Paulo, 305p.

Lovejoy, N. R. 1996. Systematics of myliobatoid elasmobranchs: with emphasis on the phylogeny and historical biogeography of neotropical freshwater stingrays (Potamotrygonidae: Rajiformes). Zoological Journal of the Linnean Society, 117: 207-257.
Ludwig, P. 2009. Was verbirgt sich hinter Taeniura motoro? DATZ (11/2009): 30-34.

Marques, F. P. L. 2000. Evolution of neotropical freshwater stingrays and their parasites: taling into account space and time. Ph.D. Dissertaion, University of Toronto, 325p.

Marques, F. P. L., D. R. Brooks \& M. L. G. Araújo. 2003. Systematics and phylogeny of Potamotrygonocestus (Platyhelminthes, Tetraphyllidea, Onchobothriidae) with description of three new species from freshwater potamotrygonids (Myliobatoidei, Potamotrygonidae). Zoologica Scripta, 32: 367-396.

Miranda Ribeiro, A. 1907. Fauna brasiliense. Peixes. Museu Nacional, Rio de Janeiro.

Miranda Ribeiro, A. 1923. Fauna brasiliense. Peixes [re-issue of 1907 work]. Museu Nacional, Rio de Janeiro.

Miranda Ribeiro, P. 1959. Catálogo dos Peixes do Museu Nacional. Museu Nacional, Rio de Janeiro.

Müller, J. \& F. G. J. Henle. 1841. Systematiche Beschreibung der Plagiostomen. Berlin. 197-198.

Nishida, K. 1990. Phylogeny of the suborder Myliobatoidei. Memoirs of the Faculty of Fisheries, Hokkaido University. 37 (1/2): 1-108.

Paepke, H. J. \& K. Schimdt. 1988. Kritischer Katalog der Typen der Fischsammlung des Zoologischen Museums Berlin. Teil 2: Agnatha, Chondrichthyes. Mitteilungen aus dem Zoologischen Museum in Berlin, 64: 155-189.

Rosa, R. S. 1985. A systematic revision of the South Amreican freshwater stingrays (Chondrichthyes, Potamotrygonidae). Unpublished Ph.D. Dissertation, The College of William and Mary, Virginia.

Rosa, R. S. \& M. R. de Carvalho. 2007. Família Potamotrygonidae. Catálogo das espécies de peixes de água doce do Brasil. Museu Nacional, Rio de Janeiro.

Rosa, R. S., M. R. de. Carvalho \& C. de A. Wanderley. 2008. Potamotrygon boesemani (Chondrichthyes: Myliobatiformes: Potamotrygonidae), a new species of Neotropical freshwater stingray from Surinam. Neotropical Ichthyology 6: 1-8.

Silva, J. P. C. B. da \& M. R. de Carvalho. 2011a. A taxonomic and morphological redescription of Potamotrygon falkneri Castex \& Maciel, 1963 (Chondrichthyes: Myliobatiformes: Potamotrygonidae). Neotropical Ichthyology, 9: 209-232.

Silva, J. P. C. B. da \& M. R. de Carvalho. 2011b. A new species of neotropical freshwater stingray of the genus Potamotrygon Garman, 1877 from the río Madre de Díos, Peru (Chondrichthyes: Potamotrygonidae). Papéis Avulsos de Zoologia 51: 139-154.

Soares, E. C. 2005. Peixes do Mearim. Fishes of the Mearim river. Editora Geia, São Luís.

Stehmann, M. F. W. 1978. Batoid Fishes. FAO Identification Sheets for Fisheries Purposes, Western Central Atlantic. Rome: FAO, United Nations.

Taniuchi, T. \& H. Ishihara. 1990. Anatomical comparison of clasper of freshwater stingrays (Dasyatidae and Potamotrygonidae). Japanese Journal of Ichtyology. 37: 10-16.

Teixeira, D. M. \& N. Papavero. 1999. A iconografia zoológica de Johann Natterer (1817 - 1836). Pp. 69-75. In: C. Ferrão \& J. P. M. Soares (Eds.). Johann Natterer e a missão austríaca para o Brasil. Editora Index, Petrópolis.

Teixeira, D. M., N. Papavero \& A. A. Bragança Júnior. 1999. A iconografia zoológica de Johann Natterer (1817 - 1836). Pp. 77-181. In: C. Ferrão \& J. P. M. Soares (Eds.). Johann Natterer e a missão austríaca para o Brasil. Editora Index, Petrópolis.

Submitted April 12, 2013

Accepted August 19, 2013 by luiz R. Malabarba

Published December 27, 2013 